\title{
Current status and challenges of ion imprinting
}

Cite this: J. Mater. Chem. A, 2015, 3, 13598

Received 3rd April 2015

Accepted 7th May 2015

DOI: $10.1039 / \mathrm{c} 5 \mathrm{ta0} 2421 \mathrm{~h}$

www.rsc.org/MaterialsA

\author{
Junqing Fu, ${ }^{\mathrm{ab}}$ Lingxin Chen, ${ }^{\mathrm{ab}}$ Jinhua $\mathrm{Li}^{\mathrm{a}}$ and Zhong Zhang ${ }^{\mathrm{ac}}$
}

Ion imprinting technology (IIT) aims to recognize ions while retaining the unique virtues of molecular imprinting technology (MIT), namely structure predictability, recognition specificity and application universality. Owing to special coordination or electrostatic interactions, ion imprinted polymers (IIPs) are generally compatible with aqueous media and have advantages over most molecularly imprinted polymers (MIPs). IIPs can achieve effective identification of water-soluble ions, especially heavy metals and radioactive elements that cause increasing concerns. The purpose of this review is to summarize recent advances of ion imprinting, focusing on the current status and challenges in fundamentals and applications that involve almost all types of ions and ion-related molecular imprinting. In addition, various smart strategies are highlighted, such as surface imprinting, stimuli-responsive imprinting, dual/ multiple components imprinting, click chemistry, and microwave-assisted heating. In this review, the elemental periodic table is first utilized as a template to introduce ion classification standards for various IIPs, including main groups, transition elements, actinides, rare earths, metalloids, anion imprinting and secondary imprinting. Finally, the challenges and possible solution strategies plus future trends are also proposed (302 references).

\section{Introduction}

Molecular imprinting technology (MIT) ${ }^{\mathbf{1}}$ has been increasingly developed to provide versatile receptors efficiently and economically. $^{2}$ In general, molecularly imprinted polymers (MIPs) are prepared by the copolymerization of functional monomers and cross-linkers in the presence of target analytes (the imprinted molecules) that act as template molecules. ${ }^{2}$ By
${ }^{a}$ Key Laboratory of Coastal Environmental Processes and Ecological Remediation, Yantai Institute of Coastal Zone Research, Chinese Academy of Sciences, Yantai 264003, China. E-mail: lxchen@yic.ac.cn; Fax: +86 535 2109130; Tel: +86 535 2109130

${ }^{b}$ College of Chemistry and Chemical Engineering, Qufu Normal University, Qufu 273165, China

'University of Chinese Academy of Sciences, Beijing 100049, China

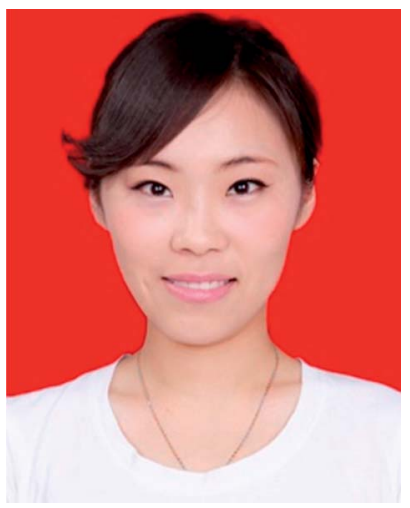

Junqing $\mathrm{Fu}$ received her $B S$ in chemistry from Qufu Normal University in 2013. She is currently an MS candidate under the supervision of Prof. Lingxin Chen, in Yantai Institute of Coastal Zone Research, Chinese Academy of Sciences. Her research interests focus on the design and preparation of novel molecularly/ion imprinted polymers and their applications.

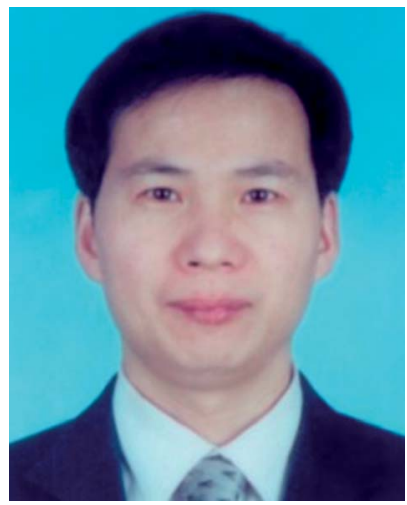

Lingxin Chen received his $P h D$ degree in analytical chemistry from the Dalian Institute of Chemical Physics, Chinese Academy of Sciences, in 2003. After 2 years of postdoctoral experience at the Department of Chemistry, Tsinghua University, China, he joined first as a BK21 researcher and then as a research professor at the Department of Applied Chemistry, Hanyang University, Korea, in 2006. In 2009, as a professor, he joined Yantai Institute of Coastal Zone Research, Chinese Academy of Sciences. His research interests include the studies of novel materials such as functionalization nanoparticles for developing nanometer biochemical analysis methods, and molecular imprinting technology. 

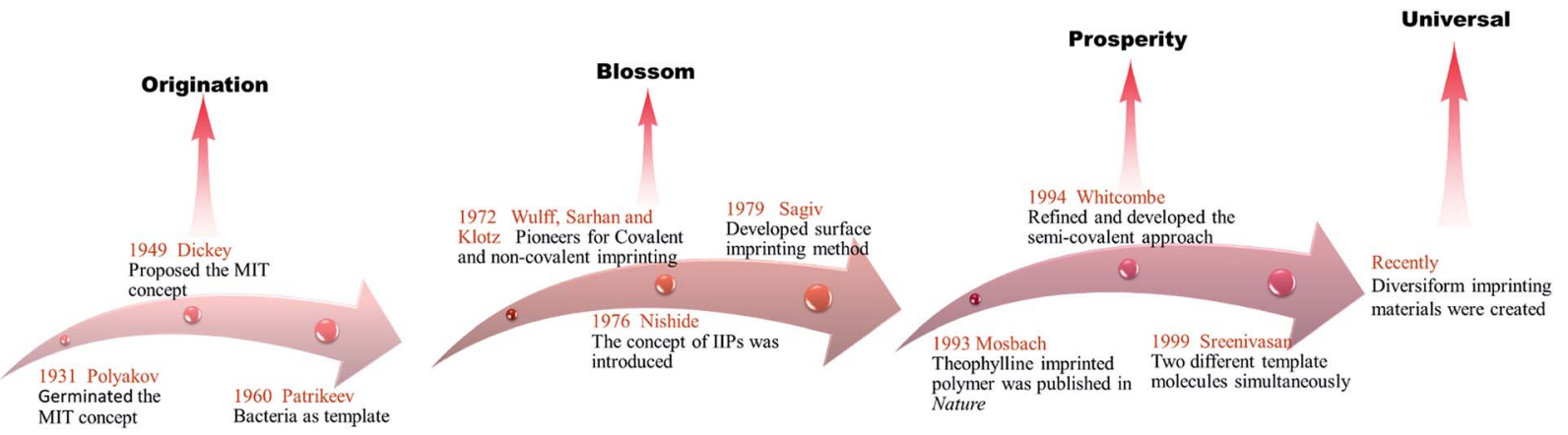

Fig. 1 A brief view of imprinting technology history.

contrast, ion imprinted polymers (IIPs) are similar to MIPs and retain all virtues of MIPs, but they recognize ions. ${ }^{3-6}$

Fig. 1 schematically illustrates a brief view of imprinting technology history. In 1931, the concept of molecular imprinting first germinated as "unusual adsorption properties of silica particles prepared using a novel synthesis procedure" proposed by Polyakov. ${ }^{1}$ These "unusual adsorption properties" have been displayed by numerous polymers, which has paved the way for the original concept of MIPs. ${ }^{7}$ In 1949, Dickey ${ }^{8}$ proposed the concept of molecular imprinting but that did not bring extensive attention. Patrikeev et al. ${ }^{9}$ resorted to bacteria as templates in 1960. As pioneers, Wulff, Sarhan and Klotz ${ }^{10-12}$ further introduced the concept of MIPs in the early 1970s and since then they have developed several approaches that come under the broad category of covalent and non-covalent imprinting. During this period of time, MIT also started to blossom the new technology on a large scale. More excitingly, IIPs were first proposed in 1976 by Nishide et al. ${ }^{3}$ using a metal ion (for example), (Cu(II), $\mathrm{Fe}(\mathrm{III}), \mathrm{Co}(\mathrm{II}), \mathrm{Zn}$ (II), $\mathrm{Ni}$ (II), and $\mathrm{Hg}$ (II)) as a template via cross-linking poly(4-vinylpyridine) with 1,4dibromobutane; this was considered as the most promising branch of MIPs. Then, surface imprinting, a method of imprinting on the surface, was first developed by Sagiv ${ }^{13}$ in 1979 using silica particles with polymerized siloxane as a surface modifier. In $1993,{ }^{14}$ theophylline imprinted polymer was synthesized and reported in Nature, after which unprecedented enthusiasm for the earlier study of MIT was formed. In 1994, Whitcombe $^{15}$ proposed and developed a semi-covalent approach. In 1999, Sreenivasan et al. ${ }^{16}$ discussed the possibility of simultaneously imprinting two different template molecules in poly(2-hydroxyethyl methacrylate), namely, salicylic acid and hydrocortisone, which provided a convincing strategy. Nowadays, MIT and ion imprinting techniques (IIT) have extended rapidly in many fields while at the same time they are accompanied by many challenges.

IIPs are of special attraction because of their ease of synthesis, high environmental stability and high ability to be reused, as well as broad applicability and high selectivity towards the target ion due to a memory effect that results from their preparation process. First, the force of metal complexes in IIPs is much larger than that of a hydrogen bond (usually present in MIPs) especially in an aqueous phase, and thereby IIPs can achieve effective identification of water-soluble ions and metal ions. Because the molecular recognition of a life system is closely related to metal ions and the multitudinous courses of the natural world that occurs in aqueous phases, the development of IITs and IIPs has important scientific significances and application values. Second, some transition metals, such as $\mathrm{Co}(\mathrm{II}),{ }^{17,18} \mathrm{Pt}(\mathrm{II}),{ }^{19,20}$ and $\mathrm{Fe}(\mathrm{II}),{ }^{21}$ not only can be used as part of the imprinting, but also as an intrinsic catalytic center

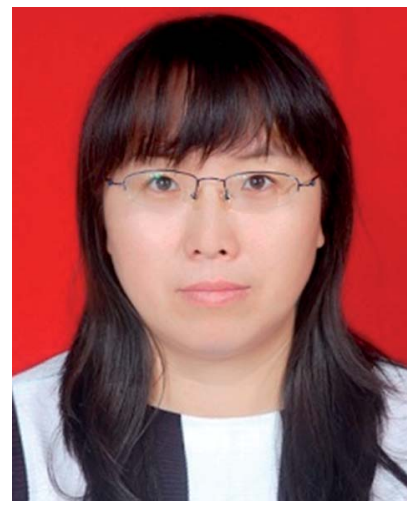

Jinhua Li received her $P h D$ in analytical chemistry from the Department of Chemistry of Hong Kong Baptist University, Hong Kong SAR, China, in 2009. In the same year, she joined the Laboratory of Environmental Microanalysis and Monitoring in Yantai Institute of Coastal Zone Research, Chinese Academy of Sciences, as an assistant professor. Her current research interest focuses on preparation of novel molecular imprinting polymers and applications to sample pretreatment and chemo/biosensors.

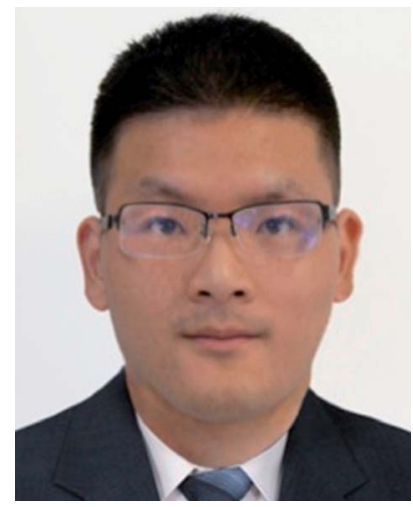

Zhong Zhang received his master degree from Nan Chang University, China, in 2012. Now, he is a doctoral candidate in Yantai Institute of Coastal Zone Research, Chinese Academy of Sciences. His current research interest focuses on the preparation of novel molecularly imprinted polymers and their applications in chemo/biosensors and chromatographic separation analysis. 
for conversion of complexes. With the aid of ion catalysis, molecularly imprinted micro-reactors can be built. And, last but not least, IIPs can reach thermodynamic and kinetic equilibrium rapidly and simultaneously compared with MIPs, owing to interaction between central metal ions.

Recently, some reviews on imprinting have summarized rapid development and wide applications of imprinting technologies and materials.,22-26 Our group ${ }^{2}$ gave a panoramic review on MIT and Whitcombe et al. ${ }^{22}$ presented a survey that reviewed 3779 references over the years 2004-2011; but neither of them focused on ion imprinting. Rao et al. ${ }^{23}$ paid more attention to some applications of IIPs for solid-phase extraction (SPE), sensors, and membrane separations. Another review by Branger et al. $^{24}$ primarily concerned metal ion IIPs, especially related approaches and techniques. Mafu et $a .^{25}$ reviewed environmental monitoring of inorganic pollutants using IIPs and $\mathrm{Wu}^{26}$ focused on anion IIPs. None of the reviews mentioned above comprehensively involve the full development status, applications and trends of IIT and IIPs. Lately, more and more IIPs and synthetic techniques have been proposed, for instance, proton imprinting ${ }^{27}$ reported in 2014, which further pushed forwards the development of ion imprinting. Hitherto, various IIPs for the majority of the elements from the first to the seventh period of the elemental periodic table have been prepared, except for some elements in metalloids, alkali metals, rare earth metals and transition regions, as seen in Fig. 2.

Herein, we review the progresses of ion imprinting, addressing design and synthesis strategies, summarizing the current status and challenges, mentioning almost all types of ions (even metal ion-related macromolecule imprinting), and emphasizing publications from 2008-2015. Various smart technologies are highlighted, including surface imprinting technology, stimuli-responsive imprinting technology, dual/ multiple components imprinting strategy, click chemistry technology, and microwave-assisted heating technology. The challenges (with possible solution strategies), and future perspectives are cautiously proposed.

\section{Fundamentals of IIPs preparation}

Similar to MIT, IIT primarily targets ions as templates and combines the ligands or functional monomers to form chelates or composites by coordinate bonds, metal bonding, hydrogen bonding and other effects, followed by the elution of template ions. Finally, IIPs corresponding to the three-dimensional structure of pores with the target ion are obtained, and this can enable the separation and concentration of ions. However, the completion of IIPs depends on various factors, ${ }^{24}$ including a sound choice of preparation components and techniques, which may become critical points to obtain ideal IIPs.

\subsection{Principles of IIPs preparation}

IIPs can be divided into two main types at present. In the first type, according to the coordination role between functional/ ligand monomers and ions (as template ions), ions themselves as target ions can achieve their own imprinting. In the other type, ions as a part of the functional monomer can contribute to the imprinting of macromolecules (especially biological macromolecules), and this can solve the challenge of macromolecules imprinting in aqueous systems. Both of the imprinting processes are generally similar, and are composed of three steps: pre-polymerization, polymerization, and removal. ${ }^{28}$ On the basis of various binding forces in the first step, three synthesis techniques are presented: covalent imprinting, ${ }^{\mathbf{1 0}, 28}$
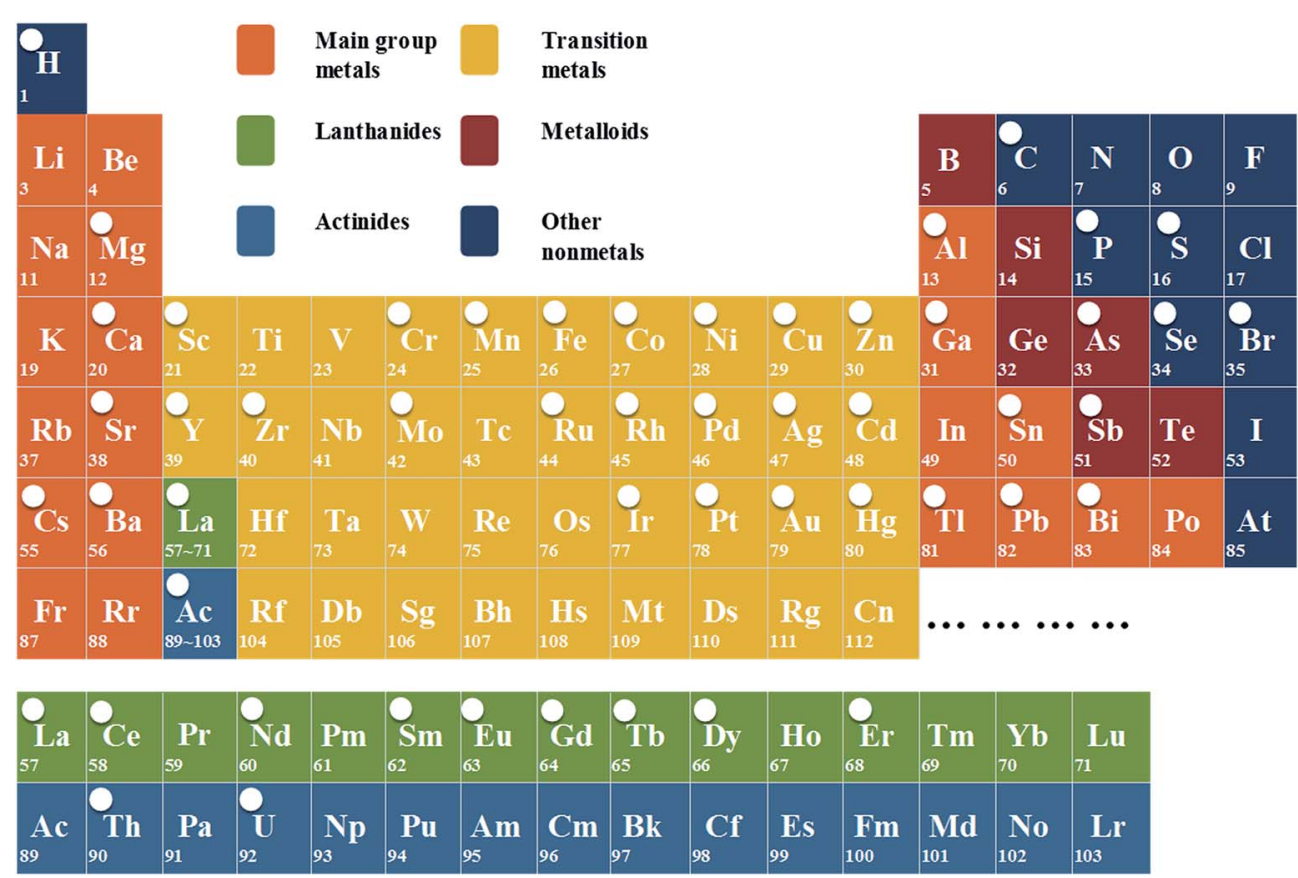

Fig. 2 Schematic illustration for all elements marked with dot notation in periodic table of elements used for ion imprinting. 
non-covalent imprinting, ${ }^{28,29}$ and semi-covalent imprinting. ${ }^{15,28}$ The principles of these three techniques for preparing IIPs are similar to those for preparing MIPs, which have been explained in detail in other publications. ${ }^{2,28}$

\subsection{Components of IIPs preparation}

In order to attain perfect IIPs, various components and reagents should be optimized, mainly including functional monomers and ligands, cross-linkers, initiators and porogens. Their types and relative proportions can affect recognition selectivity and binding capacities. Some general characteristics of the IIPs will be briefly introduced in the following sections.

2.2.1. Functional monomer and ligand. The purpose of selecting the appropriate functional monomer is to provide a functional group that can covalently or non-covalently bind with template ions, and is to ensure it has end groups to link with cross-linkers in order to obtain three-dimensional pore structured polymers. The force or molar ratio between monomer and template has a direct impact on the affinity of IIPs, ${ }^{30,31}$ and determines the accuracy and selectivity of recognition sites. ${ }^{32}$ Structures of several typical functional monomers such as acrylic acid (AA), methacrylic acid (MAA), and vinyl pyridine (VP) are displayed in Fig. 3. However, many functional monomers cannot reach the requirements of imprinting or the bonding force is not strong enough. In recent years, a lot of efforts have been made on novel, self-synthetic monomers such as thymine-3isocyanatopropyl-triethoxysilane (T-IPTS), ${ }^{33}$ ethylenediaminetetra$N$-(3-pyrrole-1-yl)propylacetamide (monomer L), ${ }^{34}$ (4-ethenylphenyl)-4-formate-6-phenyl-2,2-bipyridine, ${ }^{35} \quad$ (2Z)- $N, N$-bis(2aminoethylic)but-2-enediamide, ${ }^{36}$ 8-HQ-APTES, ${ }^{37} \mathrm{~N}$-(o-carboxyphenyl)maleamic acid (CPMA), ${ }^{38}$ and 2,4-dioxopentan-3-yl methacrylate. ${ }^{39}$ Karim et al. ${ }^{40}$ have reviewed different strategies utilized in optimizing MIP design, which can be a good reference.

As for a ligand, some similarities and differences exist compared to a monomer. The role of the ligand is specific and

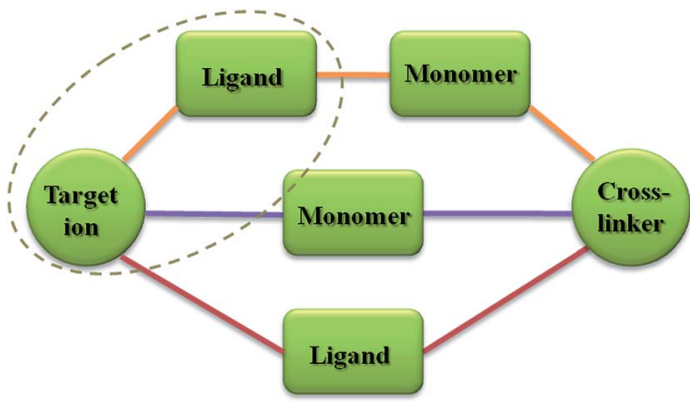

Type 1 Type $2 \longrightarrow$ Type 3

Fig. 4 Schematic illustration for three modes related to monomer and ligand.

fundamental since ion chelation is involved in the recognition process. $^{24}$ The coordination interaction between an ion and the polymer is due to electron donation from heteroatoms based on its unfilled orbitals in the outer sphere. Relatively speaking, commonly used monomers often possess universality to form immobilized covalent or non-covalent bonds for many ions, which may limit their selectivity. However, chelation is specific for certain target. As far as we know, there are three kinds of modes related to monomers and ligands for IIPs preparation (as shown in Fig. 4). In the first type, a ligand acts as an assistant monomer which contains prominent chelate groups without end groups to link with a cross-linker. So, a functional monomer is required to constitute a cross-linked structure. In this case, a ligand and monomer may form a composite monomer, which is likely to gain better effects and is often used for IIPs preparation. In the second type, just a monomer is needed to meet the imprinting conditions, and this is the most commonly used type for imprinting. Some ligands simultaneously conduct monomer and specific chelation roles, as displayed in the third type, which is uncommon but valuable.

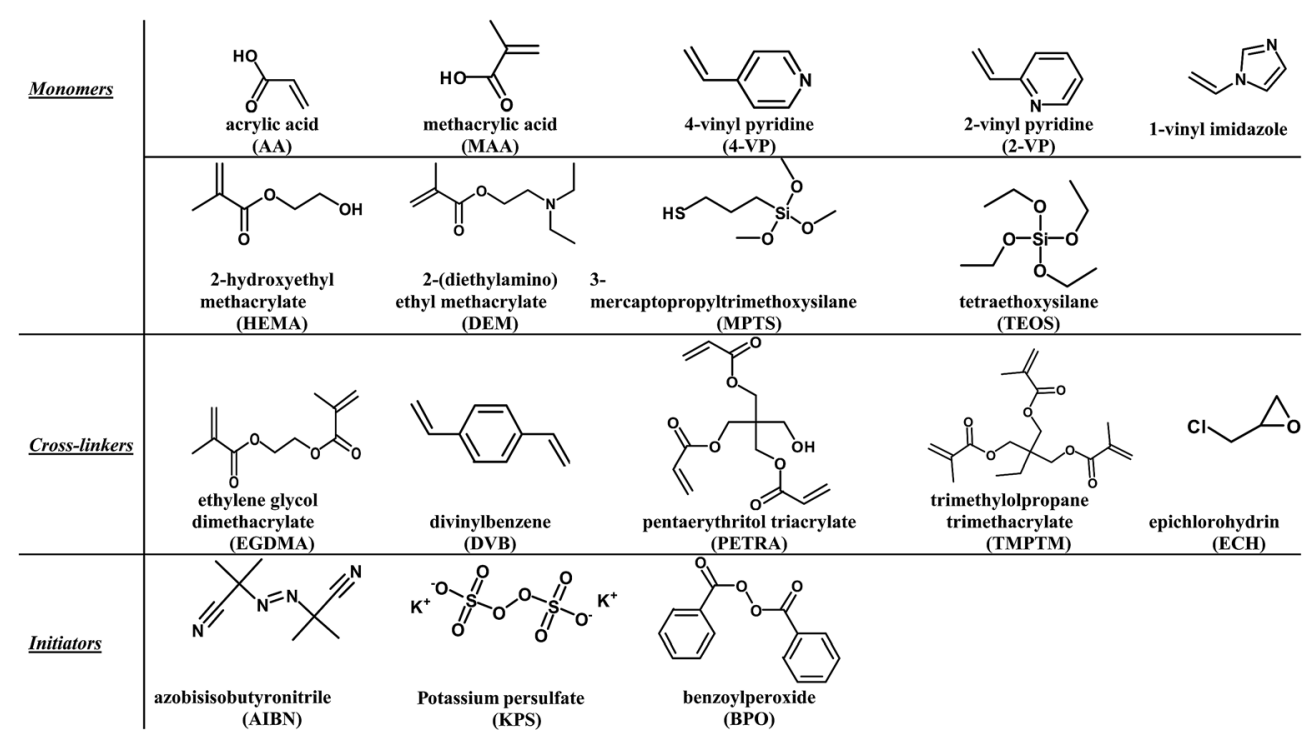

Fig. 3 Structures of commonly used functional monomers, cross-linkers and initiators. 
2.2.2. Cross-linker, initiator and porogen. Apart from stabilizing the molecular recognition site, a cross-linker also plays a major role in delivering mechanical stability and controlling the porosity of the polymer. ${ }^{41}$ Some widely used ones to date including ethylene glycol dimethacrylate (EGDMA), divinylbenzene (DVB), tetraethoxysilane (TEOS), ${ }^{\mathbf{4 2 , 4 3}}$ trimethylolpropane trimethacrylate (TMPTM), ${ }^{\mathbf{4 4 , 4 5}}$ epichlorohydrin $(\mathrm{ECH})^{\mathbf{4 6 , 4 7}}$ and pentaerythritol triacrylate (PETRA) $)^{36,48}$ are listed in Fig. 3. Besides, the dosage of cross-linkers determines the particle size and uniformity of IIPs. Many studies ${ }^{\mathbf{4 9 , 5 0}}$ have shown that finding an optimum ratio is very important to improve a polymer's properties.

In order to select suitable initiators, their effects on polymer properties, polymerization method and temperature, storage and transportation security and other aspects should be considered seriously. For polymerization methods, an oilsoluble initiator may be a good option for bulk, solution and suspension polymerization, while a water-soluble one may fit better for emulsion and aqueous solution polymerization. The typical and commonly used initiators for IIPs preparation include azo(bis)isobutyronitrile (AIBN), benzoylperoxide (BPO) and persulfate, and are shown in Fig. 3.

Porogen also plays an important role in polymerization, since it acts as both a porogen (porosity generator) and a solvent in preparation processes. The hydrogen bond parameter, dielectric constant, polarity and solubility of a porogen make a difference for polymer usability. ${ }^{51-53}$ In addition, the dosage and polarity of a porogen influence the bonding strength between functional monomers and templates as well as the property and morphology of polymers. ${ }^{2}$ Aprotic and low polar organic solvents such as toluene, acetonitrile, dichloromethane, and chloroform show a high imprinting efficiency, especially in noncovalent interaction systems.

\subsection{Preparation technologies of IIPs}

For IIPs, general polymerization technologies usually include sol-gel processes and radical polymerization based on a stepwise polymerization mechanism and a chain polymerization mechanism, respectively. A radical reaction is composed of bulk, ${ }^{54,55}$ suspension, ${ }^{56}$ emulsion, ${ }^{57,58}$ and solution ${ }^{59}$ polymerization. Bulk polymerization will provide monolithic morphology materials, while heterogeneous (suspension or emulsion) or homogeneous (precipitation, dispersion or solgel $^{60}$ ) polymerization can produce regular-shaped polymers. All the general polymerization technologies have been dealt with in many reviews ${ }^{2,24,60}$ and in book chapters ${ }^{28}$ and will not be described here.

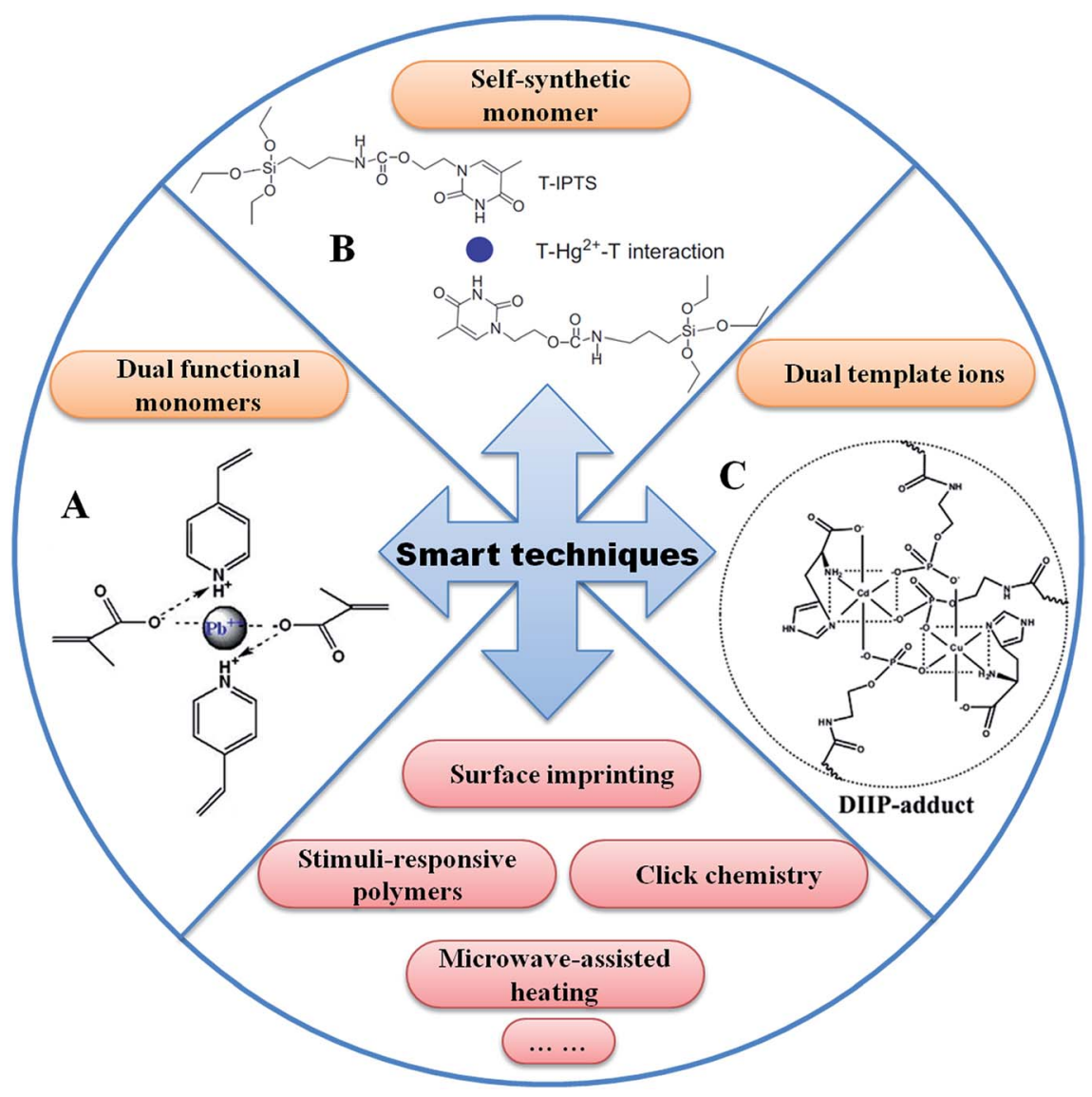

Fig. 5 Related smart techniques for IIPs preparation: (A) Pb(I)-IIPs employing dual functional monomers of MAA and 4-VP. ${ }^{84}$ (B) Schematic illustration for the interaction of $\mathrm{T}-\mathrm{Hg}^{2+}-\mathrm{T}$ employing self-synthetic monomer T-IPTS ${ }^{33}$ (C) DIIP-adduct using dual template ions: Cd(॥) and $\mathrm{CU}(\mathrm{II})$ bindings simultaneously in their respective imprinted cavities. ${ }^{85}$ 
Apart from those, many smart preparation techniques have been sought in order to seek better solutions for attractive and delicate well-designed IIPs. Among them, surface imprinting, stimuli-responsive imprinting and dual/multiple components imprinting strategies have been increasingly developed, while click chemistry and microwave-assisted heating techniques have been little reported. Related smart techniques are briefly illustrated in Fig. 5.

2.3.1. Surface imprinting. IIPs obtained by traditional synthesis methods may lead to the deficiencies of poor accessibility, slow dynamic identification and incomplete template ion removal, while a burgeoning method, surface imprinting, ${ }^{13}$ to some extent, can solve the above problems. Core-shell structured microspheres can establish binding sites on the shell uniformly which is advantageous for template ions elution and diffusion. Furthermore, various carriers are required to play a role of auxiliary supporting in the imprinting process. Amongst them, modified silica particles ${ }^{45}$ are the most commonly used, and others such as active polystyrene, ${ }^{61}$ chitosan (CTS), ${ }^{62}$ quantum dots (QDs), ${ }^{63-65}$ and magnetic nanoparticles $(\mathrm{NPs})^{57,66-69}$ are also favored.

2.3.2. Stimuli-responsive imprinting. Stimuli-responsive polymers, also called smart polymers and belonging to functional polymers, will produce corresponding specific responses when the aggregates are subjected to some external environmental stimuli ${ }^{70}$ such as magnetic, ${ }^{71} \mathrm{pH},{ }^{72,73}$ temperature ${ }^{74-76}$ light,${ }^{77-79}$ and chirality. ${ }^{80}$ For example, using $N$-isopropyl acrylamide (NIPAM) as a thermo-responsive element and AA as an interactive element, Ida et al. $^{76}$ synthesized a straight-chained thermo-responsive adsorbent with a wide range of chelating group content for the recovery of $\mathrm{Cu}(\mathrm{II})$. The end-product of poly(NIPAM-co-AA) exhibited considerably higher adsorption capacity (1 order higher) due to a higher introduction amount of the interactive element compared to previously reported crosslinked thermo-responsive adsorbents. Zhang and his team ${ }^{\mathbf{8 1}}$ designed and synthesized temperature sensitive imprinted polymer hydrogels for lysozymes through metal coordinate interaction. $N$-(4-Vinyl)-benzyliminodiacetic acid (VBIDA) via $\mathrm{Cu}$ (II) formed a coordinate complex with a surface-exposed histidine of the template. At $28{ }^{\circ} \mathrm{C}$, the imprinting cavity was in a swollen state and the monomer chelated with $\mathrm{Cu}(\mathrm{II})$, which was easily accessible for the protein, leading to the maximum adsorption capacity. ${ }^{81}$ When the temperature increased to 43 ${ }^{\circ} \mathrm{C}$, the cavity was in a collapsed state and the $\mathrm{Cu}$ (II) was blocked, resulting in a lower adsorption of the protein. ${ }^{81}$

However, dual/multi-stimuli responsive imprinted polymers are relatively less explored for ions than molecules. For instance, using 4-[(4-methacryloyloxy)phenylazo]benzoic acid (MPABA) as a photoresponsive functional monomer and $\mathrm{Fe}_{3} \mathrm{O}_{4}$ as magnetic substrate, our group ${ }^{82}$ prepared magnetic and photonic dual responsive-MIPs (DR-MIPs) using suspension polymerization. The simple, rapid and reliable DR-MIPs based method proved potentially applicable for trace caffeine analysis in complicated samples. ${ }^{82}$ For more details on stimuli-responsive MIPs, please refer to our recent review article. ${ }^{70}$ Based on the development of dual/multi-responsive MIPs, related stimuli-IIPs deserve future good expectations.
2.3.3. Dual/multiple components imprinting strategies. Although IIPs are suitable to separate and remove heavy metal ions, selectivity is still urgently required for improvements. Besides the novel, self-synthetic monomers, the strategies of dual/multiple functional monomers and dual/multiple template ions have gradually aroused increasing attention. The widely and generally used functional monomers such as MAA and VP can offer coordination for some metal ions, such as $\mathrm{Cu}(\mathrm{II})-\mathrm{IIPs}^{83}$ and $\mathrm{Pb}(\mathrm{II})-\mathrm{IIPs}{ }^{84}$ Two functional monomers can provide an excellent synergy effect to achieve fast adsorption kinetics and high binding capacity. Dual/multiple template ions imprinting is also a meaningful strategy, since multiple ions can be removed simultaneously. For example, $\mathrm{Cu}$ (II) and $\mathrm{Cd}$ (II) dual-template $\operatorname{IIPs}^{85}$ as well as $\mathrm{Cd}$ (II) and $\mathrm{Pb}$ (II) dual-template IIPS $^{86}$ have been attained and demonstrated excellent imprinting performances. More interestingly, Zhu and his team $^{87}$ synthesized a mixed As(v)-Cr(III) dual-template IIP using two functional monomers. The resultant IIPs could provide a potential material to treat mixed pollutions of $\mathrm{Cr}(\mathrm{III})$ and $\mathrm{As}(\mathrm{v})$ in a contaminated water environment.

2.3.4. Click chemistry. Click chemistry is an approach to a set of powerful, highly reliable, and selective reactions for the rapid synthesis of useful new compounds and combinatorial libraries through heteroatom links $(\mathrm{C}-\mathrm{X}-\mathrm{C}),{ }^{88}$ which was first proposed in 2001 by Sharpless, ${ }^{88}$ the winner of the Nobel Prize in Chemistry. Shortly thereafter, this smart technique was applied to the fields of drug discovery, ${ }^{\mathbf{8 9}}$ organic synthesis, polymer chemistries, ${ }^{\mathbf{9 0}, 91}$ and others. ${ }^{\mathbf{9 2 - 9 5}}$ However, reports on click chemistry applied in imprinting are rare. ${ }^{96-102}$ With the aid of $\mathrm{Cu}(\mathrm{I})$ catalysis, Li et al. ${ }^{92}$ have constructed new azo-chromophore-containing hyperbranched polymers (HP1 and HP2) from $\mathrm{AB}_{2}$ monomers through click chemistry reactions. However, the utilization of click chemistry in IIPs is relatively rare. Naeimi et al. ${ }^{102}$ obtained $\mathrm{Cu}(\mathrm{II})$-imprinted mesoporous organosilica nanocomposites as a recyclable catalyst by using click synthesis of 1,2,3-triazole derivatives. Performing related studies is imperative and will further push forward the development of IIPs and click chemistry.

2.3.5. Microwave-assisted heating. The microwave-assisted heating technique has been widely applied in synthesis, sintering, sterilization and other $\operatorname{areas}^{2}$ due to the properties of heating speed, selectivity, and efficiency, resulting from rapid energy transfer and high energy efficiency of microwave irradiation. So far, the microwave-assisted synthetic method has been applied to almost all types of polymerization including bulk, ${ }^{\mathbf{1 0 3}}$ emulsion, ${ }^{\mathbf{1 0 4 - 1 0 6}}$ suspension, ${ }^{\mathbf{1 0 7}}$ solution polymerization, ${ }^{\mathbf{1 0 8}}$ and sol-gel synthesis. ${ }^{109}$ Taking suspension polymerization as an example, a kind of magnetic MIP beads product was prepared using a microwave-assisted method for the analysis of trace triazines in complicated samples. ${ }^{\mathbf{1 0 7}}$ The resultant products exhibited good characteristics such as narrow size distribution, uniform morphology, and superior selectivity for analytes, and offered rather high imprinted efficiency factors, which proved the bright prospects of microwave-assisted imprinting. However, by now, to the best of our knowledge, no studies have been reported related to the synthesis of IIPs by a microwave- 
assisted heating technique. The technique for IIPs preparation will be a promising direction.

\section{Applications of various IIPs}

The majority of the IIPs involve metal elements, some actinide and rare earth elements from the first to the seventh period in the periodic table, and even metalloid, anion imprinting and secondary imprinting have also been successfully prepared now, as shown in Fig. 2. We present an overview of various IIPs as discussed below.

\subsection{Main group elements IIPs}

Groups 1, 2 (s-block) and 13 to 18 (p-block) in the elemental periodic table constitute the main group, including $\mathrm{Pb}, \mathrm{Sr}, \mathrm{Al}$, $\mathrm{Bi}, \mathrm{Ca}, \mathrm{Cs}, \mathrm{Ga}, \mathrm{H}, \mathrm{Sn}, \mathrm{Tl}$, etc.

3.1.1. Lead ion imprinted polymers (Pb-IIPs). Lead (Pb), one of the five heavy metals with environmental and toxicological significances, has become a research hotspot and received wide concerns. Various methods are available for the determination and removal of $\mathrm{Pb}(\mathrm{II})$, so especially $\mathrm{Pb}$-IIPs attract much attention. Table 1 summarizes the preparation of Pb-IIPs by various polymerization techniques and their related performances. ${ }^{43,68,84,110-116}$

Aboufazeli et al. ${ }^{68}$ have synthesized IIP magnetic mesoporous silica NPs for selective separation and determination of $\mathrm{Pb}$ (II) in food samples simply, rapidly and stably. Li et al. ${ }^{\mathbf{1 1 0}}$ have added nano- $\mathrm{TiO}_{2}$ to $\mathrm{Pb}$-IIPs to form covalently bound surface monolayers of the metal alkoxide in order to connect monomers and cross-linkers with excellent chemical stability. Yang et al.111 employed CTS-modified multi-walled carbon nanotubes (MWCNTs) as matrix materials to prepare a polymer layer of 15 to $20 \mathrm{~nm}$ successfully. An atomic absorption method was used to study the adsorption properties of the Pb-IIPs, which can be
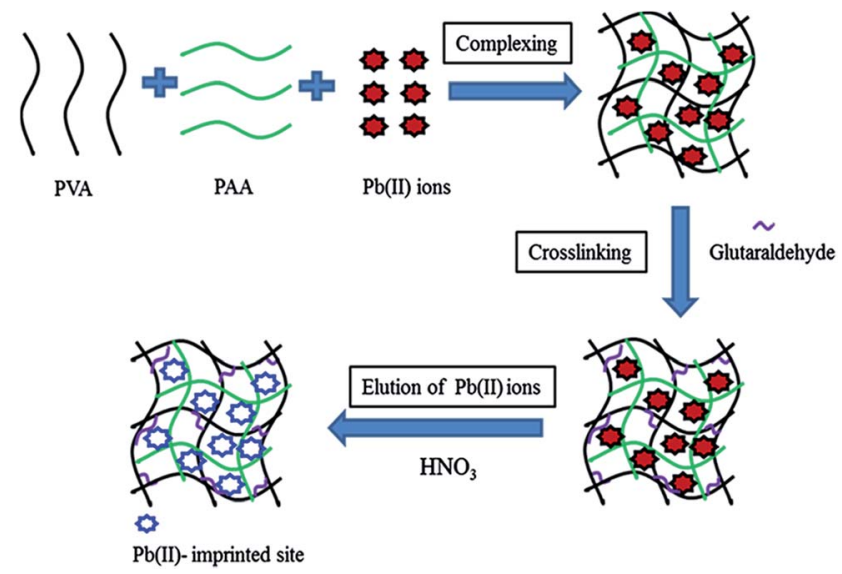

Fig. 6 Schematic diagram of preparation of $\mathrm{Pb}(\mathrm{I})$-imprinted membrane by s-INP technique. Reprinted with permission from ref. 114. Copyright 2014 Elsevier Inc.

applied to the separation and determination of $\mathrm{Pb}$ (II) in waste water. $^{111}$ By using a microporous polypropylene membrane (MPPM) as support material, Zheng et al. ${ }^{112}$ prepared a $\mathrm{Pb}$ (II) ion-imprinted composite membrane according to a three-step reaction: grafting polymerization of AA, CTS covalent immobilization, and ion imprinting. Based on inverse emulsion polymerization, Luo et al. ${ }^{113}$ prepared $\mathrm{Pb}$ (II)-IIPs using a crown ether as a functional monomer to get higher capacity and selectivity in real environmental water samples. Based on a semi-interpenetrating polymer network (s-IPN) technique, Chen et al. ${ }^{\mathbf{1 1 4}}$ prepared an innovative $\mathrm{Pb}$ (II)-imprinted polyvinyl alcohol (PVA)/ polyacrylic acid (PAA) membrane (Pb-IM), as shown in Fig. 6. The analyses indicated that the adsorption of $\mathrm{Pb}$ (II) was mainly due to the complexation between carboxyl groups of PAA and hydroxyl groups of PVA and lead ions. The material may be

Table 1 The preparation and performance of $\mathrm{Pb}-\mathrm{IIPS}$

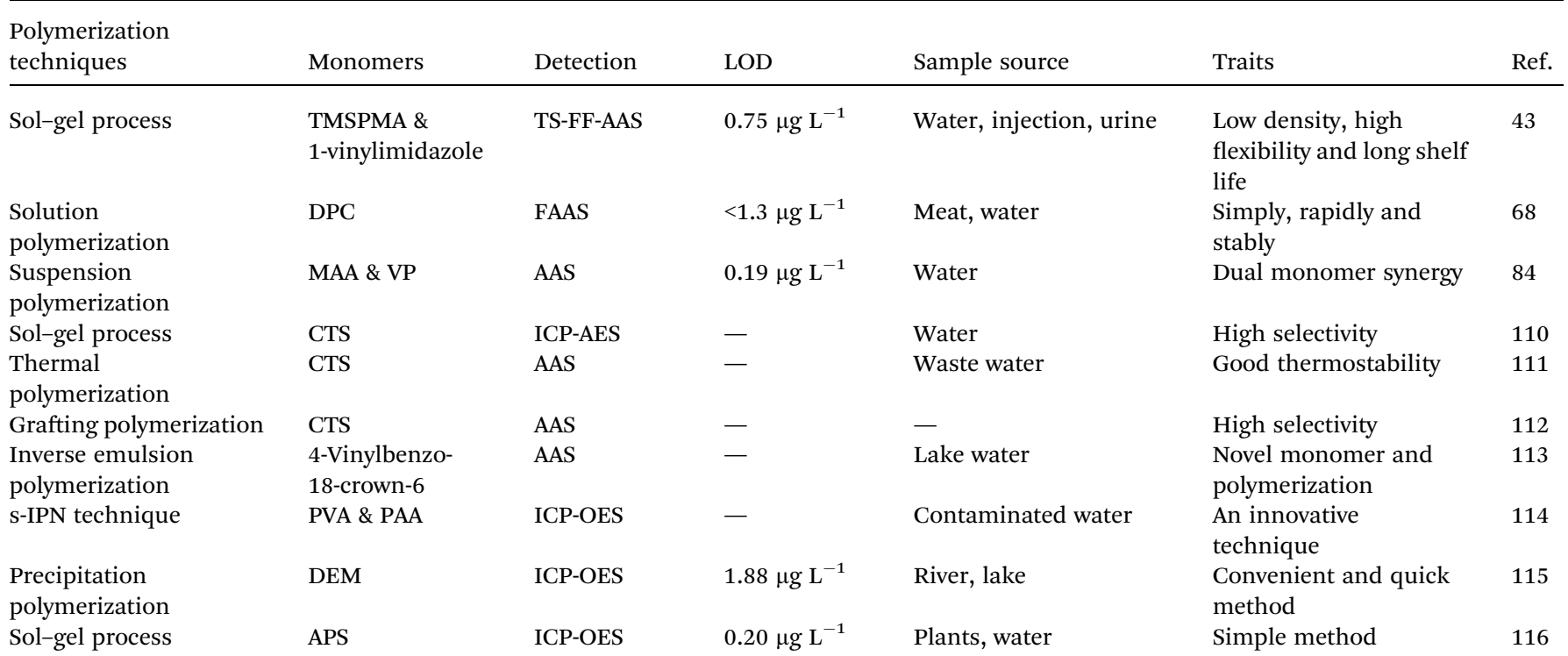


powerful for the selective removal of lead from contaminated water and the s-IPN technique can be a potential tool. ${ }^{\mathbf{1 1 4}}$

$\mathrm{Pb}$-IIPs are commonly applied to solid-phase extraction (SPE). ${ }^{43,84,115,116}$ Tarley et $a l .{ }^{43}$ have synthesized a ion imprinted polyvinylimidazole-silica hybrid copolymer (IIHC) which was used as a selective solid sorbent for pre-concentration of $\mathrm{Pb}$ (II) by an on-line SPE system coupled to thermospray flame furnace atomic absorption spectrometry (TS-FF-AAS). Our group ${ }^{\mathbf{8 4}}$ made a successful attempt on Pb-IIPs based on ionic interaction via synergy of dual functional monomers (MAA and VP) for selective $\mathrm{SPE}$ of $\mathrm{Pb}(\mathrm{II})$ in water samples. Compared to a single monomer, this strategy provides high selectivity and reliability, obvious anti-interference ability, and high extraction efficiency. ${ }^{\mathbf{8 4}}$

3.1.2. Strontium ion imprinted polymers (Sr-IIPs). Strontium (Sr), a soft silver-white or yellowish metallic element of the alkali metal group, has the minimum abundance and active chemical properties which commonly exist in mineral water and is essential trace element for human health to prevent arteriosclerosis and thrombosis. IIT is a strong pre-processing means to concentrate $\mathrm{Sr}$.

Thanks to the large specific surface area, palygorskite has strong adsorption capability for metal ions, inorganic, and organic species. Sr-IIPs have been synthesized by surface imprinting with palygorskite as a sacrificial support. ${ }^{117}$ The monolayer adsorption capacity of Sr-IIPs is $45.0 \mathrm{mg} \mathrm{g}^{-1}$ at $298 \mathrm{~K}$, $53.5 \mathrm{mg} \mathrm{g}^{-1}$ at $308 \mathrm{~K}$ and $58.5 \mathrm{mg} \mathrm{g}^{-1}$ at $318 \mathrm{~K}$. Kalal et al. ${ }^{118}$ have synthesized Sr-IIPs based on aniline-formaldehyde for extraction of Sr by SPE from tap water samples. Hrdina et al. ${ }^{119}$ synthesized crown ether modified cation exchange IIP particles, attaining $86 \pm 2 \%{ }^{90} \mathrm{Sr}$ uptake at $\mathrm{pH}=9$ when applied in urinalysis. Based on graphene oxide, Liu et al. ${ }^{\mathbf{1 2 0}}$ synthesized a thermal-responsive magnetic imprinted polymer based on mesoporous silica SBA-15 for the removal of $\mathrm{Sr}(\mathrm{II})$ in aquatic environments. In the same year, ${ }^{\mathbf{1 2 1}}$ they successfully synthesized a hydrophilic surface IIP by reversible addition-fragmentation chain transfer (RAFT) polymerization, as displayed in Fig. 7. The results showed that the polymers were homogeneous thin layers and they exhibited excellent imprinting efficiency and adsorption capacity. ${ }^{\mathbf{1 2 1}}$

3.1.3. Other main group ion IIPs. Besides $\mathrm{Pb}$ and $\mathrm{Sr}$, some main group ions based IIPs have also been synthesized..$^{27,122-135}$

Alkaline-earth metal. Willner and his group ${ }^{122}$ synthesized gold nanoparticles (AuNPs) functionalized with electropolymerizable thioaniline units and dithiothreitol ligands for alkaline-earth metal imprinting, presenting ultrasensitive and selective detection of $\mathrm{Mg}$ (II), $\mathrm{Ca}$ (II), $\mathrm{Sr}$ (II) and $\mathrm{Ba}$ (II) using surface plasma on resonance spectroscopy (SPRS). The atomic force microscopy (AFM) image showing the morphology of the electropolymerized Au aggregated composite and related schematic presentations for the electropolymerization are displayed in Fig. 8A and C, respectively. Taking $\mathrm{Ba}$ (II) as an example, Fig. 8B reveals that the association of the ions and their dissociation to from the imprinted sites are a reversible processes. And then, other main ions for IIPs are briefly introduced as follows.

$A l$. Aluminum (Al) is an element in the boron group with atomic number 13, which is a known neurotoxicant element that has contributed to some neurodegenerative diseases, ${ }^{\mathbf{1 3 6}}$ and its positively charged aqua and hydroxy monomeric forms have been found to be the most toxic species to living organisms. ${ }^{137}$ So, the selective removal of $\mathrm{Al}(\mathrm{III})$ is worth studying. In addition, some metal impurities have great influence on the properties of rare earth materials. Gao et al. ${ }^{123}$ prepared surface imprinted polymers for selective removal of $\mathrm{Al}$ (III) from $\mathrm{Pr}$ (III) and $\mathrm{Nd}$ (III) rare earth solutions. The adsorption capacity could reach $1.98 \mathrm{mmol} \mathrm{g}^{-1}$, and relative selectivity coefficients relative to $\mathrm{Pr}(\mathrm{III})$ and $\mathrm{Nd}$ (III) were 23.47 and 22.85 , respectively. With $\mathrm{N}$ methacryloyl-L-glutamic acid (MAGA) chosen as the complexed monomer, Denizli and his copartners $^{\mathbf{1 2 4}}$ prepared $\mathrm{Al}(\mathrm{III})$ imprinted poly(hydroxyethylmethacrylate- $N$-methacryloyl-L-glutamic acid) beads to be used for the selective removal of $\mathrm{Al}(\mathrm{III})$ from aqueous solutions. After that, they prepared $\mathrm{Al}(\mathrm{III})$-free PHEMAGA-Al(III) beads for selective separation of $\mathrm{Al}(\mathrm{III})$ out of human plasma, applying them to a continuous system by packing the beads into a separation column. ${ }^{\mathbf{1 2 5}}$

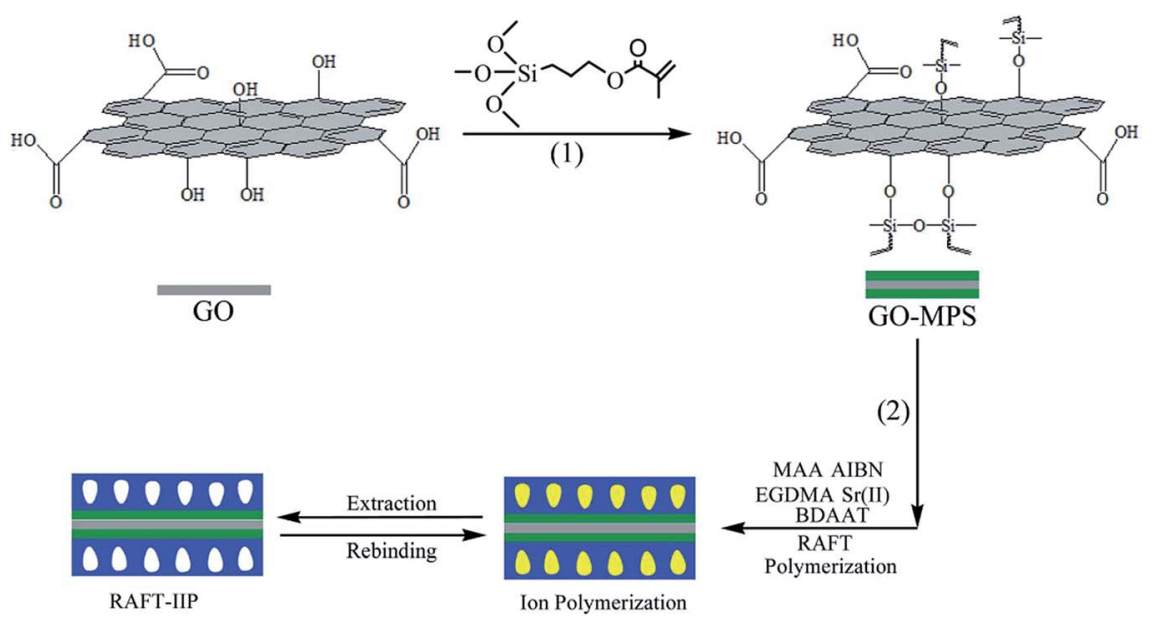

Fig. 7 Scheme depicting the ion-imprinting process on GO surface by RAFT polymerization. Reprinted with permission from ref. 121. Copyright The Royal Society of Chemistry 2015. 

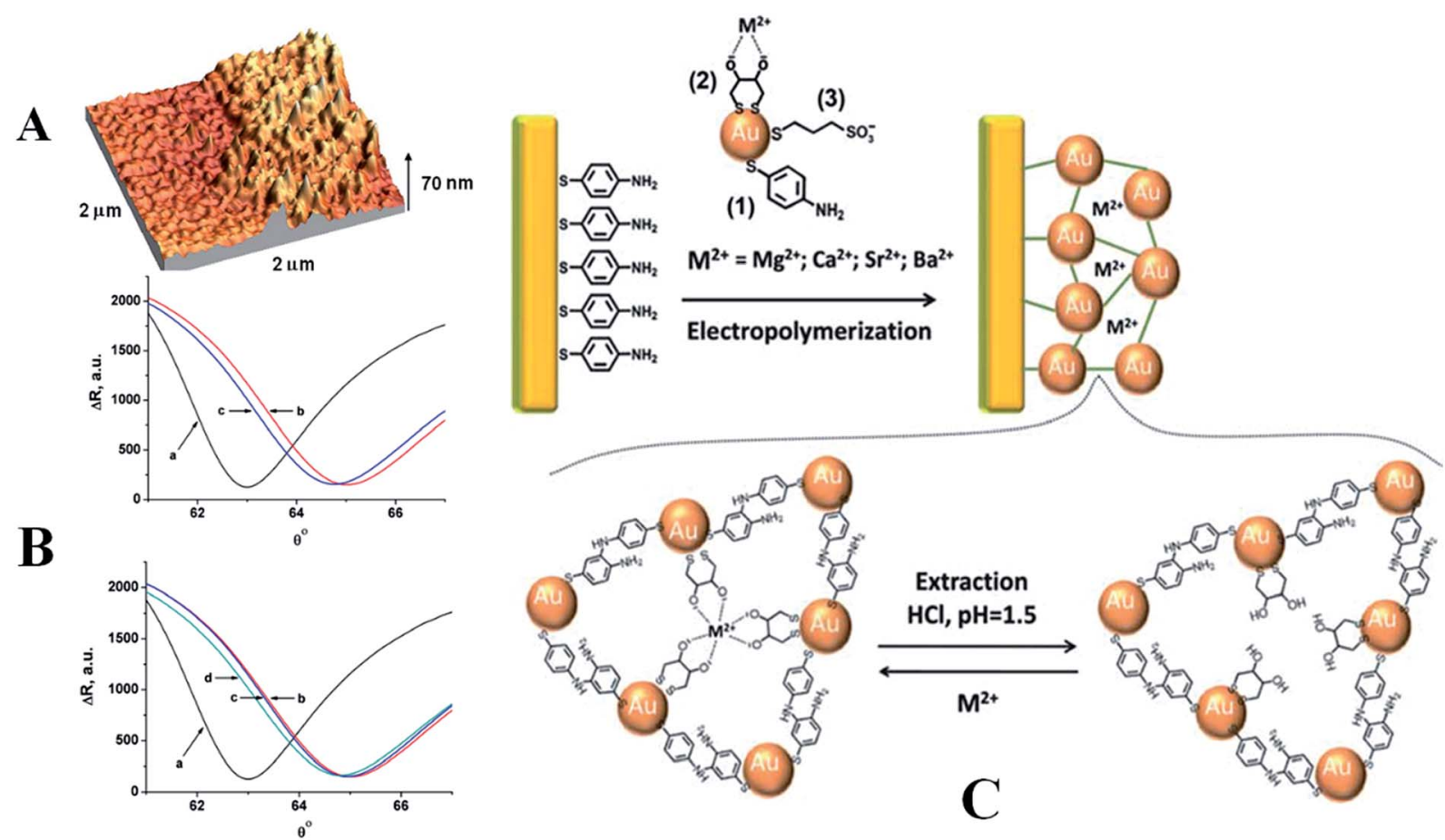

Fig. 8 A case of alkaline-earth metal imprinting: (A) AFM image of the boundary region corresponding to the electropolymerized Au NPs composite on the bare Au electrode surface. (B) Upper: SPR curves corresponding to: (a) the thioaniline-modified Au surface before electropolymerization. (b) The bis-aniline-crosslinked Au NPs composite electropolymerized on the Au surface in the presence of Ba ${ }^{2+}, 10 \mathrm{mM}$. (c) The $\mathrm{Ba}^{2+}$-imprinted bis-aniline crosslinked Au NPs matrix, following the treatment of the matrix with $\mathrm{HCl}, 0.03 \mathrm{M}$, for 5 minutes. Below: SPR curves corresponding to: (a) the thioaniline-modified Au surface before electropolymerization. (b) The bis-aniline-crosslinked Au NPs composite electropolymerized on the Au surface in the presence of $\mathrm{Ba}^{2+}, 10 \mathrm{mM}$. (c) The $\mathrm{Ba}^{2+}$-imprinted bis-aniline crosslinked Au NPs matrix, following the treatment of the matrix with water, for 10 minutes. (c) The $\mathrm{Ba}^{2+}$-imprinted bis-aniline-crosslinked Au NPs matrix, following the treatment of the matrix with water, for 5 hours. (C) Schematic presentation for the electropolymerization of a bis-aniline-crosslinked Au NPs composite on an Aucoated electrode for the sensing of $\mathrm{Mg}^{2+}, \mathrm{Ca}^{2+}, \mathrm{Sr}^{2+}$ or $\mathrm{Ba}^{2+}$ using dithiothreitol as a ligand for the imprinted metal ions. Reprinted with permission from ref. 122. Copyright the Royal Society of Chemistry 2012.

Bi. Bismuth (Bi), with atomic number 83 , resembles arsenic $(\mathrm{As})$ and antimony $(\mathrm{Sb})$ chemically and possesses strong polarization effects. The outermost electronic structure is $6 \mathrm{~s}^{2} 6 \mathrm{p}^{3}$, but the second outer electronic structure of the atom is $5 s^{2} 5 p^{6} 5 d^{10}$ which is an 18 electron structure. By forming a 2-(5-bromo-2pyridylazo)-5-diethylaminophenol complex via bulk polymerization, Bi(III) imprinted polymer was prepared for selective preconcentration of ultra-trace amounts of Bi(III) in environmental and biological samples followed by electrothermal atomic absorption spectrometry (ETAAS) detection. ${ }^{126}$

$\mathrm{Ca}$. Calcium (Ca) is essential for living organisms and the fifth-most-abundant dissolved ion in seawater by both molarity and mass, after sodium, chloride, magnesium and sulfate. To design a green material with $\mathrm{Ca}(\mathrm{II})$ and to take advantage of its abundance, one may find a good imprinting idea. For example, $\mathrm{Ca}$ (II) imprinted CTS microspheres with uniform size and morphology were synthesized ${ }^{127}$ as an effective and green absorbent in a packed column for $\mathrm{Pb}$ (II), $\mathrm{Cu}$ (II) and $\mathrm{Cd}(\mathrm{II})$ removal. $\mathrm{Ca}$ (II) was valid for tuning the cross-linking degree of CTS by a weak $\mathrm{NH}_{2}-\mathrm{Ca}$ (II) complex.

Cs. Cesium (Cs) is one of only five elemental metals that are liquid at near room temperature with a melting point of $28{ }^{\circ} \mathrm{C}$ $\left(82^{\circ} \mathrm{F}\right)$. Due to its large size, $\operatorname{Cs}(\mathrm{I})$ usually adopts coordination numbers greater than six. Zhang et al. ${ }^{128}$ prepared a surface whisker-supported IIP to selectively separate trace Cs in different water samples with satisfactory results. A CTS incorporated sol-gel process was applied to the synthesis. Rajabi et al. ${ }^{129}$ used dibenzo-24-crown-8 ether as a selective crown ether and prepared Cs IIP NPs by a precipitation polymerization strategy, followed by flame photometry determination.

$G a$. Gallium (Ga) is a soft, silvery metal with atomic number 31. Exposure to airborne particulates of GaP, GaAs and AlGaAs may result in potential health hazards and toxicity. ${ }^{138}$ Using MWCNTs as supporting materials, Zhang and his copartners ${ }^{130,131}$ have synthesized a $\mathrm{Ga}$ (III) imprinted composite sorbent $^{130}$ and electrochemical sensor, ${ }^{131}$ respectively. After removal of template $\mathrm{Ga}(\mathrm{III})-8$-hydroxyquinoline complex, $\mathrm{Ga}$ (III)imprinted materials were used for SPE and pre-concentration of Ga(III) in fly ash samples. ${ }^{130}$ And an electrochemical sensor was stepwise modified by a gold electrode with $\beta$-cyclodextrin ( $\beta$-CD) incorporated MWCNTs and imprinted sol-gel composite film, presenting the detection limit of $7.6 \times 10^{-9} \mathrm{~mol} \mathrm{~L}^{-1} .^{131}$

$H$. Hydrogen or proton $(\mathrm{H})$ is the lightest element from the periodic table and the most abundant chemical substance in the universe but is quite difficult to be imprinted. Excitingly, in 2014, Hoshino and his team ${ }^{27}$ designed proton imprinted 
stimuli-responsive nanogel particles. The schematic illustration of the preparation, reversible $\mathrm{p} K_{\mathrm{a}}$ shift and proposed mechanism of the IIP NPs is shown in Fig. 9. ${ }^{27}$ As seen, the NPs exhibited a large reversible $\mathrm{p} K_{\mathrm{a}}$ shift with $\mathrm{AA}$ as monomer. When acidic monomers were protonated in the polymerization process, the protonated acids were easily incorporated into the less polar domains of growing collapsed-NPs and were subsequently stabilized by cross-linkers. As a result, high $\mathrm{p} K_{\mathrm{a}}$ acids were imprinted in the NPs. The rational design is expected to broadly apply to other stimuli-responsive materials and will be an integral step in the creation of active proton transporters that enable effective ion transport, gas separation, and catalytic reactions. ${ }^{27}$

$S n$. The virulence of tin ( $\mathrm{Sn}$ ) metal, its oxides, and its salts are almost unknown. But certain organotin compounds are almost as toxic as cyanide. In terms of Sn-IIPs, speciation analysis, such

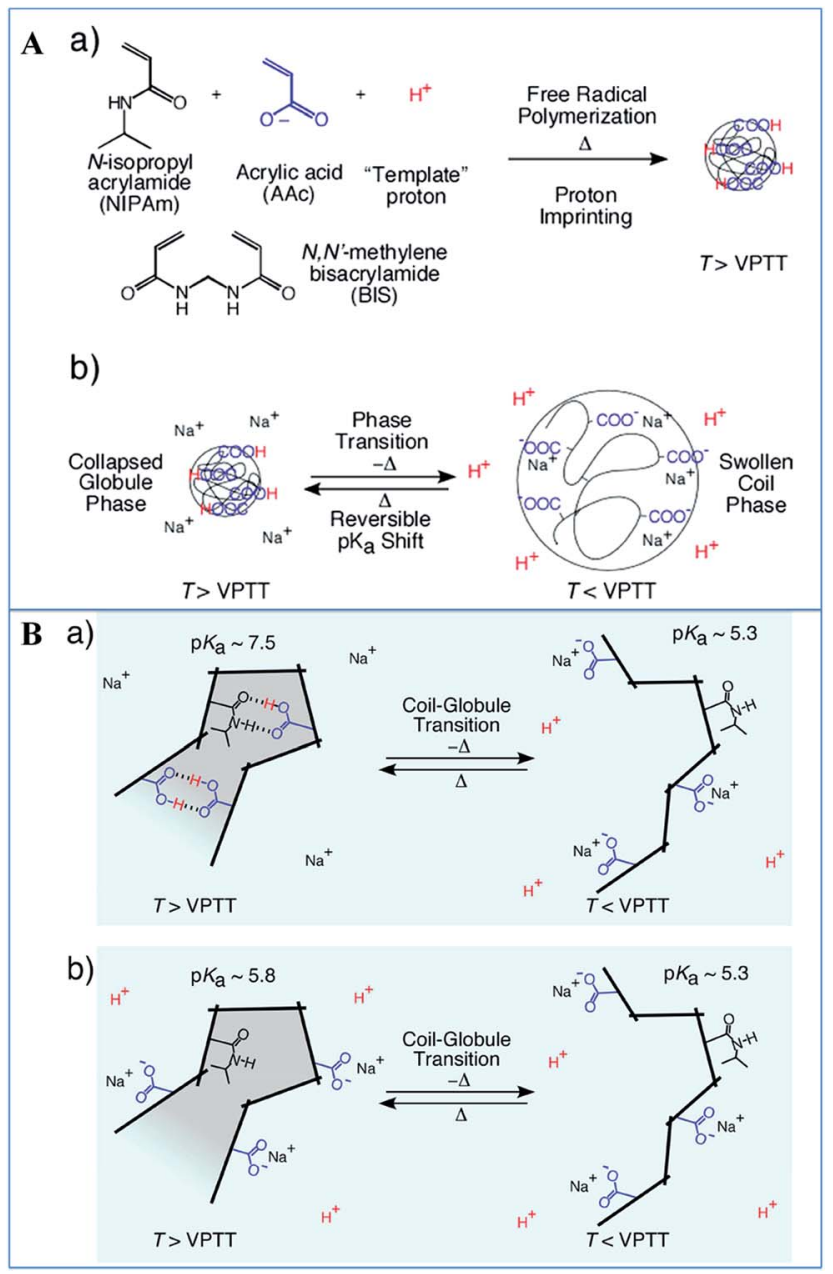

Fig. 9 (A) (a) Preparation of proton-imprinted NPs. (b) Reversible $\mathrm{p} K_{\mathrm{a}}$ shift of carboxylic acids in NPs triggered by the phase transition of NPs. (B) Proposed mechanism of temperature-responsive $p K_{a}$ shift of (a) proton-imprinted and (b) nonimprinted NPs triggered by the phase transition. NIPAm, AAc, and protons are printed in black, blue, and red, respectively. Hydrophobic and hydrophilic microenvironments are printed in gray and sky blue, respectively. Reprinted with permission from ref. 27. Copyright 2014 WILEY-VCH Verlag GmbH \& Co. KGaA, Weinheim. as various organotin compounds, has become an usual application branch. ${ }^{132,133}$ Mercedes et al. ${ }^{132}$ prepared several bulk polymers using organotin compounds (OTCs) such as monobutyltin (MBT), dibutyltin (DBT), tributyltin (TBT), and triphenyltin (TPhT) as templates following covalent and non-covalent strategies; these were used in SPE for OTCs screening in seawater. Low detection limits, nonspecific stationary phases, quantitative recovery and high enrichment factor results are responsible for its good application prospects. ${ }^{132}$

$\mathrm{Tl}$. Thallium ( $\mathrm{Tl}$ ) is known to have mutagenic, carcinogenic and teratogenic effects. ${ }^{139} \mathrm{Tl}$ can be found in nature as $\mathrm{Tl}(\mathrm{I})$ and $\mathrm{Tl}(\mathrm{III})$; its monovalent state has higher stability, whereas its trivalent state forms complexes that are of greater stability. ${ }^{\mathbf{1 3 5}}$ Darroudi and his team ${ }^{\mathbf{1 3 4 , 1 3 5}}$ prepared the ternary complex of $\mathrm{Tl}(\mathrm{III})$ at first with 5,7-dichloroquinoline-8-ol (DCQ) and 4-VP for the adsorption and pre-concentration of the target $\mathrm{Tl}(\mathrm{III})$ in aqueous solution. Then, a "mini-column" SPE system was developed using Tl(III)-IIP particles as adsorbents followed by on-line FAAS detection.

Beyond that, several other elements of the main group, especially alkali and alkaline-earth metals such as lithium (Li), sodium ( $\mathrm{Na}$ ), and potassium (K) have hardly been imprinted, as far as we are aware. Two reasons which may be responsible include: (1) they are difficult to imprint; because of their small atomic radius and low mass, some of these metal ions are not easily captured. In addition, they are difficult to be fixed by appropriate chelating agents compared to transition ions; even successful imprinting still cannot get very good selectivity. (2) They have slight removal significance; they have low damage or even benefit to organisms, that is to say, it is not necessary to remove these ions. What's more, $\mathrm{Na}, \mathrm{K}$ and other ions existing in seawater are able to be enriched by making salt from seawater with the superiorities of large output and low cost.

\subsection{Transition elements IIPs}

Transition elements, also called transition metals, refers to the metals of the d-block in the periodic table other than f-block elements (Fig. 2), including $\mathrm{Hg}, \mathrm{Cu}, \mathrm{Cd}, \mathrm{Cr}$, etc. Significantly different properties exist based on the 18 electron rule compared to other elements. Some transition metals are easy to form complexes because valence d-orbits are not filled. So, the study of transition elements is a hotspot in the field of ion imprinting. As a matter of fact, related researches to imprint transition elements have gradually reached maturity.

3.2.1. Mercury, methylmercury ion imprinted polymers (Hg-IIPs, MeHg-IIPs). Mercury ( $\mathrm{Hg}$ ) is one of the most important but toxic elements in the environment due to its high reactivity, extreme volatility, and relative solubility in water and living tissues. ${ }^{\mathbf{1 4 0 , 1 4 1}}$ As is known, the toxicity of $\mathrm{Hg}$ depends on its chemical forms. Due to their strong lipophilic characteristics, organic $\mathrm{Hg}$ compounds are generally much more toxic than $\mathrm{Hg}(\mathrm{II})$, especially methylmercury ( $\mathrm{MeHg}$ ). Table 2 summarizes the preparation and applications of various $\mathrm{Hg}$ (II)IIPs $^{33,34,45,141-147}$ and MeHg(I)-IIPs. ${ }^{35,148}$

Based on a thymine- $\mathrm{Hg}$ (II)-thymine (T- $\mathrm{Hg}$ (II)-T) interaction, our group ${ }^{33}$ synthesized a novel functional monomer, T-IPTS, to 


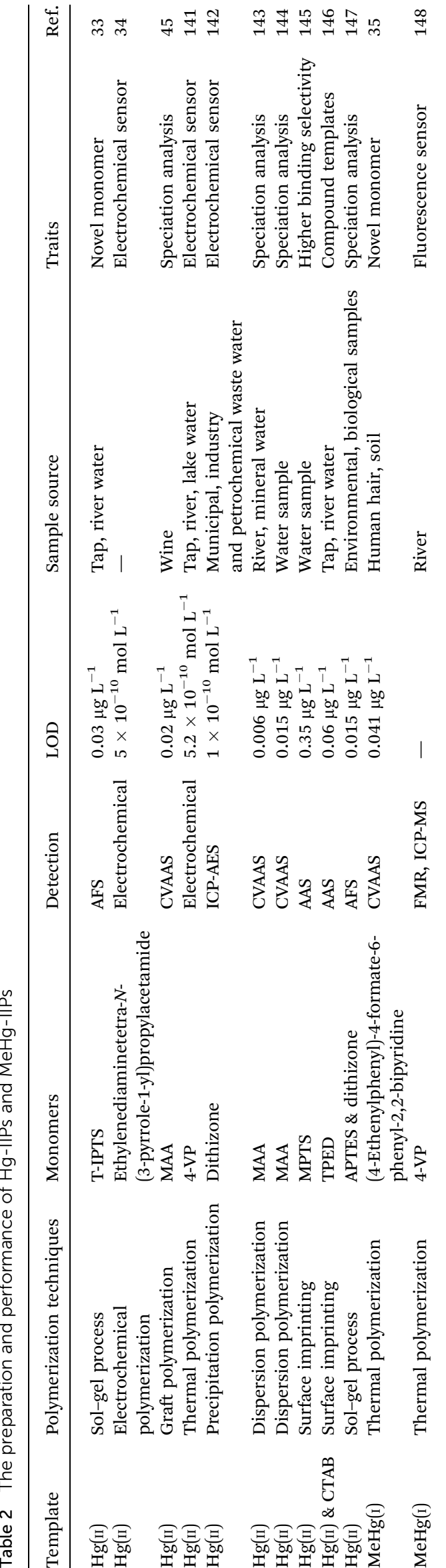

form $\mathrm{Hg}$ (II)-IIPs using a sol-gel method for the detection of $\mathrm{Hg}$ (II) in water samples by SPE coupled with AFS. Pre-concen-

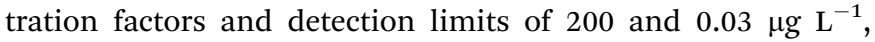
respectively were achieved. Moutet et $a l^{.34}$ synthesized a poly(EDTA-like) film in order to sense $\mathrm{Hg}$ (II) using a voltammetric method. This electrode material especially showed a great affinity towards $\mathrm{Hg}$ (II) against $\mathrm{Cu}$ (II) while being almost insensitive to $\mathrm{Cd}(\mathrm{II})$ and $\mathrm{Pb}$ (II). A simple and selective electrode modified with $\mathrm{Hg}$ (II) IIPs $^{\mathbf{1 4 1}}$ provided an efficient and cheap voltammetric sensor for the determination of ultra-trace $\mathrm{Hg}$ (II) in tap, river, and lake water. Also for sensors, Shamsipur et al. ${ }^{\mathbf{1 4 2}}$ used a carbon ionic liquid paste electrode (CILE) impregnated with $\mathrm{Hg}$ (II) imprinted polymeric nanobeads (IIP) based on dithizone. The voltammetric sensor achieved low level detection of $\mathrm{Hg}$ (II) in aqueous solutions. Wang and his group ${ }^{145,146}$ succeeded in making highly selective adsorption materials with the combination of surface imprinting and dual template imprinting.

Furthermore, $\mathrm{Hg}$ speciation analysis has been increasingly investigated. $\mathrm{Hg}$ (II) core-shell imprinted sorbents ${ }^{45}$ have been completed and tested for speciation and determination of $\mathrm{Hg}$ (II) and $\mathrm{MeHg}(\mathrm{I})$ in wine samples. Dakova's group ${ }^{\mathbf{1 4 3 , 1 4 4}}$ made related experiments for $\mathrm{Hg}$ speciation analysis. Microbeads ${ }^{\mathbf{1 4 3}}$ were prepared and applied in river and mineral waters: inorganic mercury were determined selectively in a nondigested sample, while total mercury was determined in a digested sample. A kind of nanoparticle ${ }^{\mathbf{1 4 4}}$ for mercury speciation in surface waters was synthesized and used for SPE and limits of quantification were achieved, namely $0.015 \mu \mathrm{g} \mathrm{L}^{-1}$ for $\mathrm{Hg}$ (II) and $0.02 \mu \mathrm{g} \mathrm{L}{ }^{-1}$ for methylmercury. In $2014,{ }^{147}$ we further presented speciation analysis of $\mathrm{Hg}$ by using dithizone- $\mathrm{Hg}$ (II) chelate as a template for $\mathrm{Hg}$ (II)-IIPs synthesis, as schematically shown in Fig. 10A, followed by SPE and atomic fluorescence spectroscopy (AFS) detection in environmental and biological samples. Satisfactory results have shown that the IIPs could readily discriminate $\mathrm{Hg}$ (II) from organic $\mathrm{Hg}$ (Fig. 10B and C) and get significant application perspectives for rapid and highly effective clean-up, enrichment and determination of trace $\mathrm{Hg}$ species in complicated matrices.

$\mathrm{MeHg}(\mathrm{I})$ can be bonded to many organic ligand groups, such as $-\mathrm{COOH},-\mathrm{SH},-\mathrm{NH}_{2},-\mathrm{OH}$, and $-\mathrm{C}-\mathrm{S}-\mathrm{C}-$. For instance, methionine possesses three potential binding sites, $-\mathrm{COOH}$, $-\mathrm{NH}_{2}$ and $-\mathrm{C}-\mathrm{S}-\mathrm{C}-$. Under strong acidic conditions of $\mathrm{pH}$ less than 2, MeHg(I) bonded the thioether group; under conditions of pH greater than 2, the carboxy group should be bonded; when the $\mathrm{pH}$ is greater than 8 , the amino group is bonded. Therefore, it is easy for $\mathrm{MeHg}(\mathrm{I})$ to react with proteins and amino acids.

Liu et al. ${ }^{35}$ prepared MeHg-IIPs with a novel synthesized monomer of (4-ethenylphenyl)-4-formate-6-phenyl-2,2-bipyridine. A thermal polymerized method was used for determination of $\mathrm{MeHg}(\mathrm{I})$ in certified human hair samples and certified soil reference materials using cold vapor atomic absorption spectrometry (CVAAS). The detection limit for $\mathrm{MeHg}(\mathrm{I})$ was $0.041 \mu \mathrm{g} \mathrm{L}^{-1}$ and adsorption capacity was $170 \mu \mathrm{mol} \mathrm{g} \mathrm{g}^{-1}$ of dry microbeads which was 22.6 times the amount of $\mathrm{Hg}$ (II). Fu et al. ${ }^{148}$ synthesized $\mathrm{MeHg}(\mathrm{I})$ imprinted fluorescence film with polyvinylidene fluoride (PVDF) films as a supporting medium, 


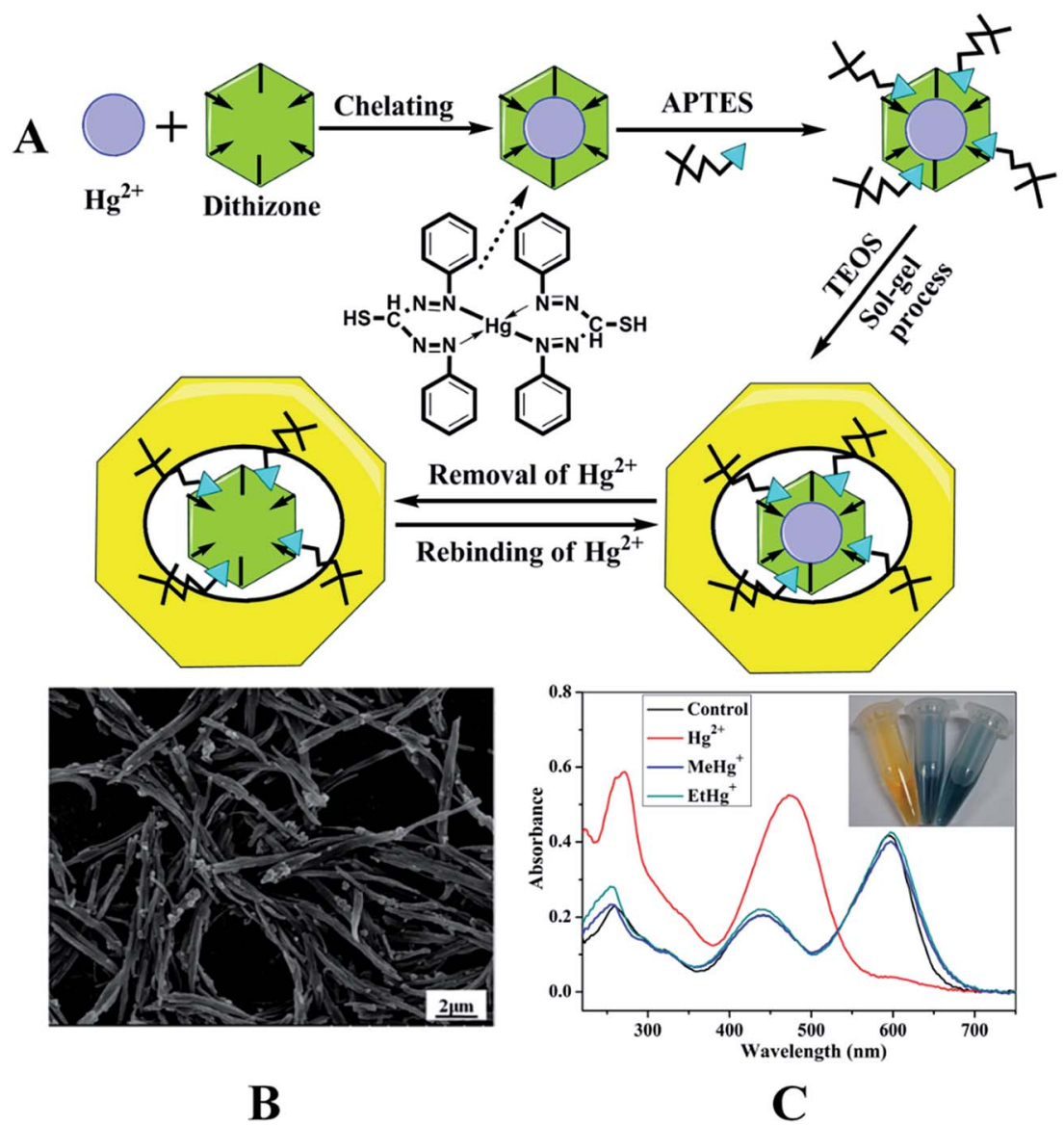

Fig. 10 (A) Schematic illustration of the preparation and imprinting process of $\mathrm{Hg}^{2+}-$ IIPs. (B) SEM image of $\mathrm{Hg}^{2+}-\| \mathrm{Ps}$. (C) UV-vis spectra of dithizone alone (control), and the dithizone with $\mathrm{Hg}^{2+}, \mathrm{MeHg}^{+}$and $\mathrm{EtHg}^{+}$, respectively. The inset image shows dithizone with $\mathrm{Hg}^{2+}, \mathrm{MeHg}^{+}$and $\mathrm{EtHg}^{+}$from left to right. Reproduced with permission from ref. 147. Copyright the Royal Society of Chemistry 2014.

4-VP as a functional monomer, and 8-mercaptoquinoline as both a complex-forming agent and a fluorescence tag. Using a fluorescence microplate reader (FMR) for fluorescence detection, the MeHg-IIP sensor showed a high selectivity against other metal ions.

3.2.2. Copper ion imprinted polymers (Cu-IIPs). Coppercontaining wastewater is also a serious environmental pollution which exists widely in the processes of organic synthesis, electroplating, printed circuit board etching, metallurgy, etc. The study of how to recover $\mathrm{Cu}$ (II) from mixed metal ion solutions efficiently is a hot topic. Cu-IIPs strategy is particularly interesting and has been summarized in Table $3 .^{\mathbf{4 4 , 8 3 , 8 5 , 1 0 2 , 1 4 9 - 1 5 5}}$

From the polymerization technique, solution and bulk polymerization seem to be more favored. Khajeh and his team $^{\mathbf{1 4 9 - 1 5 1}}$ have conducted a series of experiments through solution polymerization; for example, Cu-IIPs were prepared with 4 -VP as a monomer for extraction, along with $\mathrm{Cu}$ (II) analysis via FAAS or ICP-OES, etc. The optimization process was carried out using the Box-Behnken design (BBD) which may promote the development of imprinting technology in theoretical research. This method is suitable for analytical chemistry to optimize reaction conditions fast, reasonably, and effectively. With the aid of BBD, Naeimi et al. ${ }^{\mathbf{1 0 2}}$ developed a convenient method for one-pot synthesis of $\beta$-hydroxy-1,2,3-triazoles over $\mathrm{Cu}$-imprinted periodic mesoporous organosilica nanocomposites (Cu@PMO NCs) under ultrasound irradiation. Thanks to the model, the catalytic synthesis, using water as solvent, ultrasound irradiation, short reaction times and high yields, this work provided an economical and environmentally friendly method, which may be worth additional study. According to precipitation polymerization, core-shell $\mathrm{Cu}$ (II) imprinted polymethacrylate microspheres have been prepared $^{\mathbf{1 5 2}}$ with low cost. As for bulk polymerization, a $\mathrm{Cu}$ (II) imprinted sorbent has been prepared ${ }^{153}$ using 5-methyl-2-thiozylmethacrylamide (MTMAAm) for determination of $\mathrm{Cu}$ in sea, lake and tap water samples, hemodialysis concentrates, and multivitamin/multielement supplements. In the case of suspension polymerization, a direct imprinting method was developed to prepare porous polymethacrylate micro-particles using a complex of two functional monomers, MAA and VP. ${ }^{83}$ Tang et al. ${ }^{\mathbf{1 5 4}}$ prepared highly ordered $\mathrm{Cu}$ ion imprinted mesoporous silica (IIMS) using a co-condensation pathway. As shown in Fig. 11, ${ }^{154} \mathrm{Cu}$ (II) was imprinted in (not on) a $1 \mathrm{~nm}$ thick matrix wall. The IIMS combines the advantages of imprinting technology and typical mesoporous materials to effectively solve traditional IIP issues of low accessibility and highly 


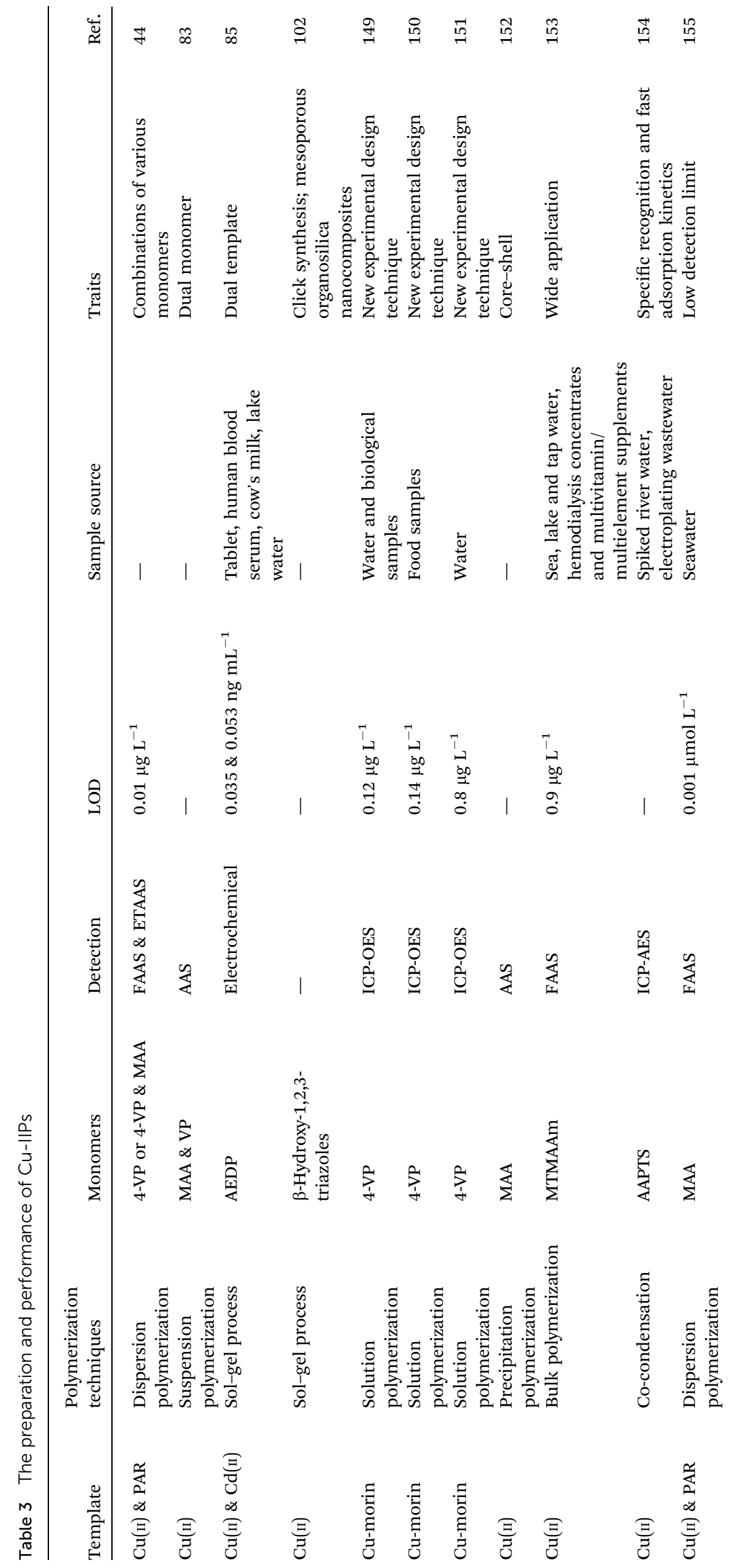




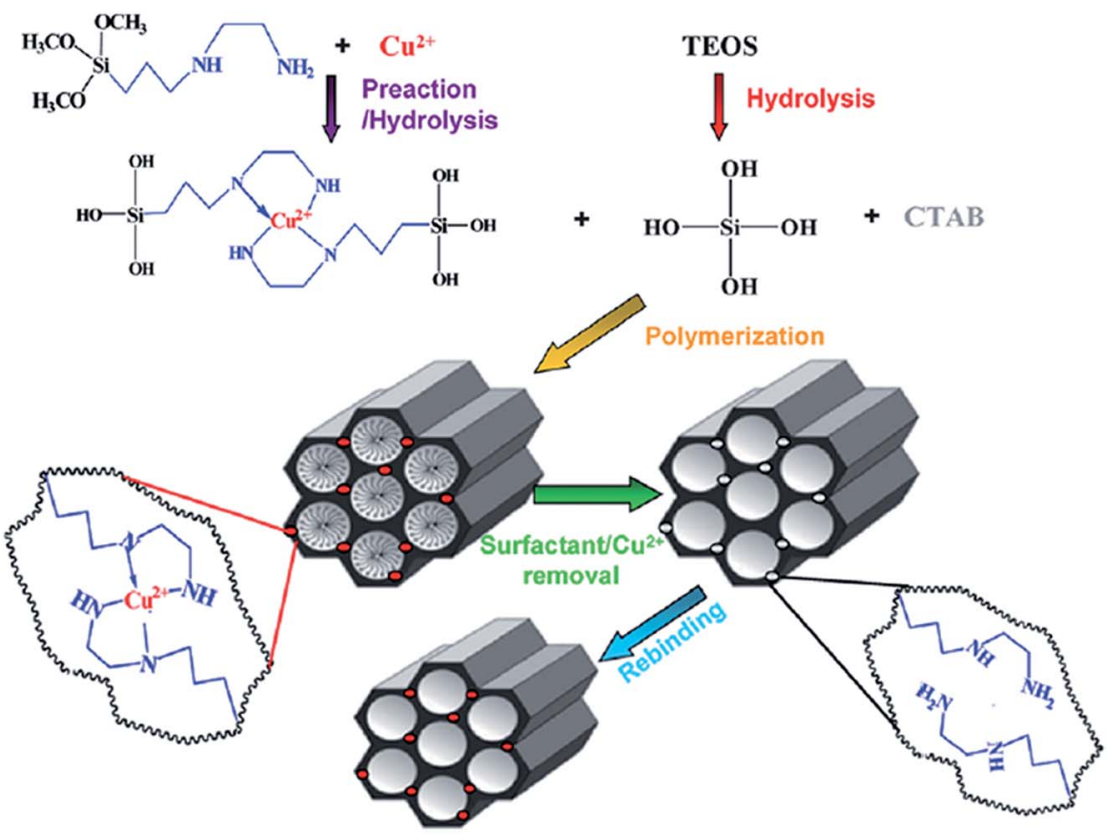

Fig. 11 Schematic procedure for synthesizing Cu ion imprinted mesoporous silica. Reprinted with permission from ref. 154. Copyright the Royal Society of Chemistry 2013

heterogeneous binding sites and to improve selectivity of classic mesoporous materials. This approach is applicable for many metal ions during water pollution treatment.

From the aspect of application, the study mainly concentrates in SPE sample pretreatments. Dakova and his group ${ }^{44,155}$ prepared a variety of imprinted materials by changing monomers and copper compound groups used for SPE. More excitingly, Prasad and his team ${ }^{85}$ developed a dual ion template imprinted polymer embedded in a sol-gel matrix for the ultratrace simultaneous analysis of a binary mixture of $\mathrm{Cu}(\mathrm{II})$ and Cd(II) in tablets, human blood serum, cow's milk, and lake water samples. Such a strategy has also been applied to pre-concentrate and successfully determine $\mathrm{Cd}(\mathrm{II})$ and $\mathrm{Pb}(\mathrm{II})^{86}$ in different seafood samples such as squid, hake, sardine, horse mackerel, grouper, and gilthead bream.

3.2.3. Cadmium ion imprinted polymers (Cd-IIPs). Cadmium (Cd), a soft and bluish-white metal, is chemically similar to the two other stable metals ( $\mathrm{Zn}$ and $\mathrm{Hg}$ ) in the 12th group, and is one of the highly toxic elements among the priority pollutants regulated by the U.S. Environmental Protection Agency (U.S. EPA). ${ }^{156,157} \mathrm{Cd}(\mathrm{II})$ is highly toxic at low concentrations and can accumulate in living organisms by smoking cigarettes, eating contaminated food, and drinking contaminated water. ${ }^{157-159}$ Surface imprinting technology with support particles like silica gel is a common design for the synthesis of Cd-IIPs. ${ }^{157,160,161}$ Table 4 summarizes the relevant studies about Cd-IIPs as below. ${ }^{36,37,46,86,157,160-164}$

Based on a sol-gel technique combining with a doubleimprinting concept, Hu et al. ${ }^{162}$ prepared a Cd(II) imprinted 3mercaptopropyltrimethoxysilane (MPTS)-silica coated stir bar for selective stir bar sorptive extraction (SBSE) of trace Cd(II) from environmental water samples via ICP-MS detection.
Candan et al. ${ }^{163}$ synthesized magnetic $\mathrm{Fe}_{3} \mathrm{O}_{4}$ porous microspheres in order to remove excessive $\mathrm{Cd}(\mathrm{II})$ in human plasma, which is expected to apply to the heavy metal detoxification in organisms. Moreover, the common application of Cd(II)-IIPs is still SPE. Zhai et al. ${ }^{36}$ designed a novel dual-ligand monomer (2Z)- $N, N$-bis(2-aminoethylic)but-2-enediamide for $\mathrm{Cd}(\mathrm{II})$-IIPs preparation, which was used as a SPE adsorbent followed by ICP-AES determination; a detection limit of $0.14 \mu \mathrm{g} \mathrm{L^{-1 }}$ was obtained. Chen et al. ${ }^{46}$ developed thiourea-modified magnetic ion imprinted $\mathrm{CTS} / \mathrm{TiO}_{2}$ (MICT) for $\mathrm{Cd}(\mathrm{II})$ adsorption and 2,4dichlorophenol (2,4-DCP) degradation simultaneously. 2,4-DCP was adsorbed onto the sorbents' surface and the degradation process occurred with the help of $\mathrm{TiO}_{2}$ photocatalysis. The maximum adsorption capacity for $\mathrm{Cd}(\mathrm{II})$ was $256.41 \mathrm{mg} \mathrm{g}^{-1}$ and 2,4-DCP degradation efficiency was up to $98 \%$. The results showed that the MICT composite was an ideal platform to accelerate the disposal of heavy metals and organic pollutants in wastewater. Pourali et al. ${ }^{164}$ described a nanosized Cd(II)imprinted polymer for selective SPE and pre-concentration of $\mathrm{Cd}(\mathrm{II})$ in food and water samples. Besides the above, Cd(II) imprinted materials also have certain developments in sensors. ${ }^{37}$ Yan et al. ${ }^{37}$ reported a fluorescent ion imprinted mesoporous silica combination with a one-pot co-condensation method based on a fluorescence turn-on sensor array for discrimination of $\mathrm{Cd}(\mathrm{II})$ and $\mathrm{Zn}$ (II). This work proved that using a simple fluorescent receptor can design a pattern-based fluorescent sensing system by taking advantage of the imprinting effect.

3.2.4. Chrome ion imprinted polymers (Cr-IIPs). Chromium $(\mathrm{Cr})$ is the first element in group 6 with the atomic number 24 . Cr pollution commonly exists in two stable oxidation states in aqueous solutions, namely $\operatorname{Cr}(\mathrm{III})$ and $\mathrm{Cr}(\mathrm{vI})$. The 


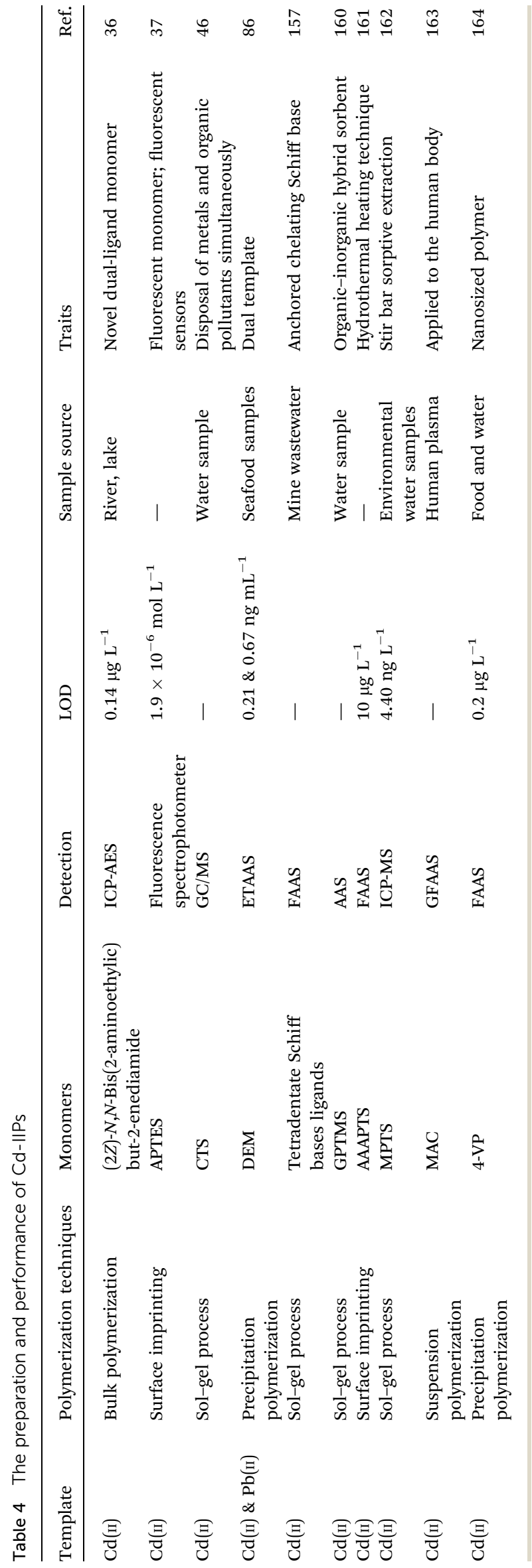

right amount of water insoluble $\mathrm{Cr}$ (III) compounds are not considered as a health hazard, while the most toxic and carcinogenic valence is $\operatorname{Cr}(\mathrm{vI}) .{ }^{165} \operatorname{Cr}(\mathrm{vI})$ is approximately $100-1000$ times more toxic than $\mathrm{Cr}(\mathrm{III}) .{ }^{166,167}$

A one-step sol-gel reaction with a surface imprinting technique on the support of mesoporous silica material (SBA-15) was utilized ${ }^{168}$ to prepare $\mathrm{Cr}(\mathrm{III})$-IIPs coupled with the determination by ICP-AES and UV spectrophotometry. The $\mathrm{Cr}(\mathrm{vI})$ content was calculated by subtracting the $\mathrm{Cr}$ (III) content from the total Cr content. Also via sol-gel process, Tavengwa et al. ${ }^{169}$ used $\gamma$-methacryloxypropyltrimethoxysilane ( $\gamma$-MPS) packaged $\mathrm{Fe}_{3} \mathrm{O}_{4}$ magnetic imprinted polymer adsorbent with $\mathrm{Cr}(\mathrm{vI})$ as a template ion and 4 -VP as a monomer to remove $\mathrm{Cr}(\mathrm{vI})$ in water. In addition, Bayramoglu et al. ${ }^{170}$ obtained bulk IIPs and applied them to remove $\operatorname{Cr}(\mathrm{vI})$ anions in water phase. Ren et al. ${ }^{171}$ prepared $\mathrm{Cr}(\mathrm{vI})$-IIPs and investigated 8 functional monomers to achieve a fast adsorption rate (the adsorption equilibrium was reached within $3 \mathrm{~min}$ ) and a high adsorption capacity (338.73 $\left.\mathrm{mg} \mathrm{g}^{-1}\right)$. The selectivity coefficient for $\mathrm{Cr}(\mathrm{vI}) / \mathrm{Cu}(\mathrm{II})$ and $\mathrm{Cr}(\mathrm{VI}) /$ $\mathrm{Cr}(\mathrm{III})$ was up to 189.05 and 96.56 , respectively. The optimized methodology is reliable and valuable, and the study of $\mathrm{Cr}(\mathrm{vr})$ and $\mathrm{Cr}(\mathrm{III})$ may be a successful case for speciation analysis.

3.2.5. Other transition ion IIPs. Besides $\mathrm{Hg}, \mathrm{Cu}, \mathrm{Cd}$ and $\mathrm{Cr}$ ions, other transition group ions have also been imprinted but with relatively few reports. A brief introduction is presented as follows.

Ag. Shawky et al. ${ }^{172}$ synthesized an ion-imprinted CTS/PVA cross-linked membrane for selective removal and pre-concentration of Ag(I) from aqueous solution. Su et al. ${ }^{173}$ combined IIT with a photocatalytic reaction to deal with the effects of trace $\mathrm{TiO}_{2}$ on an imprinted $\mathrm{Ag}(\mathrm{I})$-mycelium surface. $\mathrm{TiO}_{2}$ loading improved the adsorption ability because $\mathrm{TiO}_{2}$ bounded with adsorbents through hydrogen bonding and $\mathrm{Ag}(\mathrm{I})$ was reduced to $\mathrm{Ag}(0)$ on the adsorbents surface. Hou et al. ${ }^{174}$ prepared four kinds of Ag-IIPs with different morphologies used for the removal and concentration of $\mathrm{Ag}^{+}$from wastewater, as shown in Fig. 12 (upper). The adsorptivity of ion-imprinting single-hole hollow particles (Ag-IISHPs) was highest, as shown in Fig. 12 (Below) and the researchers tried to elucidate the adsorption mechanism. The adsorption kinetics indicated that the inner surface adsorption process was generally associated with the formation and breaking of chemical bonds.

$A u$. Ebrahimzadeh and his team ${ }^{175,176}$ have developed two $\mathrm{Au}-$ IIPs and applied them to aqueous samples and mine stone samples, which is reliable and fast, to pre-concentrate and determine $\mathrm{Au}(\mathrm{III})$. In addition, a novel chelating $\mathrm{Au}(\mathrm{III})$ imprinted resin has been prepared by Mbianda et al. ${ }^{177}$ which is highly selective to $\mathrm{Au}$ (III) compared to $\mathrm{Pb}$ (II), $\mathrm{Ni}$ (II), $\mathrm{Cu}$ (II), $\mathrm{Mn}$ (II) and $\mathrm{Fe}(\mathrm{III})$, even at the optimum binding $\mathrm{pH}(\mathrm{pH}=5-6)$ for the other metal ions.

Co. Co(II)-IIPs were prepared ${ }^{178}$ by modifying the surface of ordered mesoporous silica SBA-15; its surface area remained as much as $299.56 \mathrm{~m}^{2} \mathrm{~g}^{-1}$. Ha et al. ${ }^{179}$ obtained a ion-imprinted functional ligand derivative bearing periodic mesoporous organosilica (IIPMO) with a newly designed $\mathrm{Co}^{2+}$-imprinted ligand core. High adsorption capacity, selectivity and recyclability were achieved. Co(II) imprinted CTS was prepared by 

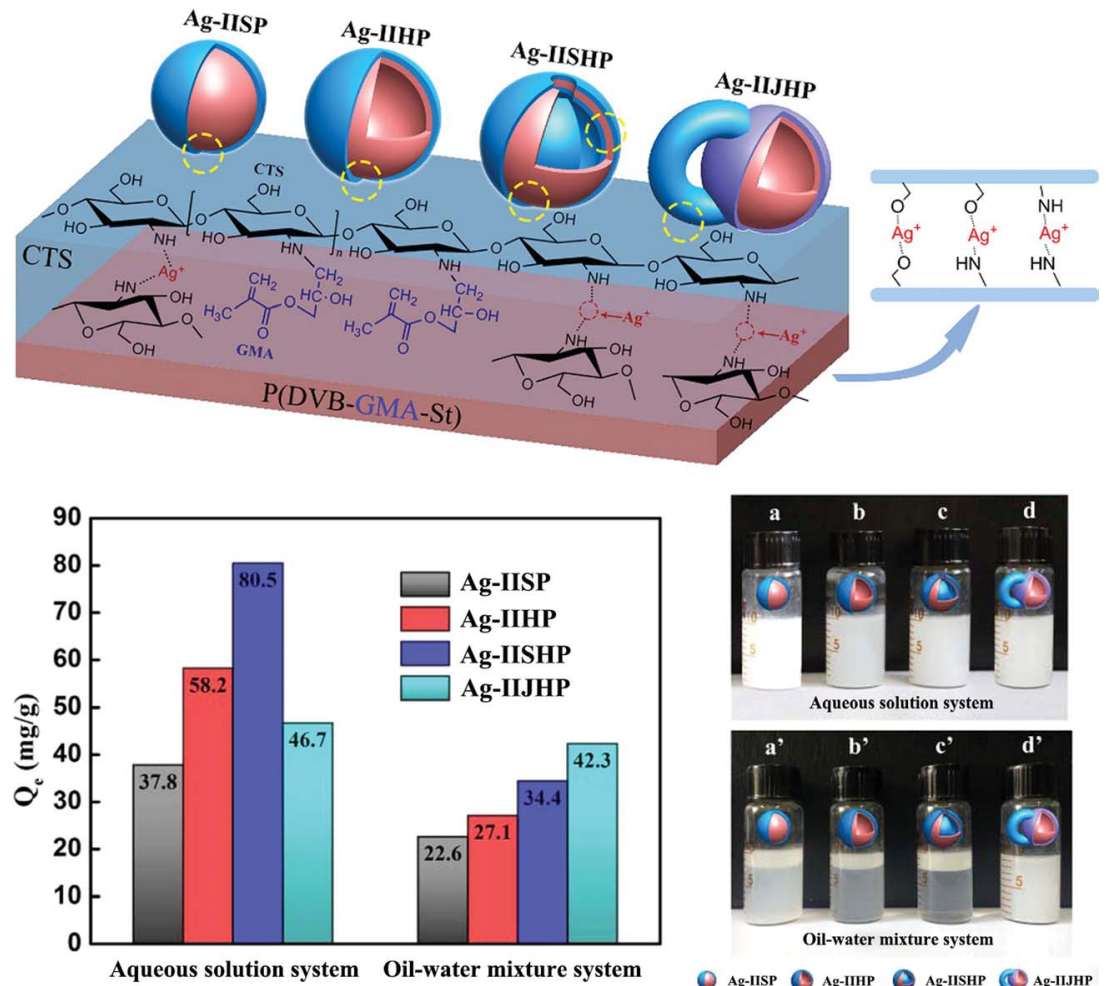

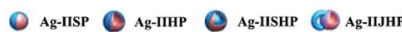

Fig. 12 (Upper) Schematic for $\mathrm{Ag}^{+}$adsorption onto the Ag-IIPs. (Below) Effects of the morphologies on $\mathrm{Ag}^{+}$absorption onto the Ag-IIPs. Reprinted with permission from ref. 174. Copyright 2015 American Chemical Society.

A
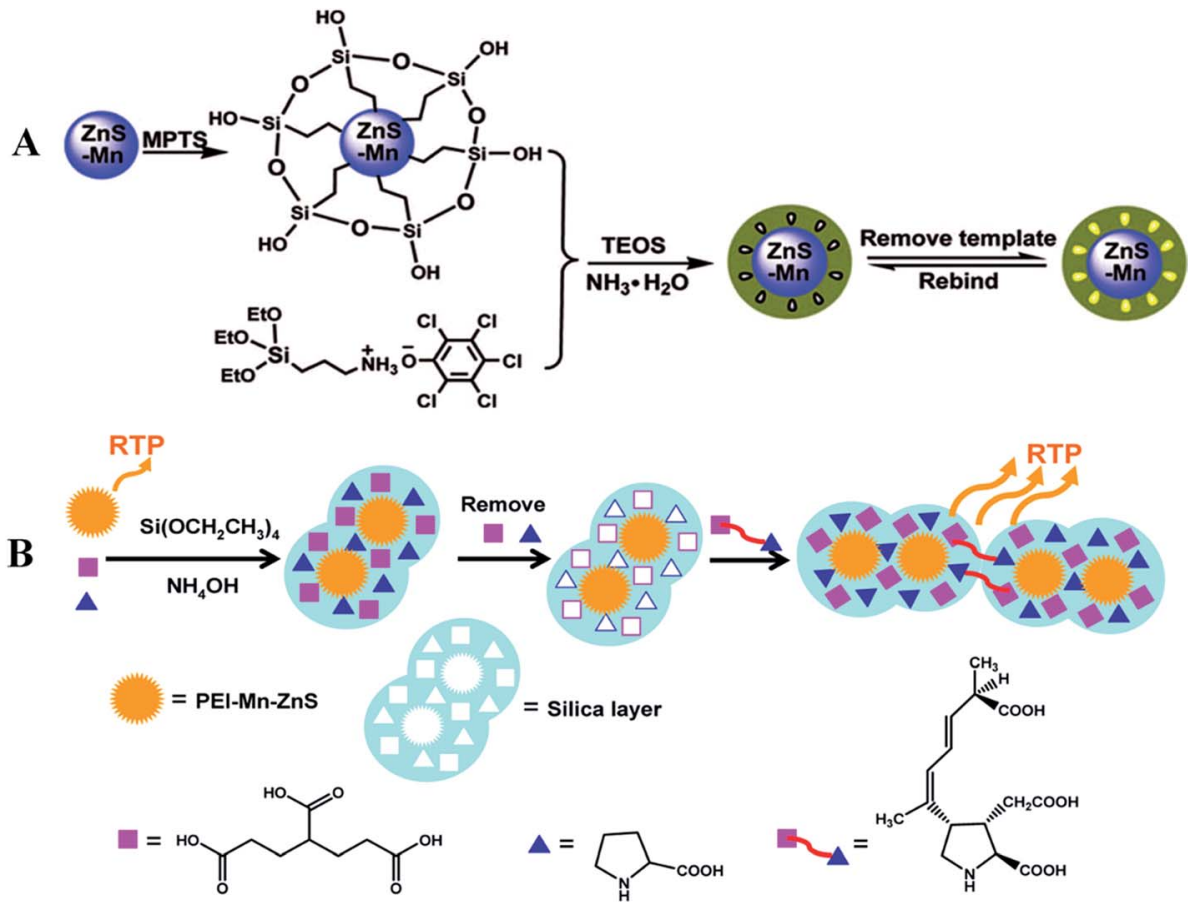

pentane-1,3,5-tricarboxylic acid (PTA)

Proline (Pro)

Domoic acid (DA)

Fig. 13 (A) Schematic illustration for fabricating MIP-capped Mn-doped ZnS QDs. Reprinted with permission from ref. 64. Copyright 2009 American Chemical Society. (B) Schematic illustration for constructing Mn-ZnS QD imbedded two-fragment imprinting silica for enhanced RTP assay of DA. Reprinted with permission from ref. 65. Copyright 2013 American Chemical Society. 
Bhaskarapillai and his group ${ }^{180}$ for its potential application in the chemical decontamination of nuclear power plants. The synthesis of metal-complexing polymer microparticles was accomplished $^{181}$ with $\left[\mathrm{Co}\left(\mathrm{C}_{2} \mathrm{H}_{3} \mathrm{O}_{2}\right)_{2}(z\right.$-histidine $\left.)\right]$ molecule as a template; it can potentially find application in the purification of histidine-tagged recombinant proteins.

$F e$. Denizli and his team ${ }^{182-184}$ aimed to synthesize Fe(III)imprinted poly(HEMA-MAGA) beads by suspension polymerization and imprinted poly(hydroxyethyl methacrylate- $N$-methacryloyl-(L)-cysteine methyl ester) [PHEMAC]cryogel by cryopolymerization for the recognition of Fe from human plasma. What's more, a composite template (Fe and CTAB) imprinted sorbent ${ }^{185}$ was prepared by a sol-gel process.

$\mathrm{Mn}$. Mn is often used as dope onto ZnS QD. Wang and his team ${ }^{64,65}$ constructed an enhanced MIP-based room temperature phosphorescence (RTP) probe by combining the RTP of Mn-doped ZnS QDs, and the schematic illustration is shown in Fig. $13 .{ }^{64} \mathrm{Hu}$ et al. ${ }^{186}$ synthesized a Mn(II) imprinted MPTS-silica coated capillary by a sol-gel technique combined with a doubleimprinting concept employed for capillary microextraction (CME) of trace Mn(II) followed by on-line ICP-MS detection.

Mo. Ren et al. ${ }^{187}$ prepared Mo(vi)-IIPs by the amino-silica surface imprinting technique with a sol-gel process. Isonicotinic acid (4-picolinic acid) served as a functional monomer and a possible imprinting mechanism was put forward for the Mo(vi)-IIPs.

Ni. Based on inverse suspension polymerization, Branger et al. ${ }^{49}$ reported the simple synthesis of $\mathrm{Ni}(\mathrm{II})$ imprinted polymer beads using mineral oil as the continuous phase for the first time. Because of the large porosity of the polymer, the template ions could be easily eluted. In 2015, they synthesized highly porous particles with good nickel binding capacity and investigated the effect of the complex structure on IIPs selectivity. ${ }^{188}$ This good exploration made it possible to establish a desired complex structure by properly adjusting the metal/ligand ratio. ${ }^{188}$ Bagheri et al. ${ }^{189}$ prepared a nanostructured IIP by bulk polymerization applied to the selective extraction and determination of $\mathrm{Ni}$ in certified reference materials (soil and polymetallic gold ore), fish, vegetables, river sediments, and river water. Also applying bulk polymerization, Saraji et al. ${ }^{190}$ synthesized a new IIP material used as sorbent in a SPE column in the presence of $\mathrm{Ni}$-dithizone complex.

$P d$. Baba and his group ${ }^{191,192}$ synthesized a Pd(II)-imprinted CTS derivative (PIPMC) using $N$-[pyridylmethyl]-CTS (PMC) in order to recover extremely low concentrations of precious metals from metal plating liquid wastes. By examining the adsorption selectivity and kinetics, the template effect of $\mathrm{Pd}(\mathrm{II})$ was studied. In 2011, they proceeded to examine quantitatively the template effect and investigated the mechanism of the imprinting process. In addition, Beata et al. ${ }^{193}$ synthesized three ternary ion imprinted complexes (Pd-PDC-VP, Pd-DET-VP, and Pd-DMG-VP) and imprinted them into a polymeric network with styrene as the cross-linker. The developed materials were successfully applied to separate and concentrate trace amounts of Pd in tap and river water, grass, and certified platinum ore samples with high reproducibility (relative standard deviation below $6.5 \%)$.

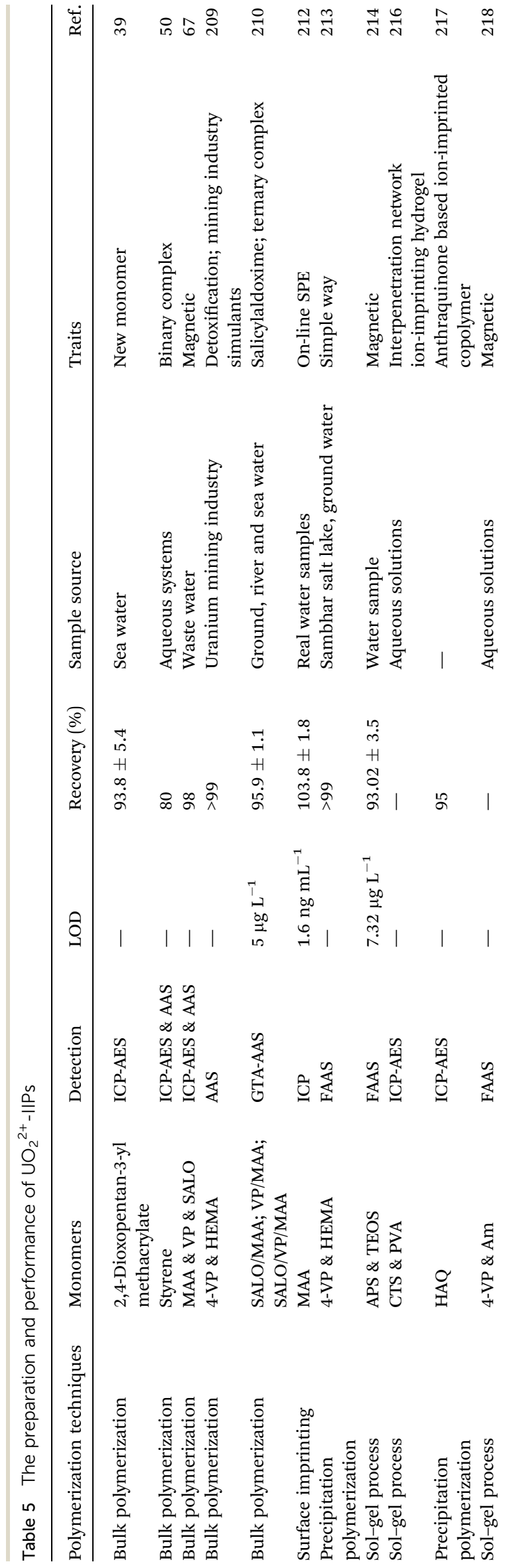


Pt. Leśniewska et al. ${ }^{194}$ obtained two Pt(II)-IIPs by acetaldehyde thiosemicarbazone (AcTSn) and benzaldehyde thiosemicarbazone (BnTSn) as chelators for SPE of Pt(II) and Pt(Iv) from aqueous solutions and the method was applied to the determination of Pt(Iv) by ETAAS in tap water, tunnel dust, and anode slime samples.

$R h$. A Rh(III)-imprinted amino-functionalised silica gel sorbent was achieved ${ }^{195}$ by a surface imprinting technique and was applied to the determination of trace $\mathrm{Rh}$ (III) in geological samples with satisfactory results. The relatively selective factor values of $\mathrm{Rh}(\mathrm{III}) / \mathrm{Ru}(\mathrm{III}), \mathrm{Rh}$ (III)/Au(III), $\mathrm{Rh}$ (III)/Pt(Iv), $\mathrm{Rh}(\mathrm{III}) / \mathrm{Ir}$ (IV) and $\mathrm{Rh}(\mathrm{III}) / \mathrm{Pd}$ (II) were $26.7,39.0,29.2,28.1$, and 43.7, respectively. Cao et al. ${ }^{196}$ prepared Rh(III)-IIPs used in a resonance light-scattering (RLS) method for the determination of Rh(III) based on the reaction among $\mathrm{Rh}(\mathrm{III}), \mathrm{WO}_{4}{ }^{2-}$ and ethylrhodamine B.

Zr. Mizuki et al. ${ }^{197}$ prepared an adsorbent $\mathrm{Zr}$ (Iv)-immobilized resin to remove $\mathrm{F}^{-}$from tap water and industrial wastewater. A $\mathrm{F}^{-} / \mathrm{Zr}(\mathrm{Iv}) /$ dioleyl phosphoric acid complex with an ideal $\mathrm{F}: \mathrm{Zr}: \mathrm{P}$ mole ratio of $3: 1: 3$ could be optimized by a model complex using computational chemistry. Silica was also usually used as a carrier $^{198,199}$ for surface immobilized Zr IIPs.

Furthermore, there are still some related works on imprinting of $\mathrm{Ir}^{, 00} \mathrm{Lu},{ }^{201} \mathrm{Ru}^{202-205}$ and $\mathrm{Zn},{ }^{206,207}$ which are not discussed here.

\subsection{Actinide elements IIPs}

Actinide elements have more lively chemical properties and most of them can form coordination compounds but present low annual output. They are dangerous with high toxicity and radiation. As far as we are aware, only uranium and thorium IIPs have been reported.

3.3.1. Uranyl ion imprinted polymers (UO ${ }_{2}{ }^{2+}-$ IIPs). Uranium (U), a weakly radioactive metal, reacts with almost all non-metal elements, with the exception of the noble gases, and the resultant compounds show increasing temperatures. $\mathrm{Li}$ et $a .^{208}$ synthesized amidoximated magnetite/graphene oxide composites, which are potential and suitable candidates for the pre-concentration and separation of $\mathrm{U}(\mathrm{vI})$. In addition, the most common and stable uranium oxide is $\mathrm{UO}_{2}{ }^{2+}$, and it has become a commonly used template for ion imprinting. For helpful expounding on $\mathrm{UO}_{2}{ }^{2+}$-IIPs, we selected some references that are presented in Table 5.

Bulk polymerization ${ }^{39,50,67,209,210}$ is most adopted in $\mathrm{UO}_{2}{ }^{2+}$ imprinting. By using bulk polymerization, Tavengwa and his team ${ }^{67}$ prepared highly selective $\gamma$-MPS coated magnetic IIPs for uranium and studied their binding properties and application to wastewater samples. Zhang et al. ${ }^{39}$ synthesized $\mathrm{UO}_{2}{ }^{2+}$ imprinted materials used for the extraction of $U$ in sea-water with a high recovery efficiency of approximately $93 \%$.

Ion imprinting is often coupled with SPE. ${ }^{\mathbf{5 0 , 2 1 1 - 2 1 3}}$ Shamsipur et $a .^{211}$ grafted IIPs on the surface of silica gel particles. On-line SPE realized determination of sub-nanogram per milliliter levels of $\mathrm{UO}_{2}{ }^{2+}$ and increased sampling frequency of the method in analysis of complex aqueous samples. Also with the help of silica gel, Milja et al. ${ }^{212}$ prepared imprinted polymer nanospheres, as schematically shown in Fig. 14, and applied them successfully in Sambhar salt lake and ground water for selective removal of uranium. The method can be extended to imprinted nano materials for other toxic metal ions and applied in pollution control processes.

Besides, chitosan/PVA cross-linked hydrogel, ${ }^{214}$ an anthraquinone based ion-imprinted copolymer, ${ }^{215}$ and magnetic ionimprinted composites ${ }^{216}$ also have been prepared, which may provide more orientations for further studies. Chen et al. ${ }^{\mathbf{2 1 6}}$ prepared a magnetic ion-imprinted composite with a uniform core-shell structure. The maximum sorption capacity of MIIC for $\mathrm{U}(\mathrm{vI})$ was $354.85 \mathrm{mg} \mathrm{g}^{-1}$.

3.3.2. Thorium ion imprinted polymers (Th-IIPs). Thorium (Th) is a radioactive actinide metal with atomic number 90 . Although +3 , +2 , and +1 states are also known, the most important oxidation state of thorium is +4 . For all we know, only Th(Iv)-IIP has been proposed. He et al. ${ }^{38}$ synthesized a new functional monomer $N$-(o-carboxyphenyl)maleamic acid (CPMA) for a Th(Iv) polymer adsorbent based on the surface coating of silica gel with a thin layer. The detection limit was $0.51 \mathrm{ng} \mathrm{mL}^{-1}$ and it showed superior selectivity, in particular for $\operatorname{Zr}(\mathrm{Iv})$ at 433.8. Wang and his group carried out a series of

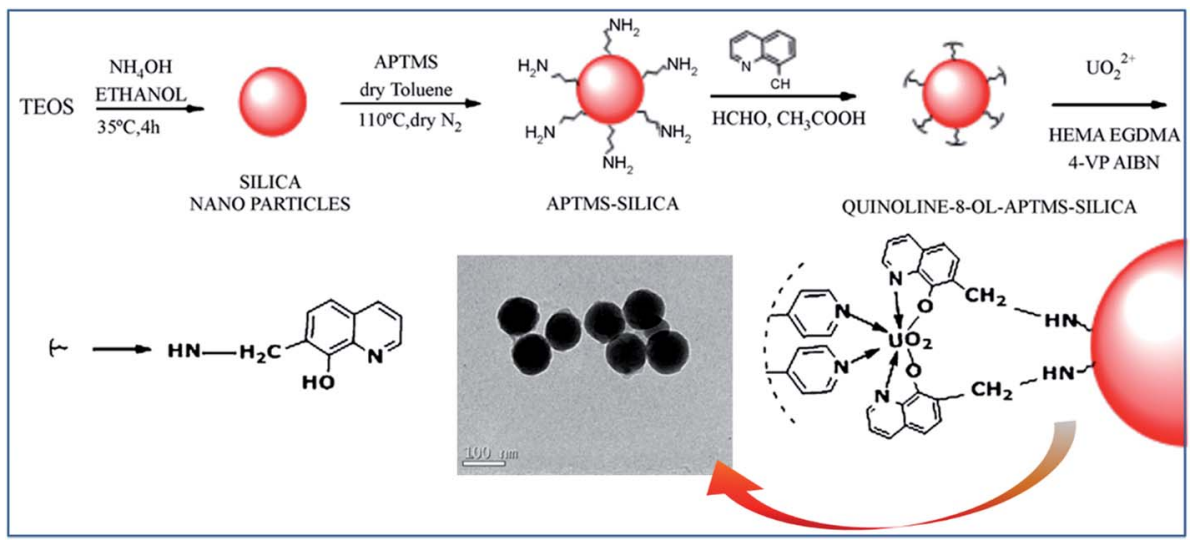

Fig. 14 Schematic representation of uranyl ion nanosurface imprinting and TEM of optimized imprinted polymer nanospheres in ethanol. Reproduced with permission from ref. 212. Copyright 2011 Elsevier B.V. 
works ${ }^{69,217-219}$ on Th(Iv) imprinting: in $2011,{ }^{218}$ using 3-methyl-1phenyl-4-(cis-acylbutenoicacid)-2-pyrazolin-5-one as the functional reagent, a surface ion-imprinted composite polymer was prepared with high affinity, selectivity, and fast kinetic process advantages. The method was rapid, sensitive, and reliable and it could be applied for the pre-concentration and determination of trace $\mathrm{Th}$ (Iv) in real samples. In the same year, ${ }^{\mathbf{2 1 9}}$ it was reported that a surface-grafted technique with MAA as a functional monomer was used to prepare Th(IV)-imprinted polymers. The imprinted matrix for Th(Iv)/U(vI), Th(Iv)/Ce(III), Th(Iv)/La(III) and $\mathrm{Th}(\mathrm{Iv}) / \mathrm{Zr}(\mathrm{Iv})$ was 58.8, 107, 106.4 and 151.7 times greater than a non-imprinted matrix, respectively. In $2013,{ }^{69}$ magnetic Th(Iv)-IIPs with salophen Schiff base ( $N, N^{\prime}$-bis(3-allylsalicylidene)-o-phenylenediamine) was obtained for separation and recognition of $\mathrm{Th}(\mathrm{Iv})$.

\subsection{Rare earth elements IIPs}

As defined by IUPAC, a rare earth element (REE) or rare earth metal is one of seventeen chemical elements in the periodic table, specifically the fifteen lanthanides plus scandium and yttrium. ${ }^{220}$ For the past few years, a good deal of functional rare earth complexes have been developed along with research involving the rare earth compounds and their complexes in biology, medicine, and materials science. This is due to the high coordination number, ${ }^{221}$ multiple coordination modes, ${ }^{222,223}$ and flexible coordination configuration ${ }^{224}$ of rare earth ions. From the above, a good foundation is provided for rare earth IIPs.

3.4.1. Europium ion imprinted polymers (Eu-IIPs). Europium $(\mathrm{Eu})$, the rarest rare earth element but with the highest reactivity, is really important in industrial applications, material science, electronics and life sciences. ${ }^{225}$ Most applications of Eu exploit the phosphorescence of Eu compounds for luminescent materials. ${ }^{26-229}$ For example, Murray and his team ${ }^{226}$ combined the imprinting technique and sensitized lanthanide luminescence to create the basis for a fiber optic sensor that can selectively measure the hydrolysis product of the nerve agent Soman in water. Alizadeh et al. ${ }^{\mathbf{2 3 0}}$ synthesized Eu(III)-imprinted NPs using suspension polymerization in silicon oil. Carbon paste electrodes impregnated with IIP were incubated in solutions containing $\mathrm{Cu}(\mathrm{II})$ and different kinds of lanthanide ions. The developed method exhibited a low detection limit of 15 $\mu \mathrm{mol} \mathrm{L}{ }^{-1}$. $^{230}$

3.4.2. Other rare earth IIPs. Using a micro-column packed with scandium IIPs as a SPE adsorbent, a new method ${ }^{231}$ was developed for the selective separation and pre-enrichment of trace amounts of Sc(III) prior to determination by ICP-MS; the method was validated using certified reference materials and was successfully applied to the determination of trace Sc(III) in geological samples and environmental water samples. Froidevaux et $a .^{232}$ obtained an imprinted polystyrene ion-exchange resin and described the synthesis and structural, thermodynamic, and photophysical characterization of complexes for yttrium (Y) and lanthanides with two vinyl derivatives of dipicolinic acid, HL1 and L2. The resin displays high selectivity for Y(III) and lanthanide cations against alkali metals and alkaline earth metals, showing applications for the production of highly pure $90 \mathrm{Y}$ and radio lanthanides for medical applications and trace analysis of these radio chemicals in food and the environment. Employing a SPE method, Rao and his team performed some imprinting applications using rare earth ions. They synthesized IIP particles via a single pot reaction for separation of Y(III) from selected lanthanides, ${ }^{233}$ and Er(III) IIP particles via thermally copolymerizing ${ }^{234}$ and photochemical polymerization, ${ }^{235}$ respectively. What's more, Nd(III) IIP materials ${ }^{236}$ were prepared as well and also had good results. Guo et al. ${ }^{237}$ prepared Nd(III)-IIPs followed by ICP-AES determination with the largest selectivity coefficient, over 110 , for $\mathrm{Nd}(\mathrm{III})$ in the presence of competitive ions such as $\mathrm{La}(\mathrm{III}), \mathrm{Ce}(\mathrm{III}), \operatorname{Pr}(\mathrm{III})$ and $\mathrm{Sm}(\mathrm{III})$. As for terbium (Tb), a $\mathrm{Pb}$ (II) templated thermosensitive heteropolymer gel for multiple-point adsorption of $\mathrm{Tb}(\mathrm{III})^{238}$ has been synthesized and characterized. The imprinted gel showed strong binding ability to $\mathrm{Tb}$ (III). With respect to $\mathrm{La}(\mathrm{III}),{ }^{239,240}$ $\mathrm{Ce}(\mathrm{III}),{ }^{241} \mathrm{Gd}(\mathrm{III}),{ }^{242} \mathrm{Dy}(\mathrm{III}),{ }^{243}$ and Sm(III), ${ }^{244}$ only a few studies are reported on their related IIPs.

\subsection{Metalloid elements IIPs}

A metalloid is a chemical element that has properties between those of metals and nonmetals. The six commonly recognized metalloids include boron, silicon, germanium, arsenic, antimony and tellurium, and even selenium is also regarded as a kind of metalloid in rare cases.

3.5.1. Arsenic ion imprinted polymers (As-IIPs). Pentavalent or trivalent arsenic (As) exists mostly in compounds. As(III), a medium reduced state, is found mainly from groundwater while oxidation state As(v) is mainly present in surface water. As for toxicity, As(III) is much stronger (10-60 times) than As(v). ${ }^{245}$ Widely used arsenic removal methods are mature and arsenic contamination in water regulations has made many achievements over the years. ${ }^{246}$ But the development of imprinting techniques has opened up new ideas and directions for solving arsenic pollution.

Liu and his group prepared a bio-based $\alpha-\mathrm{Fe}_{2} \mathrm{O}_{3}$ impregnated CTS bead (As-IFICB) ${ }^{245}$ with As(III) used for selective removal of As(III) from aqueous solutions. In the same year, an As(III)imprinted CTS resin (As-ICR $)^{247}$ was successfully synthesized and used to remove As(III) from Laminaria japonica Aresch juice. An As(v)-IIP ${ }^{248}$ was obtained by bulk polymerization with good reusability up to 20 cycles and a LOD down to $0.025 \mu \mathrm{mol}$ $\mathrm{L}^{-1}$. When comparing three functional monomers of 1-vinylimidazole, 4-VP, and styrene, 1-vinylimidazole was proved to have better selectivity and adsorption capacity of a reinforced material. ${ }^{248}$ Sun et al. ${ }^{249}$ used surface ion-imprinted aminefunctionalized silica gel sorbent to selectively remove As(v) from aqueous solution.

3.5.2. Other metalloid ions IIPs. Polymerization in a glass tube containing $\mathrm{SeO}_{2}, o$-phenylenediamine, 2-VP, EGDMA and AIBN was achieved by Yamini et $a l .{ }^{54}$ And the IIPs were applied to the recovery and determination of selenium (Se) in different real samples. For the first time, Luccas and his group ${ }^{\mathbf{2 5 0}}$ put forward the concept of atomically imprinted polymers (AIPs) for Se. The proposed method was successfully applied to determine 

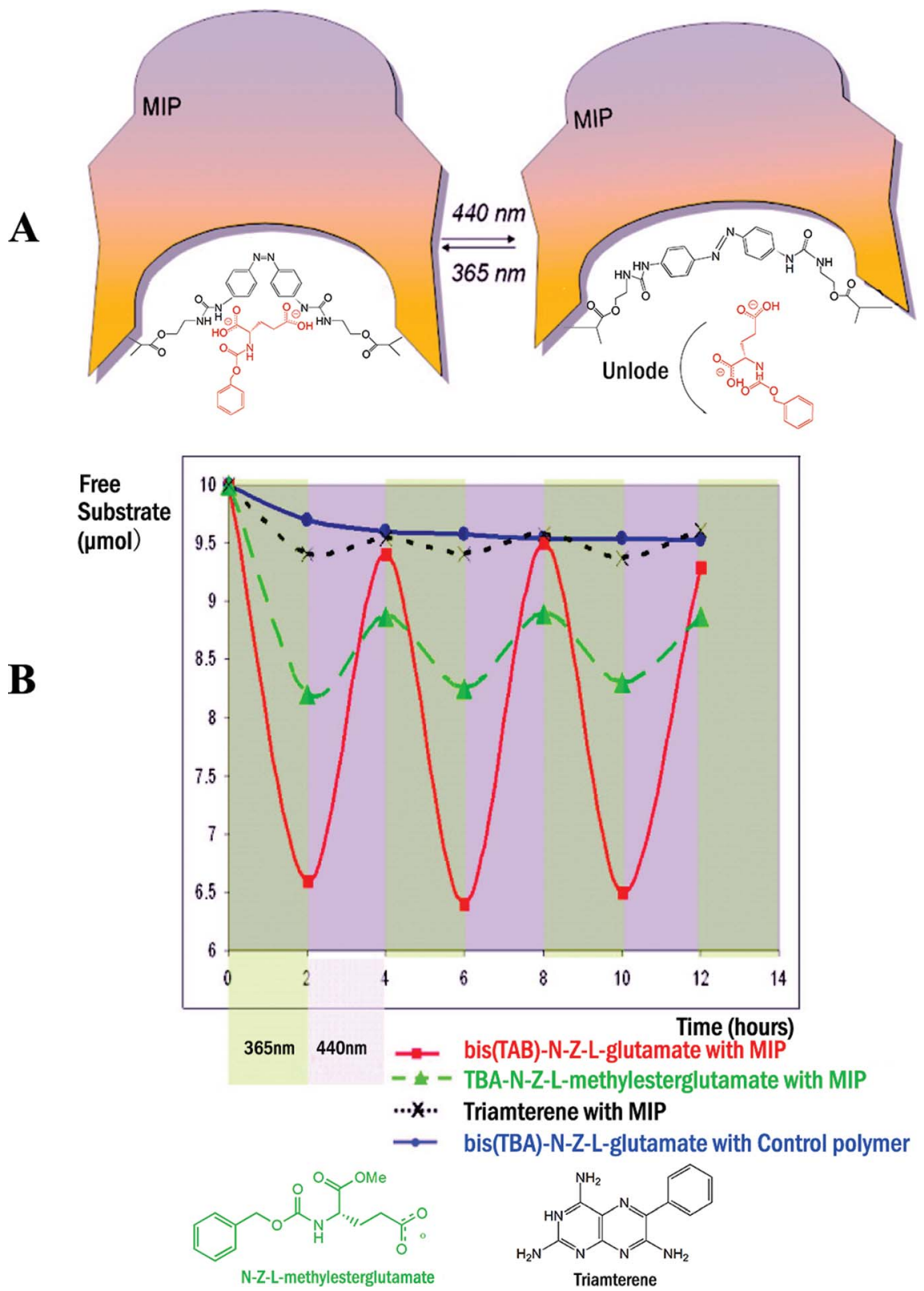

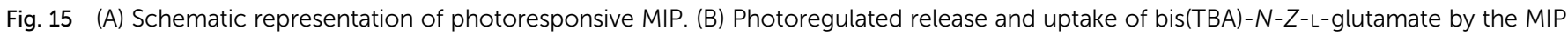
and the control polymer. The initial amount of ligands was $10 \mu \mathrm{mol}$ for $10 \mathrm{mg}$ MIP in $2 \mathrm{~mL}$ of DMSO. Reprinted with permission from ref. 269 . Copyright 2007 American Chemical Society.

Se in Brazil nuts, apricot, white bean, rice flour and milk powder samples and it was possible to perform 12 analyzes per hour via HG-FAAS online. Fan et al. ${ }^{251}$ developed a $\mathrm{Sb}(\mathrm{III})$-imprinted iodole-functionalized organic-inorganic hybrid sorbent with a sol-gel process. The experiments showed some encouraging results for adsorption capacity, selectivity, reusability and application. Combined with ETAAS, Dadfarnia et al. ${ }^{252}$ developed a SPE method using a $\mathrm{Sb}(\mathrm{III})$-IIP sorbent. If $\mathrm{Sb}(\mathrm{v})$ is reduced to $\mathrm{Sb}$ (III) first, this method could measure the total $\mathrm{Sb}$ in the juice.

Lack of study on metalloid ions imprinting may be due to the weaker valence bond force between a metalloid ion and ligand or monomer relative to the metal.

\subsection{Anion imprinting}

Besides increasing cationic ions imprinting, anionic imprinting has also gradually attracted attention. Anionic species generally include spherical $\left(\mathrm{F}^{-}, \mathrm{Cl}^{-}, \mathrm{Br}^{-}, \mathrm{I}^{-}\right)$, linear $\left(\mathrm{OH}^{-}, \mathrm{CN}^{-}, \mathrm{SCN}^{-}\right)$, triangular $\left(\mathrm{NO}_{3}{ }^{-}, \mathrm{CO}_{3}{ }^{2-}\right)$, tetrahedral $\left(\mathrm{PO}_{4}{ }^{3-}, \mathrm{SO}_{4}{ }^{2-}, \mathrm{VO}_{4}{ }^{3-}\right)$, square planar $\left(\left[\mathrm{PdCl}_{4}\right]^{2-}, \quad\left[\mathrm{Pt}(\mathrm{CN})_{4}\right]^{2-}\right)$, octahedral $\left(\mathrm{PF}_{6}{ }^{-}\right.$, $\left[\mathrm{Fe}(\mathrm{CN})_{6}\right]^{4-},\left[\mathrm{Co}(\mathrm{CN})_{6}\right]^{3-}$ ), and complex shapes (DNA, nucleotides). ${ }^{26}$ Nevertheless, still not all the anionic species possess imprinting studies. The studies of anion imprinting are seldom reported, which may be caused by the following points: some anions are either too small or less functional than other species. The electrostatic interactions for anionic molecules are less effective compared to the smaller cationic species. ${ }^{26}$ Anionic 
species are often not suitable for apolar media. ${ }^{253}$ All in all, the significant hindrance is that it is generally difficult to create well-defined recognition sites. The following paragraphs summarize the relevant studies, which are divided into four sections: phosphate, carboxylated, sulfate or sulfonate templates and other anionic template imprinted polymers.

3.6.1. Phosphate template. Powell et $a .^{254}$ chose cyclic adenosine $3^{\prime}: 5^{\prime}$-monophosphate (cAMP) as a template. ${ }^{255}$ They incorporated a fluorescent dye as an integral part of the recognition cavity to obtain an extra signal by the change of luminescence. For pinacolyl methylphosphonate (PMP), the hydrolysis product of Soman used by Murray and his team, ${ }^{225,256}$ was reversibly bound to ligand-coordinated $\mathrm{Eu}(\mathrm{III})$ as a template in the preparation of an imprinted polymeric luminescent sensor. Wulff et al. ${ }^{257}$ employed a phosphate-derived TSA template to present catalytic MIPs modelled on carboxypeptidase A. In the same year, Zhou et al. ${ }^{258}$ reported a potentiometric chemosensor for the detection of methylphosphonic acid (MPA), a degradation product of nerve agents. In addition, diphenyl phosphate (a flame retardant hydrolysis product), ${ }^{259} p$ nitrophenyl phosphate, ${ }^{\mathbf{2 6 0 , 2 6 1}}$ and phytic acid, ${ }^{\mathbf{2 6 2}}$ were also chosen as analytes.
3.6.2. Carboxylated template. Willner et al. ${ }^{263}$ prepared molecular imprinted ultrathin $\mathrm{TiO}_{2}$ films first by allowing titanium (Ti) butoxide to covalently complex with a carboxylated template molecule. Subsequently, molecular imprinted $\mathrm{TiO}_{2}$ films were used for selective recognition of chiral carboxylic acids including amino acid derivatives, ${ }^{\mathbf{2 6 4 , 2 6 5}}$ and azobenzene carboxylic acids. ${ }^{266}$ Penicillin G, a kind of $\beta$-lactam antibiotic, was developed as an imprinted polymeric receptor, which was applied to a SPE procedure for the selective pre-concentration of BLAs from environmental samples. ${ }^{267,268}$ Schmitzer and coworkers $^{269}$ used a self-synthetic monomer di(ureidoethylenemethacrylate)azobenzene and methotrexate analogue (bis(TBA)- $N$ - $Z$-L-glutamate) as a template to obtain good selective photoresponsive polymers. Photoinduced cis $\rightarrow$ trans isomerization of theazobenzene-containing polymer backbone is able to regulate the receptor sites' geometry and can regulate the release and uptake of a substrate, as shown in Fig. 15. This stimuli-responsive MIP may find applications in smart drug delivery systems. Prasad et al. ${ }^{270}$ developed a folic acid imprinted polymer-carbon consolidated composite fibersensor by copolymerizing a novel tri-functional monomer and 2,4,6-trisacrylamido-1,3,5-triazine. Relevant graphic
(A)

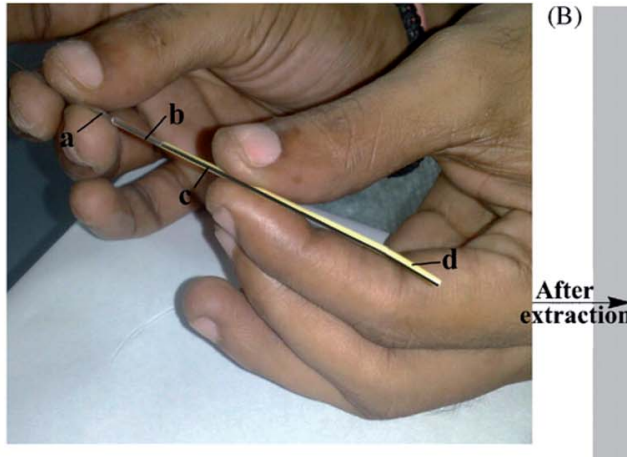

(D)

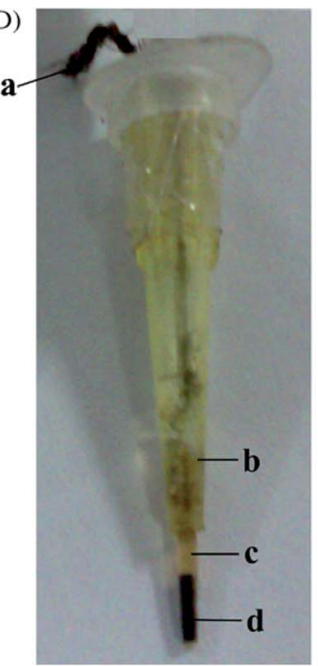

(B)

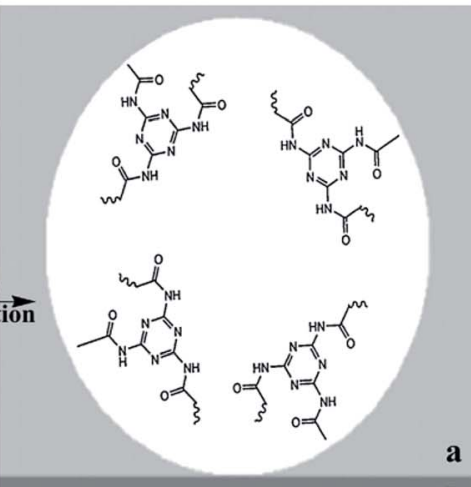

(C)

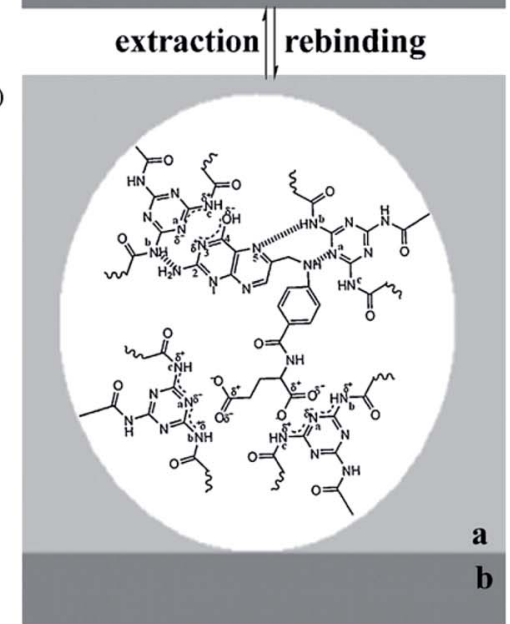

Fig. 16 (A) Picture of MIP-FA adduct-carbon composite fiber: (a) an insertable wire to push fiber out from glass capillary, (b) glass capillary, (c) fiber portion inside the capillary, and (d) pushed out fiber embossed with a visible black carbon strip. (B) and (C) show template (FA) extraction and rebinding processes in aqueous medium, respectively [(a) polymer zone and (b) carbon zone]. (D) Picture of fabricated MIP-fiber sensor: (a) copper wire, (b) micropipette tip, (c) agarose solution, and (d) MIP-carbon composite fiber. Reprinted with permission from ref. 270. Copyright 2010 Elsevier B.V. 
presentations are displayed in Fig. 16. The detection of folic acid with the MIP-fiber sensor was found to be specific and quantitative in aqueous, blood serum, and pharmaceutical samples, without any problem of non-specific false-positive contribution and cross-reactivity. For carboxylate anions, bilirubin, ${ }^{271}$ daminozide, ${ }^{272}$ enrofloxacin, ${ }^{273-275}$ and dipicolinic $\operatorname{acid}^{276}$ all have been reported as template ions for IIPs.

3.6.3. Sulfate or sulfonate template. Sevilla and his team ${ }^{277}$ created a piezoelectric quartz crystal sensor for monitoring pollutant surfactants such as sodium dodecyl sulfate (SDS). The imprinted polypyrrole film was synthesized by electrodepositing a buffer solution of pyrrole. Ibrahim et al. ${ }^{278}$ prepared a MIP for SPE of Cibacron reactive dyes, which had good adsorption and binding properties. Moreover, some sulfate or sulfonate anions imprinting experiments have been reported for 1-naphthalene sulfonic acid, ${ }^{279}$ sulfated sugar, ${ }^{280}$ and Ramazol Brilliant Red dye $(\mathrm{RR}) .^{281}$

3.6.4. Other anionic templates. Based on a surfaceenhanced Raman scattering (SERS) technique, Tian et al. ${ }^{\mathbf{2 8 2}}$ attained trace level detection of 2,4,6-trinitrotoluene (TNT) by attaching $p$-aminothiophenol functionalized silver nanoparticles to silver molybdate nanowires (Ag-SMNs). Ruikui et $a l .{ }^{283}$ prepared ion imprinting material IIP-PEI/SiO ${ }_{2}$ of chromate anion with high performance with respect to the $\mathrm{PO}_{3}{ }^{4-}$. Also for Cr, Chimuka and coworkers ${ }^{284}$ obtained a linear copolymer for selective removal of $\mathrm{Cr}(\mathrm{vI})$ from sulphates and other metal anions. Moreover, other related reports have demonstrated that arsenate ${ }^{285}$ and phenolic acid ${ }^{286}$ can also be recognized by means of IIT.

\subsection{Secondary imprinting}

Secondary imprinting means that metal ions as a part of the functional monomer contribute to the imprinting of molecules. Examples include small molecules, amino acids, proteins, and even DNA, by forming coordination bonds with metal ions. However, due to the requirement of finding metal ions which have a specific reaction with the target, secondary imprinting is much more difficult. For example, in the process of protein imprinting, the metal ions are generally used for proteins containing exposed histidine groups, and the binding forces between different proteins together with various metal ions are relatively large. Few studies in recent years are the result of the difficulty of secondary imprinting from mutual selection as described above.

An imprinted polymer of bromide ion-lanthanum nitrate modified $\mathrm{CTS}^{287}$ was prepared and $\mathrm{H}_{2} \mathrm{O}_{2}$ oxidation-extraction photometric method was used for the determination of bromide ion concentrations. A simple, low cost, selective and sensitive complex imprinted membrane (CIM) for solid-phase fluorescent detection was developed by Li et al. ${ }^{288}$ with $\mathrm{Tb}(\mathrm{III})$

A
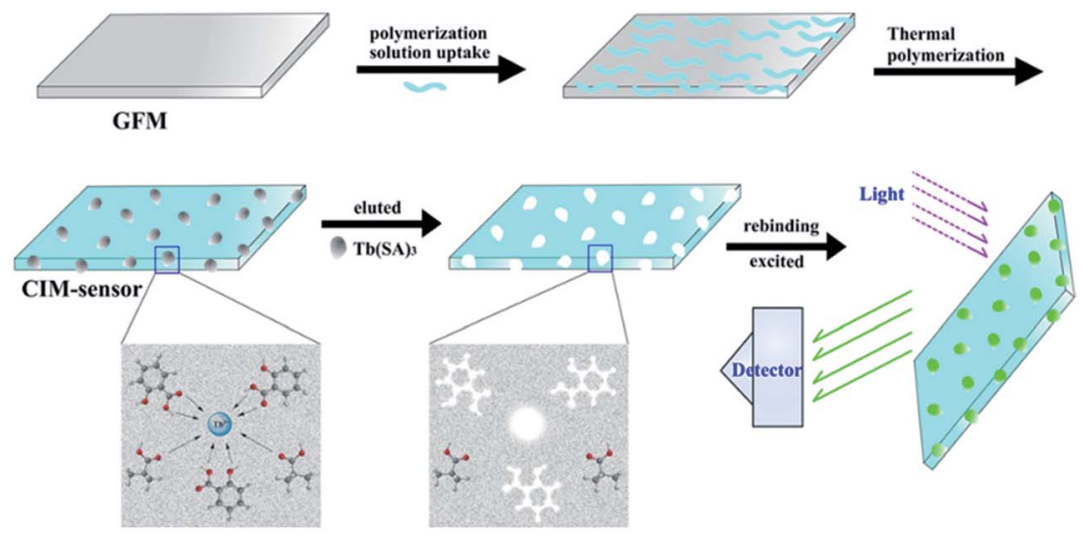

B<smiles>O=C(O)c1ccccc1O</smiles>

SA<smiles>O=C(O)c1ccccc1</smiles>

BA<smiles>CC(=O)Oc1ccccc1C(=O)O</smiles>

ASP

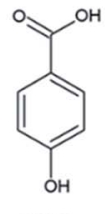

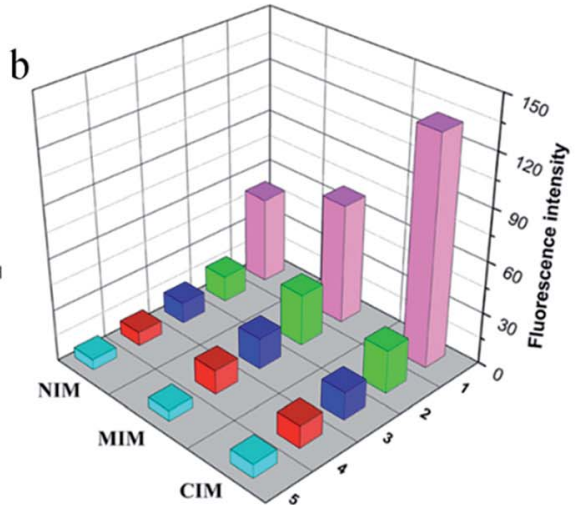

Fig. 17 (A) Schematic fabrication of the preparation and employment of $\mathrm{Tb}(\mathrm{SA})_{3}$ complex imprinted membrane based on solid phase surface fluorescent detection. (B) (a) Molecular structures of SA and its analogues. (b) Fluorescent response of CIM, MIM and NIM to SA and its analogues. (1) SA, (2) ASP, (3) BA, (4) 3-HBA, (5) 4-HBA. Concentration: $2.0 \mathrm{mg} \mathrm{L}^{-1}\left[\mathrm{TbCl}_{3}\right.$-ligand], adsorption time: 10 min. Reprinted with permission from ref. 288. Copyright 2013 Elsevier B.V. 
salicylate as the complex template. Its application with pharmaceuticals and human urine, and the imprinting process and mechanism are shown in Fig. 17A. The metal $\mathrm{Tb}$ (III) bridges the analyte salicylic acid (SA) and monomer MAA to form a complex via a coordination bond. There is no doubt that the response of CIM to SA was much higher than the responses to the other four analogues, as seen from Fig. 17B. According to Ersöz's method, ${ }^{289}$ poly(methacryloyl histidine-Ni(II)- $\mathrm{CN}^{-}$) was synthesized and able to specifically recognize the cyanide ion. The purpose of $\mathrm{Ni}(\mathrm{II})$ added is to form the coordination reaction with the template. The relative selectivity coefficients of $\mathrm{CN}^{-} / \mathrm{SCN}^{-}$, $\mathrm{CN}^{-} / \mathrm{S}^{2-}, \mathrm{CN}^{-} / \mathrm{Cl}^{-}, \mathrm{CN}^{-} / \mathrm{NO}_{3}{ }^{-}$and $\mathrm{CN}^{-} / \mathrm{SO}_{4}{ }^{2-}$ are $43.37,54.78$, 109.1, 117.2, and 167.9, respectively. Ersöz et al. ${ }^{290}$ also proposed a novel thiol ligand-capping method with methacryloylamido histidine-Pt(II) (MAH-Pt(II)) as a metal-chelating monomer attached to gold-silver-nanoclusters reminiscent of a self-assembled monolayer for cholic acid recognition via Raman spectroscopy. And they even have made an attempt for DNA recognition: ${ }^{291} \mathrm{MAH}-\mathrm{Pt}(\mathrm{II})$ as a metal-chelating monomer and guanosine as a template to form MIPs for single stranded DNA. Haupt $^{229}$ prepared nanofilament-based optical sensors for the analysis of enrofloxacin, an antibiotic widely used for human and veterinary applications, and its sensitive determination was realized with a Eu(III) developer. The synthesized polymer was anchored onto a glass support through UV polymerization. Chang et al. $^{292}$ reported a facile synthesis of a luminescence sensor based on Eu(III) for detecting chromophoric toxic chemicals. The Eu(III)-IIPs showed significant luminescence only after binding of chemicals bearing sensitizing chromophore moieties. A bi-functionalized molecularly imprinted silica (MIS) ${ }^{293}$ mediated by $\mathrm{Al}$ was prepared for SPE of quercetin in Ginkgo biloba L. The presence of $\mathrm{Al}(\mathrm{III})$ improved the selectivity and efficiency for quercetin extraction. A kind of chiral recognition of proteins having L-histidine residues on the surface with a $\mathrm{Tb}(\mathrm{III})$ complex was reported by Uzun et al. ${ }^{\mathbf{2 9 4}}$ The fluorescent NPs could be used for selective separation and fluorescent monitoring simultaneously. The recognition of Cterminal cholecystokinin pentapeptide (CCK-5) in the presence of nitrilotriacetic acid-nickel (Ni-NTA) complex was analyzed. ${ }^{295}$ At the same time, $\mathrm{Ni}(\mathrm{II})$ was removed and substituted by other divalent ions such as $\mathrm{Mg}$ (II), Fe(II), Zn(II), $\mathrm{Co}$ (II) and $\mathrm{Cu}(\mathrm{II})$ to study which would be better. A new immobilized metal affinity chromatography (IMAC) matrix ${ }^{296}$ was prepared by coordinating $\mathrm{Cu}$ (II) with CTS coated on non-porous silica gel. The grafting $\mathrm{Cu}(\mathrm{II})$ can provide a series of binding sites; for example, bovine serum albumin and trypsin can be bonded to $\mathrm{Cu}(\mathrm{II})$ steadily due to their amino acid sequences.

\section{Conclusions and future outlook}

In this review, we have summarized the current status of ion imprinting concerning the preparation and application of various IIPs. Elemental components and smart preparation techniques are outlined, and various types of IIPs are comprehensively reviewed including main group, transition, actinide, rare earth, metalloid, anion imprinting and secondary imprinting. As seen, IIPs are quite compatible with aqueous media which is remarkably advantageous over most MIPs, and can effectively identify, monitor, and remove targeted ions in aqueous/biological environments, especially heavy metals, radioactive elements and anion pollutants which all have major issues and concerns. Obviously, the selective recognition, enrichment, and removal of metal ions have important significances in environmental sustainability, human health protection, economy development, and resource recycling. Although continuous advances and remarkable achievements have been attained in ion imprinting, there are still various substantial development challenges and opportunities, for example as follows.

(1) In terms of the top concerned selectivity and mechanism issues of ion imprinting, they are always the bottlenecks and effect directions. IIT developed relatively slowly, mainly because it is often baffled by problems of low selectivity, since many ions have the same charges, similar ionic radiuses, and properties. Besides employing dual/multiple functional monomers and even creating novel monomers, dual/multiple template ions, and composite reagents, other more effective and direct strategies should be explored as quickly as possible in order to improve the selectivity of IIPs. On the other hand, explaining the imprinting and recognition mechanisms with the aid of advanced equipment is urgently required. Deep explorations of mechanisms will efficiently solve some bottleneck issues and broaden the application scopes of ion imprinting.

(2) In terms of research content and scope involving associated imprinting with common applications, innovation needs to be continuously applied. Based on thermal, electrical, optical, magnetic and other signals and multi-responses, ${ }^{70}$ combining IIT with certain testing tools can realize quantitative and continuous detection of ions, which is likely to be a breakthrough. As for secondary imprinting, using metal ions as part of the functional monomer facilitates molecules to form coordination bonds with metal ions. But in the process of protein imprinting, the metal ions are generally used in proteins that contain nudity histidine, which limits secondary imprinting. What's more, speciation analysis, which includes organic or inorganic forms, element valence and even isotope recognition, has received considerable attention because of their higher importance and applicability than simple ions. With the rapid consumption of earth's resources, strategic elements, such as uranium and rare earth elements, have increasing national concerns for their extraction and enrichment. From the above, stimuli-responsive imprinting, second imprinting, speciation analysis and strategic elements imprinting should have much more emphasis for exploration, and that will bring a series of innovations for ion imprinting.

(3) In terms of a research target, more concentration should be placed on the transition metals compared with rare earth metals, actinide metals and metalloid ions. In the future, related studies should be strengthened on the latter. Moreover, anion and secondary imprinting, even living cell imprinting, should be increasingly investigated. IIT may have more sparks with the combination with biomacromolecules (nucleotides, polypeptides, proteins, etc.) and even living cells and organisms. Recently, with the aid of unique quenching, catalytic, and 
solvent effects, some ions can drive research hotspots such as quantum dots and click chemistry related studies. ${ }^{63-65,92,102}$

(4) In terms of preparation technologies and methods, some boundedness and blindness on the selection of IIPs components still exist. The general polymerization technologies will be continuously used, but related research of combining them with other techniques and materials must be increased for appropriately improving these technologies in order to satisfy higher performance requirements. Various smart techniques and strategies are highly expected to apply for IIPs preparation. Researchers should put more concerns on the techniques and make more attempts in order to attain more variety and better IIPs. Furthermore, establishing complete and reliable guide systems, for example, theoretical calculations (computer simulation), ${ }^{31,301}$ experimental design (Box-Behnken design) ${ }^{149-151}$ and the correct metal ion-ligand stoichiometry, ${ }^{302}$ has become one important effort direction; these will greatly enrich the research connotations and effectively simplify preparation processes of IIPs. In addition, it is urgently imperative to exploit new preparation technologies and methods in order to attain higher imprinting efficiency and binding capacity of IIPs.

(5) In terms of applications, most researchers focus on separation/purification but lack in other aspects, and largescale applications of IIPs have been hardly conducted. The applications of IIPs to chemo/biosensing, catalysis, degradation, physiological and clinical researches have room for great developments. By virtue of various technologies and strategies and thereby integrating them, it is very possible that IIPs will be active in multi-aspects. Furthermore, the high throughput applications of IIPs in complex matrices are especially desirable.

As far as we know, high volume production and large-scale applications of IIPs have been rarely implemented. One major obstacle faced in transferring IIPs from lab to industry is the form factor of the IIPs synthesized, which makes them unusable for large scale applications. For instance, immaturity of preparative techniques, relatively low preparation amounts and high costs, different operation conditions, green environmental protection requirements, etc., restrict the production scale. So, continuous investigation and improvement of various preparation technologies meeting with the needs of high amounts, low cost, simple operations and eco-friendliness are urgently required. Several exploration ways are proposed:

(i) Based on the existing preparation technologies, selectivity can be sacrificed to attain high scale production of IIPs. During batch production, cost-saving is almost always the primary requirement, but selectivity is a secondary goal. The remarkable difference of operation conditions/scales between industry and a lab certainly will decrease the selectivity of IIPs to some extent; that is still acceptable to provide high amounts but moderate selectivity in IIPs. Hence, more work should be done to apply suitable existing preparation technologies to produce large amounts of IIPs.

(ii) The development of various smart preparation technologies has a promising prospective for up-scaling of IIPs production. Surface imprinting, stimuli-responsive imprinting, $\mathrm{dual} /$ multiple components imprinting strategies, and so on will

decrease preparation costs while remaining/enhancing selectivity of IIPs along with increased production efficiency and simplified processes. So, more efforts should be made to attempt new smart technologies for producing large amounts of IIPs and thereby predictable large-scale practical applications.

(iii) The borrowing, reference, coupling and integration of various technologies for IIPs preparation will be an effective way forward. For example, solid-phase synthesis possesses the advantages of high scalability, reproducibility, controllability, and easy automation, which has great potential for up-scaling of MIPs production. ${ }^{297-300}$ Consequently, that technology for IIPs preparation is highly anticipated to be utilized and widely applied for mass production.

Therefore, more related endeavors and explorations should be continuously made to introduce various technologies and strategies into IIPs preparation in order to rapidly obtain high amounts of IIPs for industrialization applications.

\section{Abbreviations}

\section{2,4-DCP \\ 3-HBA \\ 4-HBA \\ AA}

AAAPTS

AAPTS

AEDP

AFM

AFS

AIBN

AIP

AM

AMP

APTES

ASP

BA

BBD

BPO

CAMP

CCK-5

CME

CPMA

CTAB

CTS

CVAAS

DBDA15C4

\section{DCQ}

DEM

DMSO

DPC

DR

DVB

ECH

EGDMA

ETAAS

\author{
2,4-Dichlorophenol \\ 3-Hydroxybenzoic acid \\ 4-Hydroxybenzoic acid \\ Acrylic acid \\ 3-[2-(2-Aminoethylamino)ethylamino]propyl- \\ trimethoxysilane
}

3-( $\gamma$-Aminoethylamino)-propyl-trimethoxysilane

2-Acryl aminoethyl dihydrogen phosphate

Atomic force microscopy

Atomic fluorescence spectroscopy

2,2-Azobisisobutyronitrile

Atomically imprinted polymers

Acrylamide

Adenosine monophosphate

3-Aminopropyltriethoxysilane

Aspirin

Benzoic acid

Box-Behnken design

Benzoylperoxide

Cyclic adenosine $3^{\prime}: 5^{\prime}$-monophosphate

C-terminal cholecystokinin pentapeptide

Capillary microextraction

$\mathrm{N}$-(o-Carboxyphenyl)maleamic acid

Cetyltrimethylammonium bromide

Chitosan

Cold vapor atomic absorption spectrometry

5,6;14,15-Dibenzo-1,4-dioxa-8,12-

diazacyclopentadecane-5,14-diene

5,7-Dichloroquinoline-8-ol

2-(Diethylamino) ethyl methacrylate

Dimethylsulfoxide

Diphenylcarbazide

Dual responsive

Divinylbenzene

Epichlorohydrin

Ethylene glycol dimethacrylate

Electrothermal atomic absorption spectrometry 


\begin{tabular}{|c|c|}
\hline FMR & Fluorescence microplate reader \\
\hline FTIR & Fourier transform infra-red spectroscopy \\
\hline GF-AAS & $\begin{array}{l}\text { Graphite furnace atomic absorption } \\
\text { spectrophotometer }\end{array}$ \\
\hline GPTMS & $\gamma$-Glycidoxypropyltrimethoxysiloxane \\
\hline HAQ & 1-Hydroxy-2-(prop-20-enyl)-9,10-anthraquinone \\
\hline HEMA & 2-Hydroxyethyl methacrylate \\
\hline ICP-OES & $\begin{array}{l}\text { Inductively coupled plasma-optical emission } \\
\text { spectrometry }\end{array}$ \\
\hline IIPs & Ion imprinted polymers \\
\hline IMAC & Immobilized metal affinity chromatography \\
\hline IUPAC & International union of pure and applied chemistry \\
\hline LOD & Limit of detection \\
\hline MAA & Methacrylic acid \\
\hline MAC & $N$-Methacryloyl-(L)-cysteine methylester \\
\hline MAGA & $N$-Methacryloyl-L-glutamic acid \\
\hline MIPs & Molecular imprinted polymers \\
\hline MIT & Molecular imprinting technology \\
\hline MPA & Methylphosphonic acid \\
\hline MPABA & 4-[(4-Methacryloyloxy)phenylazo]benzoic acid \\
\hline MPPM & Microporous polypropylene membrane \\
\hline MPTS & 3-Mercaptopropyltrimethoxysilane \\
\hline MTMAAm & 5-Methyl-2-thiozylmethacrylamide \\
\hline MWCNTs & Multi-walled carbon nanotubes \\
\hline NIPAM & $N$-Isopropylacrylamide \\
\hline NPs & Nanoparticles \\
\hline PAA & Polyacrylic acid \\
\hline PETRA & Pentaerythritol triacrylate \\
\hline Pir & Piroxicam \\
\hline PMC & $N$-[Pyridylmethyl]-chitosan \\
\hline PMP & Pinacolyl methylphosphonate \\
\hline PVA & Poly(vinyl alcohol) \\
\hline PVDF & Polyvinylidene fluoride \\
\hline QDs & Quantum dots \\
\hline RAFT & Reversible addition-fragmentation chain transfer \\
\hline RLS & Resonance light-scattering \\
\hline $\mathrm{RR}$ & Ramazol Brilliant Red dye \\
\hline RTP & Room temperature phosphorescence \\
\hline SA & Salicylic acid \\
\hline SBSE & Stir bar sorptive extraction \\
\hline SDS & Sodium dodecyl sulfate \\
\hline SEM & Scanning electron microscopy \\
\hline SERS & Surface enhanced Raman scattering \\
\hline SPE & Solid-phase extraction \\
\hline SPRS & Surface plasmon resonance spectroscopy \\
\hline TEOS & Tetraethoxysilane \\
\hline T-IPTS & Thymine-3-isocyanatopropyltriethoxysilane \\
\hline TMPTM & Trimethylolpropane trimethacrylate \\
\hline TMSPMA & 3-(Trimethoxysilyl)propylmethacrylate \\
\hline TNT & 2,4,6-Trinitrotoluene \\
\hline TPED & $N$-[3-(Trimethoxysilyl)propyl]ethylenediamine \\
\hline TPED & $N$-[3-(Trimethoxy-silyl) propyl] ethylenediamine \\
\hline TS-FF-AAS & $\begin{array}{l}\text { Thermospray flame furnace atomic absorption } \\
\text { spectrometry }\end{array}$ \\
\hline VB & Styrene \\
\hline VBIDA & $N$-(4-Vinyl)-benzyl iminodiacetic acid \\
\hline VP & Vinyl pyridine \\
\hline XRD & $\mathrm{X}$-ray diffractometer \\
\hline$\gamma$-MPS & $\gamma$-Methacryloxypropyltrimethoxysilane \\
\hline
\end{tabular}

\section{Acknowledgements}

This work was financially supported by the National Natural Science Foundation of China $(21275158,21477160)$, the Scientific Research Foundation for the Returned Overseas Chinese Scholars, State Education Ministry, and the Innovation Projects of the Chinese Academy of Sciences (KZCX2-EW-206).

\section{Notes and references}

1 M. V. Polyakov, Zh. Fiz. Khim., 1931, 2, 799-805.

2 L. Chen, S. Xu and J. Li, Chem. Soc. Rev., 2011, 40, 29222942.

3 H. Nishide and E. Tsuchida, Makromol. Chem., 1976, 177, 2295-2310.

4 K. Tsukagoshi, K. Y. Yu, M. Maeda and M. Takagi, Bull. Chem. Soc. Jpn., 1993, 66, 114-120.

5 R. Garcia, C. Pinel, C. Madic and M. Lemaire, Tetrahedron Lett., 1998, 39, 8651-8654.

6 S. Y. Bae, G. L. Southard and G. M. Murray, Anal. Chim. Acta, 1999, 397, 173-181.

7 C. Alexander, H. S. Andersson, L. I. Andersson, R. J. Ansell, N. Kirsch, I. A. Nicholls, J. O'Mahony and M. J. Whitcombe, J. Mol. Recognit., 2006, 19, 106-180.

8 F. H. Dickey, Proc. Natl. Acad. Sci. U. S. A., 1949, 35, 227-229.

9 V. Patrikeev, A. Balandin, E. Klabunovskii, J. Mardaszew and G. Maksimova, in Dokl. Akad. Nauk SSSR, 1960, pp. 850-852.

10 G. Wulff, Angew. Chem., Int. Ed. Engl., 1995, 34, 1812-1832.

11 G. Wulff and A. Sarhan, Angew. Chem., Int. Ed. Engl., 1972, 11, 341.

12 T. Takagishi and I. M. Klotz, Biopolymers, 1972, 11, 483-491.

13 J. Sagiv, Isr. J. Chem., 1979, 18, 346-353.

14 G. Vlatakis, L. I. Andersson, R. Muller and K. Mosbach, Nature, 1993, 361, 645-647.

15 M. J. Whitcombe, M. E. Rodriguez, P. Villar and E. N. Vulfson, J. Am. Chem. Soc., 1995, 117, 7105-7111.

16 K. Sreenivasan and R. Sivakumar, J. Appl. Polym. Sci., 1999, 71, 1823-1826.

17 B. Lele, M. Kulkarni and R. Mashelkar, Polymer, 1999, 40, 4063-4070.

18 B. Lele, M. Kulkarni and R. Mashelkar, React. Funct. Polym., 1999, 40, 215-229.

19 J. Orozco, A. Cortés, G. Cheng, S. Sattayasamitsathit, W. Gao, X. Feng, Y. Shen and J. Wang, J. Am. Chem. Soc., 2013, 135, 5336-5339.

20 J. J. Becker and M. R. Gagné, Acc. Chem. Res., 2004, 37, 798804.

21 W. Sun, R. Tan, W. Zheng and D. Yin, Chin. J. Catal., 2013, 34, 1589-1598.

22 M. J. Whitcombe, N. Kirsch and I. A. Nicholls, J. Mol. Recognit., 2014, 27, 297-401.

23 T. P. Rao, R. Kala and S. Daniel, Anal. Chim. Acta, 2006, 578, 105-116.

24 C. Branger, W. Meouche and A. Margaillan, React. Funct. Polym., 2013, 73, 859-875. 
25 L. D. Mafu, T. A. Msagati and B. B. Mamba, Environ. Sci. Pollut. Res. Int., 2013, 20, 790-802.

26 X. Wu, Microchim. Acta, 2011, 176, 23-47.

27 Y. Hoshino, R. C. Ohashi and Y. Miura, Adv. Mater., 2014, 26, 3718-3723.

28 M. Komiyama, T. Takeuchi, T. Mukawa and H. Asanuma, Molecular imprinting: from fundamentals to applications, Wiley-VCH, 2003.

29 L. Andersson, B. Sellergren and K. Mosbach, Tetrahedron Lett., 1984, 25, 5211-5214.

30 M. Shamsipur, J. Fasihi, A. Khanchi, R. Hassani, K. Alizadeh and H. Shamsipur, Anal. Chim. Acta, 2007, 599, 294-301.

31 A. Koohpaei, S. Shahtaheri, M. Ganjali, A. R. Forushani and F. Golbabaei, Talanta, 2008, 75, 978-986.

32 H. Zhang, T. Song, F. Zong, T. Chen and C. Pan, Int. J. Mol. Sci., 2008, 9, 98-106.

33 S. Xu, L. Chen, J. Li, Y. Guan and H. Lu, J. Hazard. Mater., 2012, 237-238, 347-354.

34 G. O. Buica, C. Bucher, J. C. Moutet, G. Royal, E. S. Aman and E. M. Ungureanu, Electroanalysis, 2009, 21, 77-86.

35 Y. Liu, Y. Zai, X. Chang, Y. Guo, S. Meng and F. Feng, Anal. Chim. Acta, 2006, 575, 159-165.

36 Y. Zhai, Y. Liu, X. Chang, S. Chen and X. Huang, Anal. Chim. Acta, 2007, 593, 123-128.

37 J. Tan, H. F. Wang and X. P. Yan, Biosens. Bioelectron., 2009, 24, 3316-3321.

38 Q. He, X. Chang, Q. Wu, X. Huang, Z. Hu and Y. Zhai, Anal. Chim. Acta, 2007, 605, 192-197.

39 H. Zhang, H. Liang, Q. Chen and X. Shen, J. Radioanal. Nucl. Chem., 2013, 298, 1705-1712.

40 K. Karim, F. Breton, R. Rouillon, E. V. Piletska, A. Guerreiro, I. Chianella and S. A. Piletsky, Adv. Drug Delivery Rev., 2005, 57, 1795-1808.

41 O. Okay, Prog. Polym. Sci., 2000, 25, 711-779.

42 C. R. T. Tarley, F. N. Andrade, H. D. Santana, D. A. M. Zaia, L. A. Beijo and M. G. Segatelli, React. Funct. Polym., 2012, 72, 83-91.

43 C. R. Tarley, F. N. Andrade, F. M. de Oliveira, M. Z. Corazza, L. F. de Azevedo and M. G. Segatelli, Anal. Chim. Acta, 2011, 703, 145-151.

44 I. Dakova, I. Karadjova, V. Georgieva and G. Georgiev, J. Sep. Sci., 2012, 35, 2805-2812.

45 I. Dakova, T. Yordanova and I. Karadjova, J. Hazard. Mater., 2012, 231, 49-56.

46 A. Chen, G. Zeng, G. Chen, X. Hu, M. Yan, S. Guan, C. Shang, L. Lu, Z. Zou and G. Xie, Chem. Eng. J., 2012, 191, 85-94.

47 B. Gao, F. An and Y. Zhu, Polymer, 2007, 48, 2288-2297.

48 Y. Zhai, D. Yang, X. Chang, Y. Liu and Q. He, J. Sep. Sci., 2008, 31, 1195-1200.

49 W. Meouche, C. Branger, I. Beurroies, R. Denoyel and A. Margaillan, Macromol. Rapid Commun., 2012, 33, 928932.

50 S. J. Ahmadi, O. N. Kalkhoran and S. S. Arani, J. Hazard. Mater., 2010, 175, 193-197.

51 J. Matsui, I. A. Nicholls, T. Takeuchi, K. Mosbach and I. Karube, Anal. Chim. Acta, 1996, 335, 71-77.
52 T. Li, S. Chen, H. Li, Q. Li and L. Wu, Langmuir, 2011, 27, 6753-6758.

53 Z. Li, H. Fan, Y. Zhang, M. Chen, Z. Yu, X. Cao and T. Sun, Chem. Eng. J., 2011, 171, 703-710.

54 M. Khajeh, Y. Yamini, E. Ghasemi, J. Fasihi and M. Shamsipur, Anal. Chim. Acta, 2007, 581, 208-213.

55 J. O. Romaní, A. M. Piñeiro, P. B. Barrera and A. M. Esteban, Microchem. J., 2009, 93, 225-231.

56 C. J. Tan and Y. W. Tong, Anal. Chem., 2007, 79, 299-306.

57 C. J. Tan, H. G. Chua, K. H. Ker and Y. W. Tong, Anal. Chem., 2008, 80, 683-692.

58 Z. Zhang, J. Li, J. Fu and L. Chen, RSC Adv., 2014, 4, 2067720685.

59 L. Ye, P. A. Cormack and K. Mosbach, Anal. Chim. Acta, 2001, 187-196.

60 J. E. Lofgreen and G. A. Ozin, Chem. Soc. Rev., 2014, 43, 911933.

61 L. Qin, X. He, W. Zhang, W. Li and Y. Zhang, J. Chromatogr. A, 2009, 1216, 807-814.

62 F. Li, J. Li and S. Zhang, Talanta, 2008, 74, 1247-1255.

63 S. Xu, H. Lu, J. Li, X. Song, A. Wang, L. Chen and S. Han, ACS Appl. Mater. Interfaces, 2013, 5, 8146-8154.

64 H. Wang, Y. He, T. Ji and X. Yan, Anal. Chem., 2009, 81, 1615-1621.

65 L. Dan and H. F. Wang, Anal. Chem., 2013, 85, 4844-4848.

66 W. Guo, W. Hu, J. Pan, H. Zhou, W. Guan, X. Wang, J. Dai and L. Xu, Chem. Eng. J., 2011, 171, 603-611.

67 N. T. Tavengwa, E. Cukrowska and L. Chimuka, J. Hazard. Mater., 2014, 267, 221-228.

68 F. Aboufazeli, H. R. Lotfi Zadeh Zhad, O. Sadeghi, M. Karimi and E. Najafi, Food Chem., 2013, 141, 3459-3465.

69 F. F. He, H. Q. Wang, Y. Y. Wang, X. F. Wang, H. S. Zhang, H. L. Li and J. H. Tang, J. Radioanal. Nucl. Chem., 2012, 295, 167-177.

70 S. Xu, H. Lu, X. Zheng and L. Chen, J. Mater. Chem. C, 2013, 1, 4406-4422.

71 C. Gonzato, M. Courty, P. Pasetto and K. Haupt, Adv. Funct. Mater., 2011, 21, 3947-3953.

72 Y. Kanekiyo, R. Naganawa and H. Tao, Angew. Chem., Int. Ed., 2003, 42, 3014-3016.

73 Z. Chen, L. Xu, Y. Liang and M. Zhao, Adv. Mater., 2010, 22, 1488-1492.

74 H. Tokuyama, R. Kanazawa and S. Sakohara, Sep. Purif. Technol., 2005, 44, 152-159.

75 W. Zhang, X. He, W. Li and Y. Zhang, Chem. Commun., 2012, 48, 1757-1759.

76 K. Mizoguchi, J. Ida, T. Matsuyama and H. Yamamoto, Sep. Purif. Technol., 2010, 75, 69-75.

77 P. Imin, M. Imit and A. Adronov, Macromolecules, 2012, 45, 5045-5050.

78 L. Fang, S. Chen, Y. Zhang and H. Zhang, J. Mater. Chem., 2011, 21, 2320-2329.

79 Q. Tang, Y. T. Nie, C. B. Gong, C. F. Chow, J. D. Peng and M. H. W. Lam, J. Mater. Chem., 2012, 22, 19812-19820.

80 R. M. Meudtner and S. Hecht, Angew. Chem., Int. Ed., 2008, 47, 4926-4930. 
81 L. Qin, X. He, W. Zhang, W. Li and Y. Zhang, Anal. Chem., 2009, 81, 7206-7216.

82 S. Xu, J. Li, X. Song, J. Liu, H. Lu and L. Chen, Anal. Methods, 2013, 5, 124-133.

83 N. T. Hoai, D. K. Yoo and D. Kim, J. Hazard. Mater., 2010, 173, 462-467.

84 X. Cai, J. Li, Z. Zhang, F. Yang, R. Dong and L. Chen, ACS Appl. Mater. Interfaces, 2014, 6, 305-313.

85 B. Bali Prasad, D. Jauhari and A. Verma, Talanta, 2014, 120, 398-407.

86 M. C. B. Alonso, V. P. García, A. R. López, A. M. Piñeiro and P. B. Barrera, Microchem. J., 2014, 114, 106-110.

87 L. Zhu, Z. Zhu, Y. Qiu and R. Zhang, Sep. Sci. Technol., 2014, 49, 1584-1591.

88 H. C. Kolb, M. Finn and K. B. Sharpless, Angew. Chem., Int. Ed., 2001, 40, 2004-2021.

89 H. C. Kolb and K. B. Sharpless, Drug Discovery Today, 2003, 8, 1128-1137.

90 C. J. Hawker and K. L. Wooley, Science, 2005, 309, 12001205.

91 K. L. Killops, L. M. Campos and C. J. Hawker, J. Am. Chem. Soc., 2008, 130, 5062-5064.

92 Z. Li, G. Yu, P. Hu, C. Ye, Y. Liu, J. Qin and Z. Li, Macromolecules, 2009, 42, 1589-1596.

93 T. Fukushima, A. Kosaka, Y. Ishimura, T. Yamamoto, T. Takigawa, N. Ishii and T. Aida, Science, 2003, 300, 2072-2074.

94 J. P. Hill, W. Jin, A. Kosaka, T. Fukushima, H. Ichihara, T. Shimomura, K. Ito, T. Hashizume, N. Ishii and T. Aida, Science, 2004, 304, 1481-1483.

95 J. L. Mynar, T. Yamamoto, A. Kosaka, T. Fukushima, N. Ishii and T. Aida, J. Am. Chem. Soc., 2008, 130, 1530-1531.

96 L. M. Chang, Y. Li, J. Chu, J. Y. Qi and X. Li, Anal. Chim. Acta, 2010, 680, 65-71.

97 C. Xu and L. Ye, Chem. Commun., 2011, 47, 6096-6098.

98 C. Xu, X. Shen and L. Ye, J. Mater. Chem., 2012, 22, 74277433.

99 Z. Xu, D. Kuang, F. Zhang, S. Tang, P. Deng and J. Li, J. Mater. Chem. B, 2013, 1, 1852.

100 L. J. Zhao, F. Q. Zhao and B. Z. Zeng, Biosens. Bioelectron., 2014, 62, 19-24.

101 T. Y. Wang and C. Shannon, Anal. Chim. Acta, 2011, 708, 3743.

102 H. Naeimi, V. Nejadshafiee and S. Masoum, RSC Adv., 2015, 5, 15006-15016.

103 H. Chia, J. Jacob and F. Boey, J. Polym. Chem., 1996, 34, 2087-2094.

104 M. Murray, D. Charlesworth, L. Swires, P. Riby, J. Cook, B. Z. Chowdhry and M. J. Snowden, J. Chem. Soc., Faraday Trans., 1994, 90, 1999-2000.

105 X. Zhu, J. Chen, N. Zhou, Z. Cheng and J. Lu, Eur. Polym. J., 2003, 39, 1187-1193.

106 J. M. Lu, S. J. Ji, N. Y. Chen, Z. R. Sun, X. L. Zhu, W. P. Shi and Z. G. Wang, J. Appl. Polym. Sci., 2003, 89, 2611-2617.

107 Y. Zhang, R. Liu, Y. Hu and G. Li, Anal. Chem., 2009, 81, 967-976.
108 X. Liu, P. Lv, G. Yao, C. Ma, P. Huo and Y. Yan, Chem. Eng. J., 2013, 217, 398-406.

109 L. Feng, B. Pamidighantam and P. C. Lauterbur, Anal. Bioanal. Chem., 2010, 396, 1607-1612.

110 C. Li, J. Gao, J. Pan, Z. Zhang and Y. Yan, J. Environ. Sci., 2009, 21, 1722-1729.

111 X. Yang, Z. Zhang, H. Zhang, M. Zhang, Y. Hu, L. Luo and L. Nie, Chin. J. Anal. Chem., 2011, 39, 34-38.

112 X. Zheng, R. Fan and Z. Xu, Acta Polym. Sin., 2012, 561-570.

113 X. Luo, L. Liu, F. Deng and S. Luo, J. Mater. Chem. A, 2013, 1, 8280-8286.

114 J. He, A. Liu and J. P. Chen, J. Colloid Interface Sci., 2015, 439, 162-169.

115 N. G. Otero, C. T. Valino, J. O. Romani, E. P. Vazquez, A. M. Pineiro and P. B. Barrera, Anal. Bioanal. Chem., 2009, 395, 1107-1115.

116 X. Zhu, Y. Cui, X. Chang, X. Zou and Z. Li, Microchim. Acta, 2008, 164, 125-132.

117 J. Pan, X. Zou, Y. Yan, X. Wang, W. Guan, J. Han and X. Wu, Appl. Clay Sci., 2010, 50, 260-265.

118 H. S. Kalal, N. Pakizevand, H. Hoveidi, M. Taghiof, S. Tavangari and H. A. Panahi, Caspian J. Environ. Sci., 2013, 11, 53-63.

119 A. Hrdina, E. Lai, C. Li, B. Sadi and G. H. Kramer, React. Funct. Polym., 2012, 72, 295-302.

120 Y. Liu, R. Chen, D. Yuan, Z. Liu, M. Meng, Y. Wang, J. Han, X. Meng, F. Liu, Z. Hu, W. Guo, L. Ni and Y. Yan, Colloid Polym. Sci., 2014, 293, 109-123.

121 Y. Liu, X. Meng, M. Luo, M. Meng, L. Ni, J. Qiu, Z. Hu, F. Liu, G. Zhong, Z. Liu and Y. Yan, J. Mater. Chem. A, 2015, 3, 1287-1297.

122 Y. B. Amram, R. T. Vered, M. Riskin, Z. G. Wang and I. Willner, Chem. Sci., 2012, 3, 162-167.

123 F. An, B. Gao, X. Huang, Y. Zhang, Y. Li, Y. Xu, Z. Zhang, J. Gao and Z. Chen, React. Funct. Polym., 2013, 73, 60-65.

124 M. Andaç, E. Özyapi, S. Senel, R. Say and A. Denizli, Ind. Eng. Chem. Res., 2006, 45, 1780-1786.

125 A. H. Demircelik, M. Andac, C. A. Andac, R. Say and A. Denizli, J. Biomater. Sci., Polym. Ed., 2009, 20, 1235-1258.

126 H. Ashkenani and M. A. Taher, Int. J. Environ. Anal. Chem., 2013, 93, 1132-1145.

127 J. He, Y. Lu and G. Luo, Chem. Eng. J., 2014, 244, 202-208. 128 Z. Zhang, X. Xu and Y. Yan, Desalination, 2010, 263, 97-106.

129 M. Shamsipur and H. R. Rajabi, Microchim. Acta, 2012, 180, 243-252.

130 Z. Zhang, H. Zhang, Y. Hu, X. Yang and S. Yao, Talanta, 2010, 82, 304-311.

131 Y. Hu, Z. Zhang, H. Zhang, L. Luo, M. Zhang, X. Yang and S. Yao, Chin. J. Chem., 2012, 30, 377-385.

132 M. G. Gallegos, R. M. Olivas and C. Cámara, J. Anal. At. Spectrom., 2009, 24, 595-601.

133 H. Abedi and H. Ebrahimzadeh, React. Funct. Polym., 2013, 73, 634-640.

134 M. H. A. Zavar, M. Chamsaz, G. Zohuri and A. Darroudi, J. Hazard. Mater., 2011, 185, 38-43.

135 A. Darroudi, M. H. A. Zavar, M. Chamsaz, G. Zohuri and N. Ashraf, Anal. Methods, 2012, 4, 3798-3803. 
136 R. B. Martin, Clin. Chem., 1986, 32, 1797-1806.

137 M. Nicolini, P. Zatta and B. Corain, Aluminum in Chemistry, Biology, and Medicine, Cortina International, 1991.

138 K. Chang, W. Liao, C. Yu, C. E. Lan, L. Chang and H. Yu, Toxicol. Appl. Pharmacol., 2003, 193, 209-217.

139 A. Léonard and G. Gerber, Mutat. Res., Rev. Mutat. Res., 1997, 387, 47-53.

140 J. G. Wiener, D. P. Krabbenhoft, G. H. Heinz and A. M. Scheuhammer, Ecotoxicology of mercury, 2003.

141 T. Alizadeh, M. R. Ganjali and M. Zare, Anal. Chim. Acta, 2011, 689, 52-59.

142 A. Bahrami, A. B. Seidani, A. Abbaspour and M. Shamsipur, Mater. Sci. Eng., C, 2015, 48, 205-212.

143 I. Dakova, I. Karadjova, V. Georgieva and G. Georgiev, Talanta, 2009, 78, 523-529.

144 T. Yordanova, I. Dakova, K. Balashev and I. Karadjova, Microchem. J., 2014, 113, 42-47.

145 Z. Wang, G. Wu and C. He, Microchim. Acta, 2008, 165, 151157.

146 Z. Wang, Y. Shen, G. Wu and C. He, Chin. J. Anal. Chem., 2009, 37, 449-453.

147 Z. Zhang, J. Li, X. Song, J. Ma and L. Chen, $R S C A d v .$, 2014, 4, 46444-46453.

148 K. Fu, Y. Gao and K. Yao, Chin. J. Instrum. Anal., 2012, 31, 1001-1004.

149 M. Khajeh and E. Sanchooli, Environ. Chem. Lett., 2009, 9, 177-183.

150 M. Khajeh and E. Sanchooli, Biol. Trace Elem. Res., 2010, 135, 325-333.

151 M. Khajeh and E. Sanchooli, Int. J. Environ. Anal. Chem., 2011, 91, 1310-1319.

152 H. A. Dam and D. Kim, Ind. Eng. Chem. Res., 2009, 48, 56795685.

153 V. Yilmaz, O. Hazer and S. Kartal, Talanta, 2013, 116, 322329.

154 C. Kang, W. Li, L. Tan, H. Li, C. Wei and Y. Tang, J. Mater. Chem. A, 2013, 1, 7147-7153.

155 I. Dakova, I. Karadjova, I. Ivanov, V. Georgieva, B. Evtimova and G. Georgiev, Anal. Chim. Acta, 2007, 584, 196-203.

156 D. R. Greenwood, G. Kingsbury and J. Cleland, A handbook of key federal regulations and criteria for multimedia environmental control, US Environmental Protection Agency, Office of Research and Development, 1979.

157 H. Fan, J. Liu, H. Yao, Z. Zhang, F. Yan and W. Li, Ind. Eng. Chem. Res., 2014, 53, 369-378.

158 M. P. Waalkes, Mutat. Res., Fundam. Mol. Mech. Mutagen., 2003, 533, 107-120.

159 C. Giaginis, E. Gatzidou and S. Theocharis, Toxicol. Appl. Pharmacol., 2006, 213, 282-290.

160 F. Li, H. Jiang and S. Zhang, Talanta, 2007, 71, 1487-1493. 161 H. Fan, J. Li, Z. Li and T. Sun, Appl. Surf. Sci., 2012, 258, 3815-3822.

162 N. Zhang and B. Hu, Anal. Chim. Acta, 2012, 723, 54-60.

163 N. Candan, N. Tüzmen, M. Andac, C. A. Andac, R. Say and A. Denizli, Mater. Sci. Eng., C, 2009, 29, 144-152.
164 M. Behbahani, M. Barati, M. K. Bojdi, A. R. Pourali, A. Bagheri and N. A. G. Tapeh, Microchim. Acta, 2013, 180, 1117-1125.

165 G. Wallwork, Rep. Prog. Phys., 1976, 39, 401-485.

166 V. Gomez and M. Callao, TrAC, Trends Anal. Chem., 2006, 25, 1006-1015.

167 R. Rakhunde, L. Deshpande and H. Juneja, Crit. Rev. Environ. Sci. Technol., 2012, 42, 776-810.

168 Y. Liu, X. Meng, J. Han, Z. Liu, M. Meng, Y. Wang, R. Chen and S. Tian, J. Sep. Sci., 2013, 36, 3949-3957.

169 N. T. Tavengwa, E. Cukrowska and L. Chimuka, Talanta, 2013, 116, 670-677.

170 G. Bayramoglu and M. Y. Arica, J. Hazard. Mater., 2011, 187, 213-221.

171 Z. Ren, D. Kong, K. Wang and W. Zhang, J. Mater. Chem. A, 2014, 2, 17952-17961.

172 H. A. Shawky, J. Appl. Polym. Sci., 2009, 114, 2608-2615.

173 H. Huo, H. Su and T. Tan, Biotechnol. Bioprocess Eng., 2008, 13, 77-83.

174 H. Hou, D. Yu and G. Hu, Langmuir, 2015, 31, 1376-1384.

175 H. Ebrahimzadeh, E. Moazzen, M. M. Amini and O. Sadeghi, Anal. Methods, 2012, 4, 3232-3237.

176 H. Ebrahimzadeh, E. Moazzen, M. M. Amini and O. Sadeghi, Microchim. Acta, 2013, 180, 445-451.

177 M. E. H. Ahamed, X. Y. Mbianda, A. F. Mulaba-Bafubiandi and L. Marjanovic, Hydrometallurgy, 2013, 140, 1-13.

178 W. Guo, R. Chen, Y. Liu, M. Meng, X. Meng, Z. Hu and Z. Song, Colloids Surf., A, 2013, 436, 693-703.

179 M. S. Moorthy, P. K. Tapaswi, S. S. Park, A. Mathew, H. J. Cho and C. S. Ha, Microporous Mesoporous Mater., 2013, 180, 162-171.

180 P. A. Nishad, A. Bhaskarapillai, S. Velmurugan and S. V. Narasimhan, Carbohydr. Polym., 2012, 87, 2690-2696.

181 S. Chaitidou, O. Kotrotsiou and C. Kiparissides, Mater. Sci. Eng., C, 2009, 29, 1415-1421.

182 H. Yavuz, R. Say and A. Denizli, Mater. Sci. Eng., C, 2005, 25, 521-528.

183 S. Aslyü̈ce, N. Bereli, L. Uzun, M. A. Onur, R. Say and A. Denizli, Sep. Purif. Technol., 2010, 73, 243-249.

184 Ö. Saatçılar, N. Șatıroğlu, R. Say, S. Bekta and A. Denizli, J. Appl. Polym. Sci., 2006, 101, 3520-3528.

185 F. Xie, G. Liu, F. Wu, G. Guo and G. Li, Chem. Eng. J., 2012, 183, 372-380.

186 F. Zheng, N. Zhang and B. Hu, J. Anal. At. Spectrom., 2011, 26, 1521-1525.

187 Y. Ren, P. Liu, J. Feng, J. Ma, Q. Wen and M. Zhang, Chem. Eng. J., 2013, 219, 286-294.

188 K. Laatikainen, D. Udomsap, H. Siren, H. Brisset, T. Sainio and C. Branger, Talanta, 2015, 134, 538-545.

189 M. Behbahani, M. Taghizadeh, A. Bagheri, H. Hosseini, M. Salarian and A. Tootoonchi, Microchim. Acta, 2012, 178, 429-437.

190 M. Saraji and H. Yousefi, J. Hazard. Mater., 2009, 167, 11521157.

191 Y. Baba, K. Ohe, T. Ohshima and R. P. Dhakal, Solvent Extr. Ion Exch., 2007, 18, 226-231. 
192 Y. Baba, T. Oshima and S. Kanemaru, Solvent Extr. Ion Exch., 2011, 29, 509-517.

193 B. G. Żyłkiewicz, B. Leśniewska and A. Z. Wilczewska, Int. J. Environ. Anal. Chem., 2013, 93, 483-498.

194 B. Leśniewska, M. Kosińska, B. G. Żyłkiewicz, E. Zambrzycka and A. Z. Wilczewska, Microchim. Acta, 2011, 175, 273-282.

195 H. Zheng, S. Yang, J. Wang and W. Sun, Int. J. Environ. Anal. Chem., 2011, 91, 1013-1023.

196 B. Yang, T. Zhang, W. Tan, P. Liu, Z. Ding and Q. Cao, Talanta, 2013, 105, 124-130.

197 H. Mizuki, Y. Ito, S. Samatya, H. Harada, H. Kawakita and K. Uezu, Solvent Extr. Ion Exch., 2011, 29, 146-156.

198 X. Chang, X. Wang, N. Jiang, Q. He, Y. Zhai, X. Zhu and Z. Hu, Microchim. Acta, 2007, 162, 113-119.

199 Y. Ren, P. Liu, X. Liu, J. Feng, Z. Fan and T. Luan, J. Colloid Interface Sci., 2014, 431, 209-215.

200 H. Sid kalal, M. Taghiof, H. Hoveidi, N. Pakizvand, H. Vahidi, H. A. Panahi and S. Tavangari, Int. J. Environ. Sci. Technol., 2013, 10, 1091-1102.

201 X. Lai, Y. Hu, Y. Fu, L. Wang and J. Xiong, J. Inorg. Organomet. Polym. Mater., 2011, 22, 112-118.

202 E. Zambrzycka, D. Roszko, B. Leśniewska, A. Z. Wilczewska and B. G. Żyłkiewicz, Spectrochim. Acta, Part B, 2011, 66, 508-516.

203 B. G. Zylkiewicz, E. Zambrzycka, B. Lesniewska and A. Z. Wilczewska, Talanta, 2012, 89, 352-359.

204 E. Zambrzycka, U. Kiedysz, A. Z. Wilczewska, B. Leśniewska and B. G. Żyłkiewicz, Anal. Methods, 2013, 5, 3096-3105.

205 E. Zambrzycka and B. G. Zylkiewicz, Mikrochim. Acta, 2014, 181, 1019-1027.

206 F. Shakerian, S. Dadfarnia and A. M. H. Shabani, Food Chem., 2012, 134, 488-493.

207 M. Roushani, S. Abbasi, H. Khani and R. Sahraei, Food Chem., 2015, 173, 266-273.

208 Y. Zhao, J. Li, S. Zhang, H. Chen and D. Shao, RSC Adv., 2013, 3, 18952-18959.

209 D. James, G. Venkateswaran and T. Prasada Rao, Microporous Mesoporous Mater., 2009, 119, 165-170.

210 D. K. Singh and S. Mishra, Anal. Chim. Acta, 2009, 644, 4247.

211 M. Shamsipur, J. Fasihi and K. Ashtari, Anal. Chem., 2007, 79, 7116-7123.

212 T. E. Milja, K. P. Prathish and T. Prasada Rao, J. Hazard. Mater., 2011, 188, 384-390.

213 S. Sadeghi and E. Aboobakri, Microchim. Acta, 2012, 178, 89-97.

214 Y. Liu, X. Cao, R. Hua, Y. Wang, Y. Liu, C. Pang and Y. Wang, Hydrometallurgy, 2010, 104, 150-155.

215 J. Fasihi, S. Ammari Alahyari, M. Shamsipur, H. Sharghi and A. Charkhi, React. Funct. Polym., 2011, 71, 803-808.218.

216 M. Liu, C. Chen, T. Wen and X. Wang, Dalton Trans., 2014, 7050-7056.

217 C. Lin, H. Wang, Y. Wang and Z. Cheng, Talanta, 2010, 81, 30-36.

218 Z. Cheng, H. Wang, Y. Wang, F. He, H. Zhang and S. Yang, Microchim. Acta, 2011, 173, 423-431.
219 C. Lin, H. Wang, Y. Wang, L. Zhou and J. Liang, Int. J. Environ. Anal. Chem., 2011, 91, 1050-1061.

220 T. Damhus, R. M. Hartshorn and A. T. Hutton, Nomenclature of inorganic chemistry: IUPAC recommendations 2005, Royal Society of Chemistry, 2005.

221 O. M. Yaghi, H. Li, C. Davis, D. Richardson and T. L. Groy, Acc. Chem. Res., 1998, 31, 474-484.

222 A. I. Matesanz and P. Souza, J. Inorg. Biochem., 2007, 101, 245-253.

223 A. Y. Robin and K. M. Fromm, Coord. Chem. Rev., 2006, 250, 2127-2157.

224 R. Litlabø, H. S. Lee, M. Niemeyer, K. W. Törnroos and R. Anwander, Dalton Trans., 2010, 39, 6815-6825.

225 M. M. Richter and A. J. Bard, Anal. Chem., 1996, 68, 26412650.

226 A. L. Jenkins, O. M. Uy and G. M. Murray, Anal. Chem., 1999, 71, 373-378.

227 J. T. M. Koch and A. Borovik, Chem. Mater., 2003, 15, 34903495.

228 H. Kim, Y. Kim and J. Y. Chang, J. Polym. Sci., Part A: Polym. Chem., 2012, 50, 4990-4994.

229 J. Zdunek, E. B. Pena, A. Linares, A. F. Cordin, G. Orellana, K. Haupt and M. C. M. Bondi, Chem. Eur. J., 2013, 19, 10209-10216.

230 T. Alizadeh and S. Amjadi, Talanta, 2013, 106, 431-439.

231 J. Liu, X. Yang, X. Cheng, Y. Peng and H. Chen, Anal. Methods, 2013, 5, 1811-1817.

232 A. S. Chauvin, J. C. Bunzli, F. Bochud, R. Scopelliti and P. Froidevaux, Chem.-Eur. J., 2006, 12, 6852-6864.

233 R. Kala and T. P. Rao, J. Sep. Sci., 2006, 29, 1281-1287.

234 R. Kala, J. Mary Gladis and T. Prasada Rao, Anal. Chim. Acta, 2004, 518, 143-150.

235 K. Ramakrishnan and T. Rao, Sep. Sci. Technol., 2006, 41, 233-246.

236 P. G. Krishna, J. M. Gladis, T. P. Rao and G. R. Naidu, J. Mol. Recognit., 2005, 18, 109-116.

237 J. Guo, J. Cai and Q. Su, J. Rare Earths, 2009, 27, 22-27.

238 O. Guney, J. Mol. Recognit., 2003, 16, 67-71.

239 K. Uezu, T. Kuwabara, M. Yoshida, M. Goto and S. Furusaki, Anal. Sci., 2004, 20, 1593-1598.

240 P. Huo, Z. Lu, X. Liu, X. Liu, X. Gao, J. Pan, D. Wu, J. Ying, H. Li and Y. Yan, Chem. Eng. J., 2012, 198, 73-80.

241 C. X. Li, J. M. Pan, J. Gao, Y. S. Yan and G. Q. Zhao, Chin. Chem. Lett., 2009, 20, 985-989.

242 X. Gao, B. Gao, Q. Niu and J. Zhao, Acta Chim. Sin., 2010, 68, 1109-1118.

243 N. Zhang, B. Hu and C. Huang, Anal. Chim. Acta, 2007, 597, 12-18.

244 S. S. Arani, S. J. Ahmadi, A. B. Samani and M. G. Maragheh, Anal. Chim. Acta, 2008, 623, 82-88.

245 B. Liu, D. Wang, H. Li, Y. Xu and L. Zhang, Desalination, 2011, 272, 286-292.

246 D. Mohan and C. U. Pittman Jr, J. Hazard. Mater., 2007, 142, 1-53.

247 B. Liu, D. Wang, X. Gao, L. Zhang, Y. Xu and Y. Li, Eur. Food Res. Technol., 2011, 232, 911-917. 
248 Y. K. Tsoi, Y. M. Ho and K. S. Leung, Talanta, 2012, 89, 162168.

249 H. Fan, X. Fan, J. Li, M. Guo, D. Zhang, F. Yan and T. Sun, Ind. Eng. Chem. Res., 2012, 51, 5216-5223.

250 G. C. de Lima, A. C. do Lago, A. A. Chaves, P. S. Fadini and P. O. Luccas, Anal. Chim. Acta, 2013, 768, 35-40.

251 H. Fan, Q. Tang, Y. Sun, Z. Zhang and W. Li, Chem. Eng. J., 2014, 258, 146-156.

252 F. Shakerian, S. Dadfarnia, A. M. Haji Shabani and M. Nili Ahmad Abadi, Food Chem., 2014, 145, 571-577.

253 P. Ballester, G. Bates, S. Bayly, P. Beer and S. Ewen, in Recent Developments in Mercury Science, 2006.

254 P. Turkewitsch, B. Wandelt, G. D. Darling and W. S. Powell, Anal. Chem., 1998, 70, 2025-2030.

255 R. Vilar, Angew. Chem., Int. Ed., 2003, 42, 1460-1477.

256 A. L. Jenkins, O. M. Uy and G. M. Murray, Anal. Commun., 1997, 34, 221-224.

257 J. Q. Liu and G. Wulff, Angew. Chem., Int. Ed., 2004, 43, 1287-1290.

258 Y. X. Zhou, B. Yu, E. Shiu and K. Levon, Anal. Chem., 2004, 76, 2689-2693.

259 K. Moller, U. Nilsson and C. Crescenzi, J. Chromatogr. B: Anal. Technol. Biomed. Life Sci., 2004, 811, 171-176.

260 Y. Kawanami, T. Yunoki, A. Nakamura, K. Fujii, K. Umano, H. Yamauchi and K. Masuda, J. Mol. Catal. A: Chem., 1999, 145, 107-110.

261 S. Li, Y. Ge, A. Tiwari, S. Wang, A. P. F. Turner and S. A. Piletsky, J. Catal., 2011, 278, 173-180.

262 G. Cirillo, M. Curcio, O. I. Parisi, F. Puoci, F. Iemma, U. G. Spizzirri and N. Picci, Pharm. Dev. Technol., 2010, 15, 526-531.

263 M. Lahav, A. B. Kharitonov, O. Katz, T. Kunitake and I. Willner, Anal. Chem., 2000, 73, 720-723.

264 M. Lahav, A. B. Kharitonov and I. Willner, Chem. Eng. J., 2001, 7, 3992-3997.

265 S. W. Lee, I. Ichinose and T. Kunitake, Chem. Lett., 2002, 7, 678-679.

266 S. W. Lee, D. H. Yang and T. Kunitake, Sens. Actuators, B, 2005, 104, 35-42.

267 J. L. Urraca, A. J. Hall, M. C. M. Bondi and B. Sellergren, Angew. Chem., Int. Ed., 2006, 45, 5158-5161.

268 J. L. Urraca, M. A. C. M. Bondi, A. J. Hall and B. Sellergren, Anal. Chem., 2007, 79, 695-701.

269 C. Gomy and A. R. Schmitzer, Org. Lett., 2007, 9, 3865-3868.

270 B. B. Prasad, R. Madhuri, M. P. Tiwari and P. S. Sharma, Biosens. Bioelectron., 2010, 25, 2140-2148.

271 S. Chou and M. Syu, Biomaterials, 2009, 30, 1255-1262.

272 S. Yan, Y. Fang and Z. Gao, Biosens. Bioelectron., 2007, 22, 1087-1091.

273 E. B. Pena, J. L. Urraca, B. Sellergren, M. Cruz and M. Bondi, J. Chromatogr. A, 2008, 1208, 62-70.

274 E. B. Pena, S. Martins, G. Orellana and M. C. M. Bondi, Anal. Bioanal. Chem., 2009, 393, 235-245.
275 J. Yin, Z. Meng, M. Du, C. Liu, M. Song and H. Wang, J. Chromatogr. A, 2010, 1217, 5420-5426.

276 A. Gultekin, S. E. Diltemiz, A. Ersöz, N. Y. Sariozlu, A. Denizli and R. Say, Talanta, 2009, 78, 1332-1338.

277 D. R. Albano and F. Sevilla III, Sens. Actuators, B, 2007, 121, 129-134.

278 Y. S. Al-Degs, A. S. Abu-Surrah and K. A. Ibrahim, Anal. Bioanal. Chem., 2009, 393, 1055-1062.

279 E. Caro, R. M. Marce, P. A. G. Cormack, D. C. Sherrington and F. Borrull, J. Chromatogr. A, 2004, 1047, 175-180.

280 F. Sineriz, Y. Ikeda, E. Petit, L. Bultel, K. Haupt, J. Kovensky and D. P. Garcia, Tetrahedron, 2007, 63, 1857-1862.

281 G. Z. Kyzas, D. N. Bikiaris and N. K. Lazaridis, Chem. Eng. J., 2009, 149, 263-272.

282 L. Yang, L. Ma, G. Chen, J. Liu and Z. Tian, Chem. Eng. J., 2010, 16, 12683-12693.

283 Y. Li, B. Gao and R. Du, Sep. Sci. Technol., 2011, 46, 14721481.

284 V. Pakade, E. Cukrowska, J. Darkwa, N. Torto and L. Chimuka, Water SA, 2011, 37, 529-537.

285 B. Gao, J. Du and Y. Zhang, Ind. Eng. Chem. Res., 2013, 52, 7651-7659.

286 W. Bi, M. Tian and K. H. Row, J. Chromatogr. A, 2012, 1232, 37-42.

287 H. F. Wu and J. H. Qiu, Anal. Methods, 2014, 6, 1890-1896. 288 J. Huang, Y. Hu, Y. Hu and G. Li, Talanta, 2013, 107, 49-54.

289 R. Say, A. Ersöz, H. Türk and A. Denizli, Sep. Purif. Technol., 2004, 40, 9-14.

290 A. Gultekin, A. Ersöz, A. Denizli and R. Say, Talanta, 2012, 93, 364-370.

291 S. E. Diltemiz, R. Say, S. Büyüktiryaki, D. Hür, A. Denizli and A. Ersöz, Talanta, 2008, 75, 890-896.

292 H. Kim, Y. Kim and J. Y. Chang, J. Polym. Sci., Part A: Polym. Chem., 2012, 50, 4990-4994.

293 L. R. Braga, A. A. Rosa and A. C. B. Dias, Anal. Methods, 2014, 6, 4029-4037.

294 L. Uzun, R. Uzek, S. Senel, R. Say and A. Denizli, Mater. Sci. Eng., C, 2013, 33, 3432-3439.

295 E. Papaioannou, M. L. Kyriakides, R. Papi and D. Kyriakidis, Mater. Sci. Eng. B, 2008, 152, 28-32.

296 F. Xi and J. Wu, J. Chromatogr. A, 2004, 1057, 41-47.

297 A. Poma, A. Guerreiro, S. Caygill, E. Moczko and S. Piletsky, RSC Adv., 2014, 4, 4203-4206.

298 S. Ambrosini, S. Beyazit, K. Haupt and B. Tse Sum Bui, Chem. Commun., 2013, 49, 6746-6748.

299 K. Muzyka, K. Karim, A. Guerreiro, A. Poma and S. Piletsky, Nanoscale Res. Lett., 2014, 9, 1-7.

300 A. Poma, A. Guerreiro, M. J. Whitcombe, E. V. Piletska, A. P. Turner and S. A. Piletsky, Adv. Funct. Mater., 2013, 23, 2821-2827.

301 A. Bhaskarapillai, S. Chandra, N. V. Sevilimedu and B. Sellergren, Biosens. Bioelectron., 2009, 25, 558-562.

302 A. Bhaskarapillai and S. V. Narasimhan, RSC Adv., 2013, 3, 13178-13182. 